


\section{$989 \frac{126}{0}$}

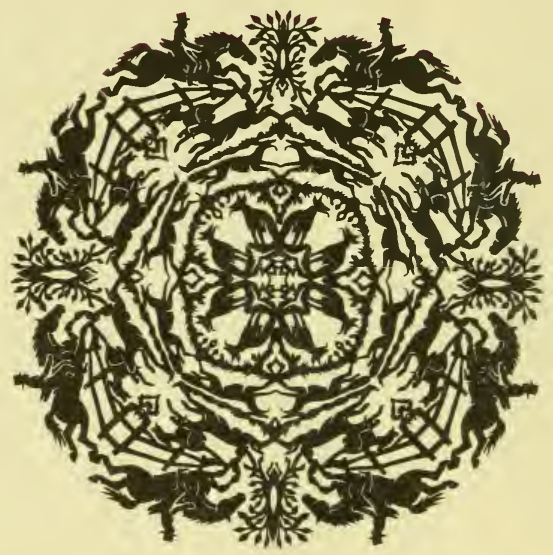

JOHN A.SEAVERNS 




RP Prara. Marah's - 


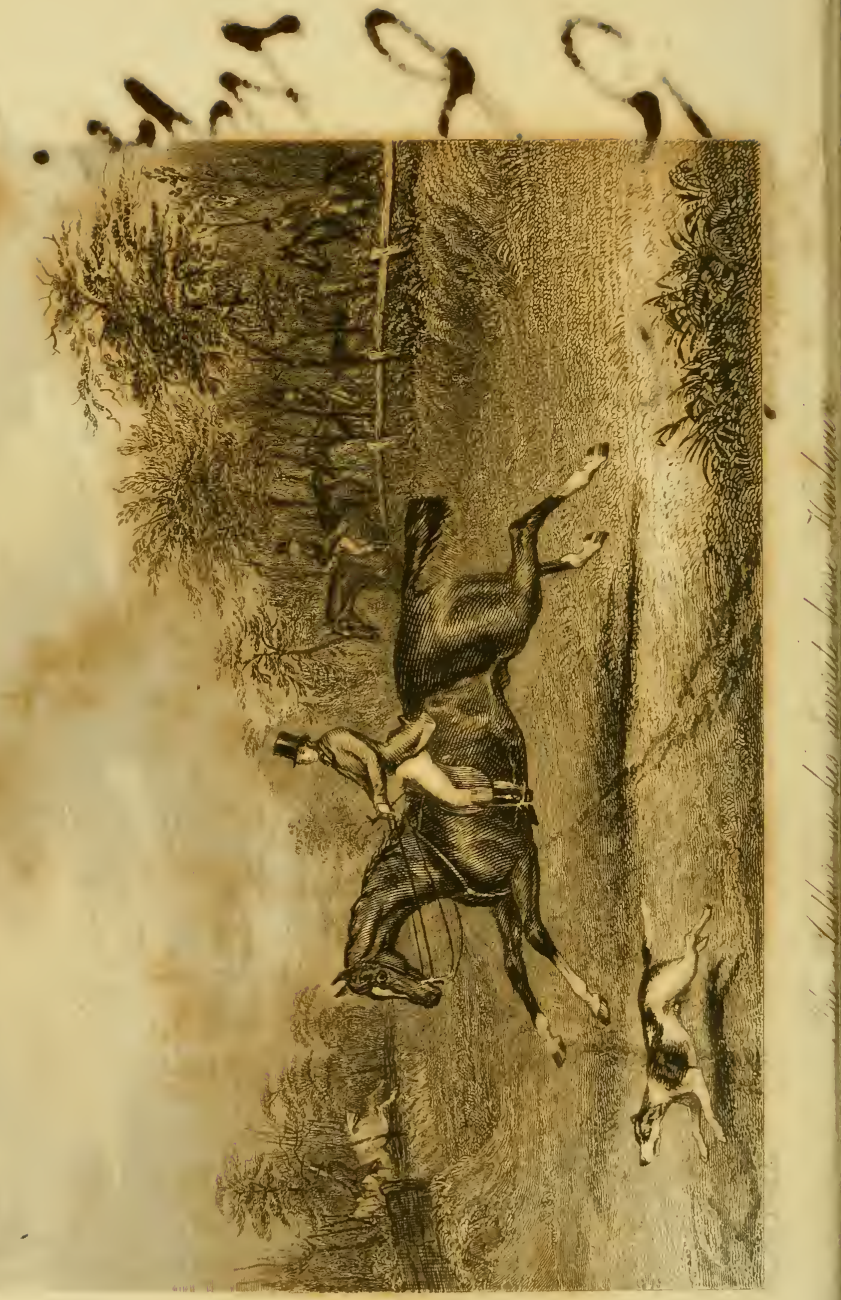


THE

\section{POCKET AND THE STUD:}

OR

\section{PRACTICAL HINTŚ}

ON THE

MANAGEMENT OF THE STABLE.

BY

HARRY HIEOVER.

THIRD EDITION.

\section{LONDON :}

LUNGMAN, BROWN, GREEN, LONGMANS, \& ROBERTS. 
LONDON:

Printed by Spottiswoon \& \& Co.

New-street Square. 


\section{PREFACE}

To

\section{THE THIRD EDITION.}

IT is a usual and indeed very naturally entertained idea, that when any book has gone through more than one edition, the work must comprise some merit to render such repetition necessary or advisable.

Taking this idea in its general bearing, the conclusion drawn is more or less a correct one: yet it may lead to very erroneous judgment as to the extent of the sale of any published work, so far as relates to the numerical quantum of copies sold; for where a work is of such a nature that the price of each volume is somewhat high, both author and publisher may feel it prudent to confine an edition to a few hundred copies: whereas, on the other hand, where the price is very moderate, it may be judicious, indeed necessary, to let the edition comprise some thousands, in order to render the work remunerative: thus one work 
may have the éclat of going through several editions, and yet, in point of copies sold, may fall short of another that is still in its first edition.

As Author of "The Pocket and the Stud," I could not but feel much gratified, that, after so monster an edition as the first was struck off, a second should so soon be requisite. I am now flattered on finding a third called for.

My first published Book was "Stable-Talk and Table-Talk," a miscellaneous work, in two large octavo volumes. These are a general compilation, touching Racing, Hunting, Riding, Driving, and most subjects connected with field sports; and further, including the purchasing of Horses, and the breaking-in and subsequent management of them.

Next followed the present work, "The Pocket and the Stud." This enters more into the detail of purchasing and managing horses in and out of the stable; treating also of the dimensions and regulation of stables, so as to render them safe, comfortable, and healthful to their inhabitants; and further, on the feeding of horses, as regards quantum and quality of food, so as to promote the well-doing of the "Stud," with an equal regard to that of the "Pocket."

That it has been thought to have tended to promote such desirable results, I trust I may 
entertain a hope, from the circumstance of this third edition being called for.

Finding "The Pocket and the Stud" was meeting a rapid sale, I wrote and published a companion to it-" The Stud for Practical Purposes and Practical Men." This work keeps in view the interest of the Pocket and Stud quite as much as its predecessor, and some particulars to a still greater extent.

It sets before the reader the consequences to be expected from the different ailments, general imperfections, and peculiar habits of the horse, whether arising from treatment or natural causes, showing where he may venture to purchase, and where it would be judicious to reject an animal under the influence of any of the imperfections or peculiarities alluded to.

"The Pocket and the Stud" has been, I am aware, a taking title to the book; for, as the world is now constituted, a vast number of its inhabitants are at once on the qui vive where anything relative to a saving of the pocket is concerned. So be it ; and under the impression that it is so, I venture to recommend "The Stud for Practical Purposes" for the reader's perusal, feeling perfectly confident that, if the hints given in 
"The Pocket and the Stud" may be the means of saving pounds in the general management of horses, its companion, if carefully read, will cause a saving of hundreds in the judicious purchasing of them; for, it must be borne in mind that, though a saving of expense in stable management is a matter of considerable importance in the long run, the preventing the purchase of that at $100 l$. which is only worth $50 l$. is a saving of $50 l$. in the onset; and, on the other hand, the affording such information as may prevent the rejection (from erroneous ideas) of that which would really meet the wants and wishes of the reader, is a matter of quite as much importance, both on the score of economy, and as a saving of time, trouble, and much vexatious search, which will only end in being obliged to put up with some imperfection at last, - and what imperfections may best be put up with, as regards the purpose for which the animal is wanted, - is the spirit and intention under which I wrote, and venture to recommend, "The Stud for Practical Purposes."

After the two last-mentioned books, both intended to effect a saving of the pocket, it struck me that one having for its intent the saving the life or limbs of the rider might be considered as of at least some use ; and, under this impression, I 
produced "Practical Horsemanship," confining its contents chiefly to its intended use-namely, tending to promote the safety and comfort of the rider. This I have attempted to do, by bringing forward such hints as long experience and much personal practice in riding horses of all sorts have taught me are likely to teach the Tyro in Horsemanship how to avoid danger under, and in, peculiar circumstances; how to counteract any evil propensities in the horse; how to sit with ease and comfort on him, and, by contracting the seat and air of a horseman, to avoid the rude jeers or jeering looks of the multitude, which an evident display of bad horsemanship is certain to produce. Nor is this book without its claims as to saving the pocket as well as the neck; for as fine condition often doubles, and its reverse halves the original price of a horse; so riding him to show him to the best advantage, or so as to go like a brute, in many cases as much increases or diminishes his value. The old anecdote of a dealer's man asking whether he was to ride a horse he was put upon "to buy or to sell," is corroborative of my opinion on this point; and I fearlessly assert, that if a bad horseman were to get a good one to ride his horse to show him, or were to do the same

A 4 
thing himself, it would with many horses make half the difference in the price to be obtained.

My last production, published by Messrs. Longman, "The Hunting Field," though not intended for the perusal of the generally penurious man, is still intended to, and I hope does, tell the uninitiated, who mean to indulge in an amusement that cannot be enjoyed without expense, how they may avoid useless expenditure, inasmuch as it attempts to show them the proper kind of horse to purchase, the amount of work a given number are equal to, and how to ride them in the field with the least labour and exertion, both to themselves and their stud; by doing this, all horsemen know that a moderate horse will, in some men's hands, do wonders and gain a character, where a first-rate one, with an injudicious rider on him, will never be able to keep his proper place with hounds; and what cost perhaps a couple of hundreds will shortly be estimated as worth sixty for a mere park hack. Thus I trust each of these books will be found, in its particular bearing, not merely to conduce to the interest of the reader as regards his comfort, safety, and enjoyment, but his pecuniary resources also.

H. H. 


\section{PREFACE}

10

THE FIRST EDITION.

Whenever a man ventures to give hints or offer advice to others on the management of their property or affairs (be the nature of them what it may), he lays himself open to a charge of both arrogance and presumption, unless he can bring forward a good reason for fancying himself qualified for the task; for it not merely implies, but plainly states, that he conceives he knows more about the matter than the generality of those for whose perusal he writes. It, therefore, becomes not only a matter of proper respect to them, but a duty he owes himself, to explicitly state that, in offering advice, he does not consider his qualifications for the task to arise from any fancied superiority or particular perspicuity of intellect in general matters, but from the very homely cir.cumstance of practical experience in those on which he writes. 
I feel that I stand in the very delicate position that I have described, in venturing to lay the present work before the public : therefore, if ever a book imperiously called on its author for a preface or introduction, it is absolutely indisp.nsable to "The Pocket and the Stud."

I trust most of my readers will agree with me, that supposing, from a particular turn of mind, a man had made the manufacturing of chronometers his study from childhood, and that if circumstances had compelled him to serve two apprenticeships to that art, he could not be accused of presumption if, after such experience and practice, he ventured to give advice on the management of a watch to those of far superior attainments in mind in other matters, but who may not have had the same knowledge and practice FORCED on them, as regards the subject on which he ventured to give advice, or, in more modest phrase, the same experience and practice.

Now, I am precisely in the situation of such a man, and I trust the liberality of my readers will give me credit for acting only on the same principle in offering advice on the subjects of the present work. I have had a great part of the knowledge I possess, and the practice I have had in these matters, FORCED on me by untoward 
circumstances, over which I had no control; and to those who may not have the same knowledge, and have not had the same practice, I offer my sincere congratulations that they have not been placed in the like predicament, for Fate has it vouchsafed to give this knowledge and practice is me as a matter of pleasure, but has buffetted both into me in some of her most angry moods, or at all events, a great part of both are the result of her will and decree.

There are, beyond doubt, numberless men who possess more knowledge of, and have had more practice in, the matters contained in this work than I can boast; and I am equally willing to give them credit for being able (if they felt inclined to do so) to lay the result of that knowledge and experience before the public in better form and terms than I can : to such men, of course, this work would be useless; but I trust that to thousands of others it will not be found to stand in the same position.

That there are many GENTLENEN better judges of horses or their management (as GENTLEMEN's horses) than myself, I make no doubt; that there are many dealers, breakers, trainers, and others concerned in the sale of horses that know more, I must also, of course, admit; but it might, perhaps, 
be difficult to find a man precisely in my situation-namely, that of one born, bred, educated for, and as, a private individual - who, in addition to the knowledge in matters required of a gentleman, has, as I have before stated, been forced to acquire the knowledge of the minutiæ of the business and avocation of men in a directly opposite position in society; but, as such is the fact in my case, I feel it a duty I owe my readers to give a short statement of the circumstances that have caused such an apparent anomaly.

I am not of sufficient consequence to render it a matter of the slightest importance to my readers what may be my name; they will probably be still more indifferent as to what was the origin, is the extent, or who may be collateral branches of my family: suffice it to say, that, though it has ever been a family addicted to spending fortunes, I am the first member of it who ever attempted to make money by business. Had they or any of them ever had foresight enough to have done so, I should, probably, never have written " The Pocket and the Stud." I am the last of that family, except one. If the rest were living, I suppose I should be considered a kind of scapegrace, who had sullied their fair fame; at least I judge so, as my surviving aristocratic relative will not 
PREFACE TO THE FIRST EDITION. xiii

let me come "between the wind and his nobility," because, forsooth, I did not choose to starve or beg while I could turn my knowledge of horses to account.

Where I was born is, of course, of as little consequence to my readers or the public as who $I$ am; perhaps many of both may say it matters little whether I had ever been born at all: the where I should never, therefore, have mentioned, but from its coincidence with my propensities. I shall therefore state the locality.

Whether these sporting propensities were predestined or not, I know not; but I was born on Enfield Chase, and in a house stated to have been a hunting-lodge of one of our hunting monarchs; as probably it was, for a farm called the Dog Kennel stood within half-a-mile of the house. A curious old place this said house was, boasting its four rows of eight windows in front, save three on the ground floor, substituted by the entrance to the hall, where deers' horns, rusty pikes, cutlasses, and God knows what, first delighted my boyish eyes. At two years old I made my first début on the back of an animal; this I did in the following somewhat rude and rustic manner-namely, being daily taken by my nurse to meet the bullocks coming home from labour, on the back of one of 
xiv PREFACE TO THE FIRST EDITION.

which, I am told, I rode in great state up the old avenue to the yard. Thus, so far as riding goes, I may truly say that I rode before I walked. My practice in this particular did not, therefore, begin very late in life. This, as a matter of course, soon led to a pony being wanted, and at six years old I was first blooded by Lady Salisbury's huntsman on seeing my first fox killed. At eight years old I could ride my father's horses as straight as he could; at twelve boasted two of my own; and at sixteen had a regular stable of them, with an allowance, that only made it a matter of surprise that I did not soon go-some. where-headlong. However, I did not then, though I have since, at times, been about as happy as if I were there; but let me in gratitude allow I have also had hours, days, and years, when I felt as if I were on the diametrically opposite tack.

It may be asked, from what I now say, or, very probably, from what I have written, whether I was ever at school? Yes, reader, I have been at various schools, some of them very odd ones, but never at the sort of school that, if the question were asked, it would refer to. No; mamma would not part with her only one, so I was managed in this way at home. I loved hunting and horses enthusiastically, and hated Horace and Homer 
as cordially as any young gentleman living: but the bargain was, - Horace, Homer, and hunting, but not the one without the other; so, as I knew that from this decision appeal was useless, I took lessons from the huntsman and tutor at the same time. Manhood came on, and for years my good star was in its ascendancy, till death began to be busy in our family, and as our property, or rather incomes, depended on lives, not on deaths, if cordial good wishes for their health could have kept them alive, many of the departed would be to this day still "living." Suits in Chancery ensued; some lost, others gained, - which will account at once for the vicissitudes of different periods of my life, and for the seeming incongruity that I am aware exists in what I have at times written, namely, my acquaintance with scenes, manners, and men so much at variance with each other; in fact, from the habits of the peer to the tricks of the dealer. Yes, reader, I have been behind the curtain, where both are actors; kind Fortune leading me, a willing and delighted spectator, in the first case; stern Fate obliging me to dive into the mysteries of the other. But, at the same time, I must allow that I have dived into many curious scenes and places voluntarily, from mere curiosity. I have sipped chambertin in a ducal 
xvi PREFACE TO THE FIRST EDITION.

residence, tête-à-tête with its noble owner. I have drunk half-and-half with Tom Crib in his parlour. I have dined in noble halls where aristocracy, beauty, and brilliancy, dazzled the sight and charmed the senses. I have dined at farmers' clubs where drink dubbed every man "a right good fellow," which stentorian lungs declared " nobody could deny." I have danced in princely drawing-rooms, and so "faith I have" at Donnybrook Fair. I have been presented at more than one court; so I have at the racket-court at the Fleet and Queen's Bench prisons. I have also gone to very recherché dinners in the latter place, where two honourables, a noble lord, one of the most fascinating women living, myself, and one whose name we frequently see mentioned as about our present court, formed the party. So have I (when I had a farm on my hands) dined in a field on cold bacon on a lump of bread. I have had a stable full of hunters of my own, so have I stabled a hundred horses belonging to other persons. I have given tradesmen a cheque for their bill for follies that now I wonder at. I have received one of another sort when in business for sending in my own. I have sold many of my own horses when it was a matter of indifference to me whether I sold one. I have been twice - once for six and 
PREFACE TO THE FIRST EDITION. xvii

once for eight successive years - in a situation where hundreds of horses-some my own and some the property of others - passed every year through my hands. I have driven my own four horses; so have I scores of teams belonging to coach proprietors; so was I once, when very closely screwed up in pecuniary matters, very near driving one as an addition to my limited means, with this very consoling addendum to any other feelings I might have on the occasion from the mouth of the worthy proprietor:- "I am sorry that just now I have no vacancy on a pleasant coach to give you, but there is the mail, that poor was killed from last week, going through forest, where the road is always in a shameful state; if you would like that till I can get you a better, I will put you on it with pleasure." Though not a very particular man, I thought the share of pleasure on my part in undertaking a night mail that another had been killed from, would be very small indeed; so this vicissitude - namely, driving as a paid coachman - has not been added to the many of my life.

Let me hope that this rough sketch will suffice to account, first, for any seeming incongruities in what I may have at different times written; but, 
xviii PREFACE TO THE FIRST EDITION.

above all, that it will show that, if early initiation in all horse affairs, constant practice, and consequent experience, can be admitted as an apology for a work containing hints and advice on such subjects, the intent with which it is written will be taken into the favourable consideration of the public, and plead in extenuation of any deficiency there may be in the mode in which it has been carried out. 


\section{ONTENTS.}

\section{INTRODUCTION.}

The Author's Apology for instructing his Readers. - Advantages of Experience. - Obstacles in the Way of profiting by it. - Necessity of their Removal 1

\section{CHAPTER I.}

Suggestions as to the best Way of buying a Horse. Advice of a judicious Friend indispensable.-Never buy for yourself. - How to choose an Adviser. What Kind of Horse to choose. - Different Sorts of Dealers, Breeders, \&c. $\quad$ - $\quad$ - $\quad$ - $\quad$ - $\quad$ - 9

\section{CHAP. II.}

Stable Management. - Ventilation. - Warmth.-Different Treatment for different Horses. - Dryness. Wide Doors.—Stall Posts. - Racks. - Windows. Balls. - Mangers. - Head Collars. - Collar Shanks. - Muzzles. - Lofts. - Objections to keeping Hay in them. - Different Materials for Stable Floors. Causes for hanging back. - Stable Drainage. Stable Requisites. - Necessity of Rule. - Saddle and Harness-room. — Stoves. - Boxes - . 


\section{CHAP. III.}

Different Kinds of Food. - Hay. - Straw. - Oats.

- Beans. - Bran. - Malt. - Barley. - Carrots. Chaff

\section{CHAP. IV.}

Stable Economy. - How to set about it. - Evils of improper Directions. - The right Sort of Instruc. tions.-Ingenuity of Servants. - Choice of a Groom. - Ordinary Cost of Keep. - Tabular Statement. Veterinary Surgeons. - When to be consulted. Illustrative Anecdotes $\quad-\quad-\quad \cdot \quad \cdot \quad-146$

\section{CHAP. V.}

The different Value of different Horses. - The best Judge of a Horse. - Cases in point. - The Price of Perfection

\section{CHAP. VI.}

Different Modes of keeping Horses. - Chaque Pays, chaque Mode. - The Kind of Horse best suited for different Carriages.-On Single-horse Carriages and Pair-horse ditto. - The Pros and Cons of keeping Carriage-horses and Hunters at Livery. - Jobbing of Horses. - Summary of the Work - - - 187 


\section{THE POCKET AND THE STUD.}

\section{INTRODUCTION.}

THE AUTHOR'S APOLOGY FOR INSTRUCTING HIS READERS. ADVANTAGES OF EXPERIENCE. - OBSTACLES IN THE WAY OF PRofiting BY IT. - NECESSITY OF THEIR REMOVAL.

"Prologue precedes the piece, in mournful verse, As undertakers walk before the hearse."

In these words commences the prologue to a play: why should they not serve for an introduction to this volume, - not being so inapt to the subject as they may at first appear? First, then, in commencing a preface, I am an undertaker; and in beginning the work, $\mathrm{I}$ am an undertaker still. There is, however, this difference between us; I endeavour to make my work go on as cheerfully as I possibly can - my brother undertaker makes his proceed as mournfully as possible. He feels it his duty to walk before his work; whereas I see no advantage in my walking before mine, though I shall feel much flattered if others will only be kind enough to walk after it; not that in- 
ducing them to walk is by any means its purport quite the contrary, its aim is to tell them how to ride, with as little waste of money as possible. In this, I trust, I lay myself under no imputation of conceit or arrogance; inasmuch as the chief part of the advice I give is, that they should act on that of others. In so doing I have, to the best of my judgment, done one of my duties to my readers. I suspect the wishes of my brother undertaker and my own differ materially as regards our friends, as I sincerely hope the day is far distant when I shall do my last duty by them.

Whatever may be a man's occupation in life, or whatever his possessions, there can be no doubt but that (setting aside the common contingencies of luck) the carrying on of his pursuits with advantage to himself, and also probably to others, depends chiefly on proper and judicious management; and, in like manner, the rendering of his possessions as valuable as their nature will allow, depends chiefly on the manner in which they are treated.

A vast number of persons find themselves so situated that their possessions, be they of what kind they may, so far from affording them pleasure or profit, produce but little of either, although they spare no expense in their management. It might be supposed that such persons would, at least, gain experience, as some equivalent for their 
money; if they did, the dearness of the purchase, or its reverse, would depend on how much that experience had cost, and how much it had been wanted. To many it would be cheap at one half their fortune, for it might save the other. A great many do not get it so cheap. I know some who have spent about eighty per cent. of their capital, and, so far as I can perceive, have not yet got hold of any of this valuable commodity (experience); or, at least, if they have, they do not seem to make use of it. I conclude they excuse themselves for not doing this, as a well-known character in Leicestershire did for not stopping, on his friend getting a most desperate fall. Being asked if his friend was not seriously hurt: "I should think he was killed," said he, "from the way I saw him lie; but the pace was too good to stop to inquire."

Now with respect to gaining experience by constant loss, the fact is, many do gain it; but what they do gain is not of the right or useful sort. They merely gain that which tells them they are losing money; but they do not gain that which would make them act more judiciously. And why they do not is very easily accounted for. Instead of attributing their losses or disappointments to any error in their management, they will generally impute it to their ill-luck, and in a certain degree they are right; but their ill-luck consisto 
in something very different from what they suppose or wish to be supposed.

We will suppose a groom puts on a horse's head collar in such a way that, if the animal merely rubs his head against the manger, the collar comes off; he gets loose, gets kicked by another horse, or in some way gets hurt; a veterinary surgeon is sent for; the horse remains for weeks unable to work; a heavy bill comes in; and after all the horse is blemished. Case the first.

As soon as the horse is got into work, the owner rides him to a friend's house, where he intends dining; is somewhat late, so rides fast; gets the horse heated; gives him to any person who comes to take him on his arrival; no particular direction or caution is given; the horse, in all probability, gets cold. Again comes the veterinary surgeon; and as of course came the cold, so of course comes the vet.'s bill; whether of course it is paid is another matter, and not to our purpose here. Case the second.

The owner now wishes to drive this same horse in harness; the groom undertakes his management. $\mathrm{He}$ is, perhaps, put into a gig at once. "Oh, Sir, he won't kick; " but he does. "IVho would have thought it!" Why any one knowing anything of putting horses in harness would have thought it very likely that he would; for his being "quiet as a lamb," is no guarantee that he will not 
PUTTING THE SADDLE ON THE RIGHT HORSE. 5

kick the first time he is put in harness; he does, and lames or scarifies himself. Case the third.

"What an unlucky brute that is," exclaims the owner; "he is always getting into some mischief." Now luck, good or bad, had nothing to do in either case: mismanagement and want of proper precaution brought on each catastrophe."

"How very unfortunate you are with ALL YOUR horses, James," cries the cara sposa; "they cost you as much in surgeon's bills as in their keep!"

The owner and the lady are both right in what they say, though their correctness is so in a different way from what they mean. The horse is an unlucky brute to belong to one who knows little of the management of horses; the gentleman is unfortunate, in trusting to that management. Perhaps some of my readers may recognise such a case. The ill-luck is their not knowing how to manage better. This they will never know, so long as they hold so erroneous an idea as to the nature of their ill-luck; for while any man can flatter himself that he is managing anything as well as it can be managed, he would conceive it not only to be an act of supererogation, but of absolute folly, to attempt to manage it better. And there is nothing hypothetical in the idea, that if a thing is done as well as it can be done, it cannot be done better ; this conviction is very rife amongst 
persons who do anything, when estimating their own qualities and acts.

This very prevalent idea may appear to border very closely on over-weening vanity on the part of those who entertain it, but candour must induce us to exculpate many of such persons from so serious a charge; for, if we fairly consider the case, it requires a good deal of time, practice, observation, and modesty, to teach a man that he really is managing anything badly. He may find that what he manages does not answer his wishes or expectations: but, unless he seeks or has the opportunity of seeing another person's mode of managing the same thing, and also sees it succeed under a different management, what is to tell him that his own mode is and has been wrong? Practice and good sense combined may, in time, certainly show him his errors, and teach him to adopt other and perhaps better modes; but this does not even follow by any means as a matter of course"cœlum non animum mutant qui trans mare currunt." A man in doing anything may change his mode; but if acting only on the suggestions of his own mind and invention, he must be more fortunate than his neighbours, if he does not find it necessary to make several alterations in his plans before he produces one solid improvement. Practice and experience, though very sure, are generally very slow and very expensive teachers; and 
if a man sets out with general mismanagement of anything, though time and practice may eventually get him in the right road, he will find a strong purse also necessary to back him on his journey; and with all this, he will yet remain in error, if he continues to attribute his failure to ill-luck. He would, under such impressions, still blunder on in the wrong way, and would not change his plans; by doing which he has at least the chance of hitting on a good one, or at all events on some better one than the last.

A man with a less extravagant opinion of his own abilities would neither continue long in any habitual error, or even trust to himself in adopting other modes, if he could avail himself of the advice or suggestions of those of more experience and practice; it does not follow that he must look for a man of superior mental attainments to himself in order to derive benefit from his advice; he may feel perfectly satisfied that the qualities of his own mind are infinitely superior to those of his adviser. For a little reflection would convince us that, however great may be our natural abilities, and however highly they may have been cultivated by education, a common plumber's labourer might be able to give us a lesson in hydraulics that would excite our surprise, or, at least, our curiosity and admiration. It is true, the plumber's man may make sad havoc even 
with his mother tongue; and, if he were told that the Missouri emptied itself into the Caspian Sea, would, of course, believe it. $\mathrm{He}$ is not one to apply to for geographical information, we must allow; but the man of education need not laugh at the other's ignorance. If he did I would ask him if he could oblige me by putting on a sucker to my pump? Not he, for the life of him; though a bit of leather and nails are all that is wanted. If, therefore, he wants to interfere with pumps, he had better seek information from others before he puts them out of order by adopting his own ideas, and pursuing his own plans in matters that he knows but little about. It is much the same with horses.

There are many persons to whom I stand in the position of the plumber, as well as of the chronometer maker mentioned in the preface. To such I offer no apology for soliciting their attention to these pages; for, in this case, I trust I am not guilty of presumption. Nor do I offer any apology to those who know more of the subject than myself; for, of course, I do not write for their instruction. 


\section{CHAPTER I.}

SUGGESTIONS AS TO THE BEST WAY OF BUYING A HORSE.ADVICE OF A JUDICIOUS FRIEND INDISPENSABLE.-NEVER BUY FOR YOURSELF. - HOW TO CHOOSE AN ADVISER.WHAT KIND OF HORSE TO CHOOSE.-DIFFERENT SORTS OF DEALERS, BREEDERS, ETC.

Looking at horses in a general way, so far as they are kept by gentlemen, we must chiefly regard them as objects of show and amusement; for though utility may also be added, this is but a secondary consideration with such persons in their inducements to keep them. Whether, however, we consider them as objects of luxury or utility, or as both, the keeping them in the best health and condition becomes an object of material moment-as regarding kindness to the animal, vanity as to his general appearance as belonging to ourselves, and also as a matter of pecuniary consideration; for I do not know any saleable article whose price is more enhanced or deteriorated by its appearance than the horse! and that appearance, barring accident or illness, depends wholly on the mode in which he is treated; and, in fact, both accident and illness greatly depend on his treatment also. If it was 
not so, why do we daily see one man losing heavy sums by his horses (independent of their general expenses of keep, attendants, \&c.); another losing only the amount of those general expenses; a third making them nearly keep themselves; and a fourth making them do this altogether, and also occasionally putting something in his pocket by them? This all arises from the different way in which these different men first buy, and then treat their horses.

All men, or at least ninety-nine out of a hundred, who can ride or drive a horse decently, are fully satisfied that they can also buy him. Now, though riding or driving, even moderately well, is not a matter of very easy attainment, or learnt by the generality of those who keep horses, and though to do both well falls to the lot of very few indeed, the buying part of the business is far more difficult still. Yet such is the infatuation of most persons, that though they find they rarely, if ever, buy a horse fitted for their purpose, and, as a matter of course, lose heavily by all that are not, experience seems entirely thrown away on them, and they persevere in buying for themselves to the day of their death - the only circumstance that could prevent their still going to market.

There are certainly some men, who, if they are in want of a horse, but really know little about the matter, will ask a friend, perhaps a first-rate 
judge, "to look out for them:" that is, they are disposed to honour such a friend by permitting him to trot about to twenty different dealers' stables and see perhaps forty horses out, and for what? That the purchaser may then go and pass his judgment on these same horses! I do not know what such gentlemen may think while making such a request; but this I know, unless a man had made up his mind to the honour of becoming their groom, I should certainly recommend him to decline that of being their tout.

I scarcely know a piece of greater impertinence than that of a man who is in want of a horse asking another, in the common term, "to look out for him." One might certainly, without giving any offence, say to another, "I want a brougham horse, and should like such a colour and size, and intend going to such a price; if, in your walks or rides, you should happen to see anything of the sort, would you oblige me by dropping me a line saying to whom he belongs?" To which may be added (whether true or not), by way of a sweetener, "If you tell me you think him a clever one, I am sure I shall like him; and I dare say buy him."

Here is merely a little friendly and gentlemanly commission given from one man to another; no trouble given to a friend to save your own; and as the friend does not, in such a case, select the 
animal, or tell you he is one he recommends you to buy, you pay him no ili compliment in not doing so.

It is true there may not be many men on whose judgment we should choose to rely; that is, there are very few men whom one that is a good judge himself would depute to buy him a horse; but supposing a man is not a good judge, and is not fortunate enough to possess a friend who is, and would undertake the task of purchasing or advising, in that case, supposing the person wanting an animal knows some one who he is aware is not a first-rate judge, but is still a better one than himself, he would do better to trust to him than to go to market himself, inasmuch as it would be better the friend should buy him a horse a little thick in the wind, than that he should buy one for himself with the same complaint (or some other), and a little down in his eyes into the bargain.

I have been told that, as a child, if I was shown any thing, my first exclamation used to be, "Let me do that my own self." This held good in doing anything, whether it was to me possible or not. No doubt the general result of this was cut or bruised fingers, ending in a lusty roar. Still it did not cure me; I was at the same thing on the next occasion presenting itself. Perhaps some of my friends and acquaintances of mature age may 
be actuated by the same desire of doing certain things themselves, with equally unfortunate results.

I have an acquaintance who boasts that he never does anything without getting the advice of his friends. This is quite true: he does not. He gets it, but no one who knows him will ever accuse him of acting on any one's advice but his own; and if one may judge by the results of what he does, I should say his counsellor has not usurped all the wisdom of the bar for the benefit of his client. I could say pretty much the same thing of many of my friends, who retain the same counsel when purchasing their horses.

The office of purchasing anything for friends, is one that a sensible man would certainly rather avoid than seek; for should he, in point of quality or price, by superior tact or judgment, save a friend thirty, forty, or fifty per cent. in the purchase, he would first find it difficult to persuade that friend that he had done so, or that the friend could not have done as well for himself. Then should the horse or article purchased turn out ever so well, he will barely get thanks for what he did: but should he or it not realise every expectation formed, he will not only get constant and sundry direct and indirect hints on the subject, but, worse than all, will probably find that he will be expected to turn salesman. Should he 
get the purchase off without loss, all that will be thought is, that it was no more than his absolute duty to do so. If any loss accrues, it will probably be delicately insinuated, that had the friend purchased on his own judgment this would not have happened; though it may be perfectly well known that he never made a purchase in his life by which he did not lose. But then, of course, that all arose from ill-luck, not from want of judgmentfor this is a want to which very few are subject, when judging themselves; though their thinking so is the best possible proof that they do labour under such deficiency.

Notwithstanding these stumbling blocks in the way of obliging another, no man of good feeling or good-nature would, where his judgment was properly appreciated, refuse to purchase for a friend, if, from any circumstance, his doing so would render a service; but then, purchasing for a friend is quite a different thing to playing jackal and starting the game for Mr. Lion to select from, or forking out the chesnuts to save Mr. Pug the risk or trouble of doing it himself. To be requested by a friend to look at a horse he has found, is a compliment; to be sent to find one for the friend to look at is diametrically tive reverse.

Now, if a lady flattered me by a commission to find her a horse, the case would be widely different 
- I would not object to find her a hundred, if I could, to select from. With nineteen ladies in twenty the look of the animal is a matter of paramount importance. A particular mark, shade of colour, mane, tail, ears, legs - even countenance, are all scanned: each fair equestrian has her own ideas and predilections as to what are beauties, or the reverse. Then the style of going is another consideration; for it is not altogether whether the animal goes well, but whether the going suits the lady's ideas. It is not necessary that a horse should be altogether of a good sort, to be very clever as a lady's horse; for beauty, safety, and pleasantry is all that in ordinary cases is requisite. If I picked out twenty horses, each of whom I knew would carry a woman well, if a lady objected to every one, I should feel in no way mortified or offended; for the fact would be, they would not be objected to as unfit for the purpose, but merely because they did not hit the taste of the lady. The other qualifications she leaves to be appreciated by those more informed on such matters.

A man may say he has a right to please his taste in horses as well as a lady. No doubt he has so; and if he looks out for himself he may look at all the horses on sale in London if he pleases, till he becomes, like some I know, who are such marked men among dealers, from the numbers they look at without buying, that it is with 
reluctance a dealer will order out a horse for them to look at. However, so long as such gentlemen do not attempt to trouble others to be on the "look out for them," it is all well enough. For though a man may be disposed to humour, and get dealers and others to humour, the caprices of a woman, he must be of a much more accommodating disposition than I-or, I should say, most others - if he would do the same for a man.

But we will suppose a man wishes to avail himself of the better judgment of another person, yet at the same time, reasonably enough, wishes to indulge his own taste as to general appearance. Let him get the person, whose judgment he wants, to take a walk with him, and as he will see in his walk all sorts of horses, he has only to show the style of one he likes for certain purposes: the thing is then easy enough to manage.

Supposing a man to be a known first-rate judge, there are two distinct classes of persons for whom he may, in a general way, safely purchase, without subjecting himself to the several disagreeable results I have mentioned. First, a man who is a perfect judge himself; for, if from want of opportunity, time, or any other cause, he asks an equally good judge to purchase for him, he will mention (if it is not already known) the style of horse he likes for any particular purpose, then the purpose for which he is wanted, and the 
price he intends to give; and what is usual among such men, will give a cheque, or the amount of money for the purchase. Such a man knows horses too well to expect you to send him perfection; but he will feel certain that the horse sent him will be fit for the intended purpose, and the purchaser will feel equally certain that what he does send will be properly estimated. And even supposing the horse does not quite answer expectation, knowing all the difficulties of the case, there will be a proper appreciation of the pains taken and judgment used in the selection. If, from any peculiar whim or fancy of the owner, the horse does not quite suit his wishes, he will have sense enough to lay the blame on himself, and not on the purchaser; and should the horse even turn out bad or unfortunate, good sense will tell him that the same thing, or some other, might have occurred had he purchased for himself. Nor will his confidence in the purchaser's judgment be at all shaken by the circumstance. These are by far the pleasantest of all men to have to act for.

The other is the case of one who knows nothing at all about horses, and has sense enough both to know and admit that such is his situation. He will also mention the purpose for which he wants the animal; may, perhaps, state the colour he would prefer, or the size, or about the size he 
wishes, if necessary: he will know that if he states the purpose to which the horse is to be applied, and whether show or use, or both combined, be wanted, the proper horse for the purpose will be sent him, whether it is to carry eight stone or eighteen, to draw a brougham or a pony carriage! Possibly, nay, most probably, the horse sent will be quite a different sort of animal to the one he would have purchased for himself. In fact, the one being a judge, and the other no judge at all, it is twenty to one but it will be so; for if not, there would be no use in employing another person. What is, however, generally the result? He finds the one sent carries or draws him pleasantly and safely; he has got what he wanted for his use, and probably writes and tells the purchaser he would not take twice the money given, if it was offered him, to part with his purchase. He would be quite right in refusing it, unless the same judge would good-naturedly undertake to get him another; and even then he would be wise to hesitate. It is bad economy in a man, who is not conversant with buying and selling, to part from anything that suits him for profit on its sale; nor should such a man, if suited, ever part from a horse which, taking him on the whole, does his business well and comfortably, under the idea of getting perfection. He will not get it, though dealers may assure him that he will. 
MAN AND HORSES OF THE RIGHT SORT. 19

They thrive by keeping alive hopes in this particular: let a man give money enough, and change often enough, he will be ruined by it.

My first, best, and most strenuous advice to any man wanting horses, not being a thorough, good, practical judge, yet wishing to keep the money together, I shall write in large characters -

\section{NEVER BUY FOR YOURSELF.}

I am quite satisfied that most men who are good judges would, if they studied their pecuniary interests only, very often do much better by letting an equally good judge buy for them, than by purchasing for themselves. I have an acquaintance whom, if I wanted a hunter, or, indeed any sort of horse, I would certainly get to purchase for me, with quite as much confidence in his judgment, indeed, I will say more, than I should have in my own. In such a case, I should at once send him so much money; beg him to give that, less or more if I could afford it, and send me the nag. If on seeing him I did not quite like his looks, I should be certain there was a something to fully make amends for any little falling off in this particular. If on riding him we did not seem comfortable together, I should be satisfied it arose from some want of management on my part, and 
I will be bound I should find myself right in confiding in my friend's judgment.

I must correct what I perceive I have said in one particular. I have stated that I would as readily take my friend's opinion of ANY horse as my own. If I had added of any really good sort of horse, I should have been right; but if I wanted a selling, money-making direct, London horse, I would in such a case prefer my own judgment and taste, simply for this reason - I have had more of such horses pass through my hands, and think I know London taste better, from having mixed more among a certain class of society than he has - a class who would regard show and fashion before intrinsic worth or merit in their horses, or, indeed, in many cases, in their acquaintance. Such is precisely the sort of horse my friend is not a judge of, and is the reverse of one he would own or purchase for any one else. $\mathrm{He}$ is a capital sportsman, capital judge of horses, and, moreover, a capital fellow, but hates worthless animals in horse or man, though both may be turned to account in London by a man who knows how to manage them, and this is all such horses or such men are fit for. In saying that good judges would often do well in letting an equally good judge purchase for them, it must be observed, I say their pecuniary interest, without reference to their amusement, their whims, or caprices. As 
a proof of this, it is quite well known there are many men who have been employed by dealers to go to fairs and other places, to purchase horses for them, and have always on the average bought well for their employers. These men have turned dealers, and when buying for themselves have been as unfortunate and injudicious in their purchases as before they were successful and prudent. I know one most respectable person who has rung the changes on being dealer's man and dealer himself several times over. He never succeeded for himself, but always did so when employed for others.

The fact I have stated must at first appear somewhat unaccountable; but a little consideration will show that it arose from a very natural cause. I have said the person was a respectable man; I need not, therefore, say he was an honest one. Why he did not succeed as a dealer did not arise from ill-luck, imprudence in his business, or from not being a good salesman; but from buying badly for himself. The cause was this. No man knew better the kind of horse to buy to pay; and when employed for others, his good judgment and honesty never allowed him to buy any other; but when laying out his own money, he departed from those fundamental rules that should invariably guide every man in purchasing to make money, or, at least, to avoid loss. He would sometimes give c 3 
an imprudent price, because he fancied a horse; sometimes would let a money-making horse escape him because he did not fancy him; and at other times would be tempted by a comparatively low price to buy one that his judgment condemned. But when acting for others he allowed no whim, fancies, or price to hoodwink his good judgment as to what ought or ought not to be purchased. If, therefore, such a man would allow fancy to mislead - in fact direct his judgment, - what may we not expect one to do who does not buy expressly for sale, and is not an experienced buyer for any purpose.

Many a good judge is often so captivated by some peculiar point in a horse, either as to beauty or qualification, that he is tempted to buy him against his judgment; he has a right to do so if he can afford to pay for his whim, but he would not buy such a horse for another. In laying out the money of another person, or in giving advice to another, he would only look at intrinsic value; that value might consist in beauty, or action, or both; but he would use his best efforts to get his friend or employer value for his money - in short, would only buy a horse likely to " keep the money together."

If a man fell in love with a beautiful face and faultless figure in woman, accompanied by the temper and disposition of a very fiend, perhaps 
nothing could induce him to forego possessing his idol; but, where his senses would not be so fascinated, he would not select such a one as a wife for a friend. I have seen good judges thus infatuated with a horse who, taking him in all particulars, was about as desirable an acquisition in his way. This is another idol. I congratulate the man who gets both; but looking to the latter only, if good judges, when buying for themselves, will sometimes get into such scrapes, what have the bad ones to expect?

The man who is not a horseman must further bear in mind the very different situation in which he will stand if he gets a horse that does not suit him, to that of the man who knows what he is about. If the latter gets hold of a horse with certain failings, he knows how to cure or palliate them; or if not, to so far hide them as to enable him to get rid of them, and the brute with them. The man who is not a horseman can do neither.

Whatever may be the faults in a horse that he may purchase, they will be shown in all their deformity, when in his possession; very probably be made worse. Then Tattersall's " to be sold for what he will fetch," is the only remedy. There some other Mr. Green gets accommodated; the original one (notwithstanding the lesson) no doubt going to market again : he will then probably get the significant colour changed, and gets done 
Brown. This do possibly makes him look very Black, till he again sells, and again buys one who, on his mounting him, makes him look very Pale, and throws him. This makes him Black-andblue: he sells him, and gets another bargain. Before mounting, he looks at his bruises; he finds they are Green; and when he is mounted, the people look at him, and declare he is $\mathrm{Mr}$. Green again. I have given what I know to be good advice to such persons; that is - not to buy at all. If, however, they are determined to run the risk of doing so, I will tell them the sort of horse they will have a chance of not losing much by; and, on the other hand, the sort by which they must lose.

Every man knows the purpose or purposes for which he wants a horse; but as possibly he does not know the sort fit for the purpose, let him at least show this much judgment - let him buy one that has been satisfactorily doing the same sort of work he wants him for, and one that has been seasoned to it. Such a horse, from many circumstances, he may have the opportunity of buying at a fair price; in short, at something like his ordinary value. I am now only alluding to road horses, for we will not suppose any man insane enough to contemplate buying hunters unless he is a good judge of them; and, indeed, unless he is this, and a good horseman to boot, he will have no occasion, or, I should think, inclina- 
tion to possess them. Mrs. Glass says, "first catch your hare;" but she supposes you to be already a cook, otherwise she would probably have said "first make yourself a cook:" so I should say, first make yourself a horseman, then get the hunters.

When I recommend the tyro among horses only to buy such as he has seen doing in a satisfactory way the description of work for which he wants them, I must give him another caution, and that is, to consider whether he is judge enough to decide whether the horse has done this work in a proper manner; for a satisfactory way, as the term is here applicable, renders it by no means a definite one; as the question may be put, "satisfactory way" to whom? For if it is only satisfactory to a person who does not know how work ought to be done, the buyer may get possession of a brute that he will not find it very easy to get rid of under considerable loss. Doing work as it ought to be done, and only doing it somehow, just makes the difference, in two horses of similar age, soundness, and appearance, of being worth a hundred and forty, or only forty. It is true there are many persons who are content if their animal does his business anyhow, provided he does it; and if they are satisfied with this, and have bought such a treasure at his proper value, he is as good value to them as the best 
stepper that ever looked through a bridle; but as men, who are not judges of horses, are generally equally astray in their ideas of how they should do their business, the chances are they give as much for a brute as for a clever nag. This will never "keep the money together;" for though a man may fancy his brute to be as good, and worth as much, as such a horse as the Marquis of Anglesey would ride or drive, if he attempts to sell him he will find the whole of his mistake, and only one fourth of his money, as the consequence of purchasing for himself. It therefore becomes equally necessary for such a man to consult a judge as to how a horse does his work that has been at it, as it does to take the opinion of such a man in purchasing one to put to work that he has not been doing.

The next thing to be looked at is how the horse has been treated, for to bring one from good or careful management to the reverse is certain loss. If a man who has a farm of poor land was to purchase cattle from the rich feed of Lincolnshire, he must lose by every head he buys, to a dead certainty. I did not mean an equivoque by the expression, but let it stand, for probably some of them at least would die; but if a lot of Scots or Kerries are put on the same land, they will not only "keep the money together," but materially increase it. 
So it is with horses; almost all of them will improve on additional care; but every one will lose in condition, and consequently in value, by a want of that care to which they have been accustomed. If a man wants a horse to stand heat and cold, wet and dry, three or four sweats a-day, with permission to clean himself against a post, nothing but a country butcher's hack would do it. If, not intending to use a horse thus unfairly, he wants a quick buggy horse that can step over his seven miles into town in about thirty minutes, go back in the evening, and do this, we will say, five times a-week, and keep in condition, he must get one that has been used to it, or he must bring him to it by slow degrees.

One of the best buggy horses I ever had I bought of a Whitechapel carcass butcher, merely from seeing him come into town, certainly at the rate of sixteen miles an hour, with a heavy man and two calves in the cart; but I gave eighty-five guineas for him, and the good butcher showed me two other nags, nearly as clever, and in as fine condition as hunters. He prided himself much on this; in fact they could not be otherwise, for, partly from good judgment, and partly from the nature of his business, his horses had the three great promoters of condition - good care, plenty of corn, and fast work.

Now if any man bought one of these horses, 
and gave him less work and less corn, he might do very well, and look well, but he would not be in the condition our friend the butcher had him. With the same feeding and less work he would get fat, foul, good for little, and perhaps either vicious or sluggish; with less corn and the same work he would become thin, dispirited, and debilitated; with the same corn and work, and bad care, he would get colds, swelled legs, inflamed lungs, farcy - in short, out of condition in every way. The butcher's horses were treated in the precise way to keep them in the highest state of health and condition, and whoever had bought them, the more or less he departed from the same way, the more or less would they lose tip-top condition-that is, such condition as is in all cases necessary to horses called on to exhibit both speed and lasting quality. This is not, of course, necessary to all horses; but whatever the horse's business may be, to enable him to do that with ease to himself and owner, he should be in the best possible condition for the work he has to perform; in fact his condition, and consequent capability, should be such as to qualify him for greater exertion than he is daily called upon to perform, if we wish him to do his ordinary work pleasantly to himself and to his owner. Although I regret to say there are not so many kind horsemasters in the world as the animal deserves, still 
there are many; but there are also many, who, intending to be the most indulgent masters living, are, from not knowing what is and what is not kindness to animals, quite the reverse of what they wish to be.

I have an acquaintance for whom I purchased a very clever horse, and, when in proper condition, a very strikingly-handsome one. In this sort of condition he was last spring, when I sent him to his present owner. No man was more disposed to be kind than his new master; still when I saw the horse in his stable, only two months afterwards, he was no more the same horse than he was the Hero, or any other. He was one of the handsomest coloured greys I ever saw, except Old Isaac, who was precisely the same. When I sent him to his new master he shone like a bottle, was as round as one, and all the muscles in their right place. His mane and tail, both of which were particularly handsome, looked like spun glass; and his legs, which were remarkably good, felt and looked clean and firm as iron. When I next saw him, his coat was dead as a scrubbing-brush, and in many parts somewhat of the same colour; his mane and tail a kind of dust colour, and felt as if they had been washed with greasy water; his muscles flabby, and his legs filled and flaccid; in fact, if he had bought the horse of a dealer, and had given a hundred for him, the man would 
have been quite justified if he had been asked to take him back, in offering fifty as the maximum price in his then condition; though no doubt had such a case occurred, the owner would have set down the dealer as a rogue for making such an offer. Now none of this falling off in point of condition arose from any ill usage or intended unkindness, but solely from want of judicious management. He had come from a stable where all was done right; he went to one where all was done wrong. It would have been uncourteous in me to say so on seeing him : indeed, I conceived it to be unnecessary, considering the horse told this pretty plainly himself. Of some of his master's peculiarities in managing horses at work I shall, perhaps, have occasion to speak by way of elucidation of some other matters; I have said enough for my purpose here.

I have said that every horse will suffer from coming from a good master to a bad one: this is indisputable. I have also added that most horses will improve by coming to a better home than the one they may have left; but the inexperienced purchaser must bear in mind that better treatment does not always mean increased feeding or diminished work: that must, of course, depend on the quantity the animal had had of each. If the feeding had not been in adequate proportion to the exertion, the horse would improve either by in- 
creased feed or lessened exertion; but a man might get into a serious predicament by taking one from high feeding and strong work, and only riding or driving him three or four miles a day at the rate of six miles per hour, though he might, to a certain degree, diminish the very high feed he had been accustomed to. For instance, there are numberless horses going in coaches, omnibuses, and occasionally one in a cab let out for hire that do their work well, quietly, and are in good condition; but give them to a man who would only require what would hardly be exercise to them, he would find many of them take a very extraordinary mode of showing their gratitude for the indulgence; and, vice versâ, give a lady or gentleman's fat pet to a Newmarket jockey, merely to ride between the heats, if he had several races to ride during the day the boys would kill him by merely bringing the clothes from the starting to the ending post of each race.

For these reasons, I would strenuously recommend persons who do not understand the purchasing or management of horses, yet wish to avoid inconvenience and loss, under no circumstances to make purchases on their own judgment, if they would not suffer in person or pocket. For even supposing they go to a perfectly honest dealer, he is not to judge as to what is likely to suit. He will not sell them a lame or vicious horse : but it 
is not to be expected, if he has an unpromising young one, or a seasoned horse that is a brute, that he is to chronicle the imperfections of his own property, or to be philanthropic enough to keep such an animal, lest another person should be inconvenienced by purchasing him. If, on the other hand, such a person as I have mentioned goes to a rogue, of course he is done every way, both as to price and qualifications.

We will suppose a much stronger case, and one where there is the least probability of deception on one hand, or error on the other; viz., where a man not conversant with horse affairs goes to purchase of another of similar character (two respectable tradesmen, we will say): the one, having no further use for his horse, wishes to sell; the other, wanting a horse, wishes to buy; the animal is known by both parties to have done his work quietly and honestly for the last twelve months, and never to have been during that time (in the common phrase) "sick or sorry." Here, says or thinks a man, I am surely certain to get precisely what I want, and cannot err in buying. He will find he may though; for if the fresh purchaser wants such a horse for a different kind of purpose, or intends to treat him differently, be it with more or less indulgence, what the horse has been seen to do with his last master will be no guarantee of his doing equally 
"INCIDIT IN SCYLLAMI QUI VULT," ETC. 33

well with his new one. But we will suppose the new one does intend in every particular to treat and use him as he has been used and treated before; surely a person might say, "In such a case I may venture to buy without better advice than my own." Certainly you may, and possibly - I will say probably - the horse will suit you; and if so, you would do little harm in buying; but, should you want to sell, very probably you would, even under these favourable auspices, lose half your money; for this reason - though the horse may have done his work honestly enough, he may be but a brute after all. His former purchaser may have bought him of a dealer who behaved as well as could be asked of him, - namely, selling a sound, quiet animal ; but, depend on it, he got from the kind of customer to whom he sold, sixty for what was only worth thirty. The owner tells you, as a friend, true enough, "I am no horse-jockey" (upon which I dare say he much piques himself); "I do not want to make money by my horse; and though I ran the risk of how he would turn out, and have proved him a good horse" (mem. qucere), "I only want what I gave for him." Nothing can be fairer than all this. Still, though your friend is "no horse-jockey," you will find, if you want to sell, as he would if he had wanted to sell (unless he had found you, or some other knowing as little), that you are done clean out of thirty; the only dif- 
ference being, the dealer knew he was selling at sixty what was only worth thirty, your friend sells for sixty what he believes to be worth that sum, though only worth half of it: you are both done, and your pocket derives no benefit from your friend not being "a horse-jockey." Still, purchasing under such circumstances is perhaps the best and safest mode by which such persons can go to work, if they are determined to purchase for themselves.

We will now suppose that a purchaser of the class I have alluded to, buys a young horse of a farmer, miller, or some such person, who bred him; and to such sources such purchasers are much in the habit of going. I possibly may have known instances where such purchases have been made, and the purchaser has not lost by them. If I have, the instances have been so few, that I cannot bring any case to my recollection; and, where they have occurred, probably the not losing arose from not attempting to sell. Low-priced hores are generally wanted for purposes where use without show is wanted. I have occasionally wanted such a horse. I trust I need not say I never bought a raw young one for such a purpose; consequently, personally, I never had dealings with farmers for low-priced horses; but I have seen many of these forty-pound bargains, and, generally speaking, precious bargains they were. Such men always, without exception, value 
such beasts much above their mark; and then, as if the circumstance, like charity, covers many sins, they tell you "they bred them." So you see written up, as an inducement to the passer-by, "home-brewed ale," and "home-made sausages," when, Heaven knows! the chances are that those who partake of either delicacy will wish they had been made a thousand miles from home. Such men breed from any mare that will breed; get a common country forty-shilling sire; or, if their aspiring thought carries them so high, some thorough-bred one, whose shape, make, blood, and performance bring him to about the same price; they thus get a living beast probably inheriting all the combined imperfections of both parents, put him (very properly, if they kept him there) to plough at two years old, ride him at three, and at four - provided he will carry you on his back (for mouth or action is, of course, not attended to) — he is sold as a "loickly thing" at forty or thereabouts. "He has never been in anybody's hands but their own" (so much the worse). "They know what he has cost" (very doubtful this); "he must be worth that." Why? Forsooth, because, like the beer and sausages, he was manufactured at home.

Going to topping farmers and breeders is quite another affair. Such persons, being known as breeders of horses of a superior class, are sought out by private gentlemen, or by such dealers as 
Elmore, Anderson, and other first-rate men in the trade. Such breeders find that when they have a superior horse, they can get a long price for him; and, on the other hand, when they unfortunately breed a bad one, or, at least, a bad-looking one as to shape and action, that they can get very little for him; and, indeed, such dealers as I allude to would not buy him at all. Breeders of this class, therefore, unlike the small farmers, soon learn to distinguish between fine horses and ordinary ones, and know that having bred a horse will avail them nothing, unless they have bred a good one. They soon learn the value of London action for London horses; and also racing action, or something very like it, for horses intended to be made first-rate hunters of. Such horses range in price from ninety to a hundred and fifty; for, now-a-days, a fine young horse, with first-rate action for harness, is worth quite as much as one intended for a hunter. It is true that when the one becomes a hunter, he may be worth considerably the most money; but it must be borne in mind, that the horse with fine action is almost certain to make a first-rate harness-horse ; but the one with equally promising action as a hunter may not be worth a farthing as such when put to the test. Therefore, although the purpose for which the latter bids fair is of a higher order than that for which we design the former, the chances against realising our hopes being so many more 
WHEN THE "STUD" ASSISTS THE "POCKET." 37

against the hunter than the harness-horse, their value, till tried, is about the same.

Such breeders as produce this superior sort of horse for sale are very proper persons for three distinct classes to apply to, of course supposing each man of each class to be a good judge; namely, first-rate dealers, men of large fortune, and men of very little fortune. The first applies to them as (in a general way) the best source from whence he can get horses suited to his purposes of trade. He then, as a matter of course, puts such persons about his purchase as will make him what he wants.

The man of fortune goes or sends to such breeders because he wishes to have both fine and clever horses; and knowing the enormous price he must give for such as he would like when made hunters of, he buys a young horse, puts him under a man who knows the precise qualifications in a horse to meet the wishes of his master or employer, and, as far as it can be done, he rides and makes the horse into what is wanted. It is perhaps an amusement to the owner to see the young horse improving (that is, when he does improve). If he stands the ordeal, and becomes a good and perfect hunter, he made a fortunate purchase ; but, knowing what I do of young ones, if he made such a hit this year, I should recommend him not to expect to do so the next. He must wait his turn. 
There is only one 6 on the six sides of a die; so we must not expect to throw it twice running. We may, and often do; but sometimes we may throw ten times without the 6 : so it brings it to about the same odds. They are quite as great against a young horse turning out first-rate as a hunter.

The other man is the man of moderate means. He goes to the same source if he wishes to have very fine horses, because he cannot afford to give three or four hundred for a very fine horse-a made and proved first-rate hunter. This man instead of paying for having his horse made, makes him himself, and succeeds more or less, according to circumstances; but if he attempts to do this, we must suppose he has fine judgment, fine riding, and fine nerve to back him; in which case, though he will not, of course, succeed with all horses alike, still he will make them all into moderate, good, or capital hunters; and, barring accidents or great ill-luck, will make money by them; and so he ought who gets plenty of bruises by land, and occasionally half drowned by water; for this is a little sauce piquante that a man may expect with the first and second courses in trying to keep his place.

I have now got among a different class of men from those I set out with, and for whom only the foregoing has been written. I have mentioned three distinct classes who go to the best breeders 
for horses, and find their account in so doing. I trust, however, that by mentioning the advantage of such persons purchasing from first-rate breeders I shall not induce men of less pretensions in horse affairs to go there; for if they do, they will find their losses even greater than in buying from the small farmer, inasmuch as they cannot be supposed to be in any way better judges of superior horses than they are of those of an inferior class; and as the price in one case will very far exceed that in the other, so will the penalty they will pay for want of judgment be proportionably greater: they will, in fact, give a hundred and twenty for what is worth sixty, instead of sixty for what is worth thirty; and will also find that they will lose by such valuable young horses in a still greater proportion than even what I have stated as relating to the purchase money.

It is not probable that the man who is not a judge of what is and what is not a promising horse will be found a good horseman, or one, either by treatment or otherwise, likely to bring on and improve such an animal; and it is only by improving a young horse that he is to be made worth more money than he was when purchased. The higher the class of horse, the higher will be the class of men he will be destined for ; and the higher the class of men, the more particular are they (generally speaking) as to the qualifications 
of their horses; and as much more as the man of fortune and family would lose in the estimation of others than the common man by coarse and vulgar habits, or by the want of refined ones, so much more will first-class horses lose in value than ordinary ones, from wanting those niceties in certain qualifications expected from superior animals. A boring, heavy, dead mouth, or a light, pleasant one, will, in a horse of equal pretensions as to breed, shape, beauty, just make the difference between two hundred and fifty to carry the master of the pack, or eighty to carry the whip, though both are equally good horses, and, in other respects, equally good hunters.

If a man who is not a good judge of horses, or a good horseman, thinks he can bring forth in a young one all the qualifications I allude to as to action, carriage, mouth, fencing, and temper, let him buy him: should he succeed, I shall willingly allow I was wrong in attempting to check his ardour in purchasing; but as I conceive there is quite a possibility that he will fail, if he does, there is also a possibility that he may regret not taking my advice; which is, to such a man, "Do not buy young horses yourself for yourself; or, if you get one, do not attempt to teach him anything yourself for yourself, or for anybody else." I do not mean to say that it is at all impossible for a man who may be by no means a good horseman to make a young horse into a something to suit 
himself, his style of riding, and his ideas of what is pleasant, and this would quite suffice if he makes up his mind to keep the horse for one of their lives, or both, should they end them together - a finale by no means to be considered as an impossible event under such circumstances, for most extraordinary are the opinions of some men as to what is pleasant and what is safe in the action or habits of a hunter, or indeed a horse for any purpose.

I remember, as a boy, frequently meeting General White with hounds, that is, occasionally seeing him for the first ten minutes after a find with the Duke of Richmond's, but much oftener with Lord Newburgh's harriers, with whom I occasionally took a day when living near their kennel. The worthy General walked a good sixteen or seventeen stone, and stood an honest six feet, whether on the ground or on his horse, for when in a gallop such was the peculiarity of his seat, that he stood equally straight and upright in either case. The General piqued himself on his riding, and still as much on two extraordinary fat pig-like animals that he rode, and thought and affirmed them to be two of the finest horses and best hunters living. To see him in a gallop on these mountains of flesh was aw.ful; he rode with both bridoon and curb-reins together in his hands, on which he had accustomed them to hang, and bore till he could not have kept his seat, or 
rather stand, without this fulcrum, and they would not know what to have done without the General as a support to their heads: command of their mouths, of course, he had none, but when he plumped down on his saddle they took it as a signal to stop, and stopped accordingly. Of the General's fencing I have heard him speak loudly himself, but as I never saw anything of it, or any one who had, I can say nothing on the subject.

I anticipate the observations of some on reading what I have written, and can fancy I hear them say, "It requires no ability to tell a man when he has done wrong that he has done so." No one can deny the truth of such an aphorism. I will add something further: it does not require abilities of any high order to tell a man where he has done wrong, though this may be somewhat more difficult: it may also be added, that if any man takes upon himself to tell another when or where he has done or will do wrong, he ought to feel himself competent to tell him how to do right. I allow he ought; but whether he can is quite another affair.

If a man wanted such information as was applicable to the general tenor of his conduct in life, he could not fix upon a man less qualified than myself: in short, in fixing on me as a finger-post to point out the right way, his selection would be a most unfortunate one, not having been prominent 
"A BOAT, A BOAT, UNTO THE FERRY." 43

in wisdom as regards my own career in life; but as in the present case, I only venture advice on the very subordinate acts of purchasing and treating horses, though I cannot say I shall do any good in giving it, I at all events try to do so ; and in point of fact, I have not only promised to tell a certain class of men where they act injudiciously, but I further promise to tell them how they may act with more prudence; for if I show them in how many ways they must suffer in making their own selections of horses, and then purchasing for themselves, I conceive it to be tantamount to recommending them to let others purchase for them. It would be an act of greater arrogance than I hope I have ever yet been guilty of, if I could suppose any one would act on my advice, merely because I give it. But if they find that by acting on my advice (which is, to act on the advice of others) they avoid losses they have hitherto sustained, so much the better ; if instead of this they choose to act as they have hitherto done, they will be only where they were.

Supposing (to bring forward a personal case) I fancied myself a waterman, and wanted a boat; I might go to Searle, and fall in love with one of his wager-boats, that carries one, not, as we say in coaching, "outside" or "inside," but as those boats do, half out and half in ; I might show my taste in having purchased a very pretty sort of aquatic race-horse; for which, no doubt, honest 
as Mr. Searle doubtless is, seeing me a Mr. Green he would make me pay a pretty price, well knowing, at the same time, it would be about as useful to me as a pair of dancing boots to a whale, and that the chances would be ten to one but that I upset it the moment I got into it, thus reversing the boat and the order of things at the same time; I underneath, the boat playing leap-frog over me - a kind of aquatic pastime I should possibly not have the opportunity of repeating. Serve me right! What business should I have buying boats? Now if I wanted some such watermachine, and had sense enough to depute some friend conversant with such matters to get me one, I doubt not but he would have sense enough to get me a good-sized flat-bottomed punt, that I could shove about and sit or stand in at my ease, like a bear on a timber-float, a passenger who not unfrequently makes use of such a mode of transit in the far West.

There are few of my readers, I dare say, who could be induced to think that in purchasing horses they are in about the same situation as I should be in going to boat market. Such, however, is the case with very many of my acquaintances; they do not certainly run the risk of being upset in a river, but their pockets get upset to a certainty, and sometimes both their vehicles and bodies also; the only difference being, that these occurrences take place on dry land. 


\section{CHAP. II.}

STABLE MANAGEMENT. - VENTILATION. - WARMTH. - DIFFERENT TREATAENT FOR IIFFERENT HORSES.-DRYNESS. - WIDE DOORS. - STALL-POSTS. - RACKS. - WINDOWS. BALLS. - MANGERS. - HEAD COLLARS. - COLLAR SHANKS. - MUZZLES. - LOFTS. - OBJECTIONS TO KEEPING HAY IN THEM. - DIFFERENT MATERIALS FOR STABLE FLOORS. CAUSES FOR HANGING BACK. - STABLE DRAINAGE. STABLE REQUISITES. - NECESSITY OF RULE. - SADDLE AND HARNESS ROOM, - STOVES. - BOXES.

WE will now suppose a person to have got, through the good offices of a friend, as many horses as he intends to keep, and those of a fair sort for the purposes in view. Of course I put race-horses out of the present consideration. We will now have a look at

\section{The Stable.}

If I should say that about one stable in a hundred is built so as to be perfectly comfortable, healthful, convenient, and workmanlike-looking, I should be giving odds in favour of the planners of them. Doubtless horses live that have been kept in all sorts of stables, and sometimes in rery bad ones; but horses also die that have been kept in them; and many of these stables have been the 
occasion of more deaths than they are accused of. Provided the horse is comfortable and healthy, it certainly matters not, as an abstract fact, where he is kept; but it is not very easy to know, but by consequences and the effect of time, whether he is comfortable, or healthy. He may be comfortable, but not healthy. He also may be healthy, but not absolutely comfortable. I grant this cannot go on ad infinitum, without our finding it out; but then the evil is done, either in a temporary way or in a lasting one. It is really singular, or rather remarkable, how constantly we see very clever men permitting all sorts of annoyances to exist about them, and though we may daily hear them regretting the existence of the evil, yet take no steps towards remedying it. The suffering these inconveniences to go on very frequently arises from sending for a mechanic in the first instance, instead of consulting their own common sense. The mechanic's interest is, of course, to make a job; consequently, if twenty shillings would do it, he recommends what will first cost five pounds in the undoing, five pounds in materials, and then another five pounds in doing up again. The consequence is, the evil is allowed in many cases to go on, rather than incur a heavy expense.

I have frequently heard people complain of the damp of their stables, and the water hanging on the walls; in almost every case this dampness is 
to be got rid of, with the exception of, in some cases, the water on the walls. [This sometimes arises in stables near the sea coast from the mortar having been made with sea sand, instead of the proper dry material. Such walls will universally give in damp weather, or indeed when warmed by the heat of the horses.]

In almost all other cases, dampness in stables arises either from ground damp or want of ventilation. Of this any man may judge from different circumstances, and, generally speaking, the remedy need not be attended with any very serious expense: drainage and raising the floor will mostly have the effect in one instance, and making proper vents for the heated vapour to escape near the roof will also nearly always be sufficient in the other.

Where a stable has the defect described, it should be remedied at once, or the horses taken out of it; for if they are not, sickness will sooner or later cause double the expense of the remedy.

A lady may be very comfortable who, during six months in the year, never stirs from her own heated apartments, unless to get into her carriage, where a chaufferette keeps that to the same tem perature, while it conveys her to the still more heated atmosphere of a rout. She is comfortable, and for a time fancies herself in unimpaired health; but the habitual lassitude, the physician's carriage 
at the door, and the cheek from which the tint of nature is fast receding, tell a tale that, if long unheeded, ends in the necessary sojourn in another climate - sad prelude to the tomb of loveliness and probable worth.

On the other hand, the sturdy wife of the labourer, while she pursues her daily occupations, within doors and without, has little perhaps to boast of as to absolute and general comfort. She has health and bodily activity - knows no real suffering; but the effect of exposure to the elements without, and her usual occupations within, produce a coarseness of frame and general appearance at variance with feminine beauty, though conducive to health and strength.

The heated, unnatural, and vitiated air of most of our London stables, though they may not show their effects in the appearance of the horse, or seem to affect his vigour, when required merely for a park drive, would tell tales if the same horse was called on for severe and long-continued labour. Here the effect of his debilitated constitution would soon tell something was wrong, and probably in'flammation of the lungs would quite satisfy us of the fact.

On the contrary, the stable where proper warmth is wanting, and where currents of cold air are frequently permitted to enter, though not perhaps so comfortless as to cause suffering to the horse, 
or to directly injure his health for certain purposes, would shortly show him as an animal, both in ap. pearance and condition, as totally unfit, internally and externally, for that fast work to which valuable horses are put-externally from having the coat of a bear, and internally from its having been impossible in such a stable to have carried him through that discipline necessary for such purposes. Such a stable, after a sweat, would be death, though the cart-horse might live and have his health in it.

Various have been the plans suggested and drawn for the elevation of stables, and in many cases the taste and talent of some of our first-rate architects have been called for in the erection of them. This is all very well, so far as it gratifies a very pardonable vanity in men of large fortune, who pique themselves on their studs of horses, among their other valuable possessions. They, as a matter of course, have many friends who indulge in similar pursuits, and consequently vie with each other in the arrangement of their stables, as much as their ladies do in that of their nursery, boudoir, or conservatory. Such expensive and tasteful decorations, internal and external, of course, add nothing to the comfort of the animal. All that is required in stables for the well-doing of the horse amounts only to this: they should stand dry, be roomy, lofty, warm, yet with the 
means of abundant ventilation when required; for in fact, even in the severest weather, ventilation is indispensable: it is in this particular, more than any other, where the healthfulness of stables usually falls short of what it should be; however warm a stable may be, it should be perfectly $d r y$. The moment anything like steam is seen hanging about, that stable is unhealthy, and colds and debility, with all their concomitant evils, follow as sure as night follows day. Many a first-rate stable have I entered in the morning, when even the clothes on the horses' backs felt damp, the walls and windows, of course, streaming with water. To speak to a groom on the consequences of permitting this to continue would be words thrown away; he will fancy it keeps his horses fine in their coats, while the fact is, it has a directly opposite tendency - it produces debility and ill health, and if horses so circumstanced can look blooming in their coats, they must be made of different materials from any that I ever had to do with. It may be that while horses are in this pest-house, and consequently are in a state of comparative perspiration, their coats may stick to their skins. So they would if they came out of a warm-bath. But take them into the air: if their coats do not stand on end, and thus let every particle of cold wind on to their skins, I am much mistaken. The coachman or groom, on seeing this, will say, perhaps — "You see now what bringing 
them out of the warm stable does!" I should, on the other hand, say, if he had sense to understand it, "You see what putting him into your wet warm stables does." I quite approve of the warmth; but there is some difference between the fine dry warmth of a well-aired, well-warmed dining-room, and the damp heat of a washhouse, with a copper boiling in it. I ridicule the idea of those who talk of keeping horses in a natural state of temperature: that is, natural, according to their ideas of what is natural, by which they mean cool, or rather cold. The fact is they mistake what is natural to the horse: heat is natural to him, not cold - that is, it was natural to him in his original state, and we by use have rendered it the same to him in his present one. He will thrive under a tropical temperature: but let it be remembered, a tropical heat is a dry one. A cook will bear the heat of his kitchen, with fires, and hot hearths round him; the damp, heated air of a forcing-house would shortly kill him, though his kitchen is the warmer berth: but the air there, though hot, is dry. The warmth of the stable is comfortable and healthful to the horse, if it is only a proper warmth: it only becomes injurious when the warmth is from a wrong cause : proper warmth should be gained by excluding the cold air, not by keeping in damp and heated exhalations from the horses' bodies. 
Most good stables have quite a sufficient number of windows to admit as much air and light as any one could desire; and also as many flies during the summer months as could be wished, and rather more. But these apertures, from their general situation, are totally inadequate to the escape of the vapour: it therefore becomes condensed, thus converting the stable into a dripping well. All the windows required in a stable, in a general way, are as many as will afford sufficient light: there should always, where practicable, be a sufficient number placed towards the north, for this reason - they can be made to fit close enough to exclude cold in the winter, and in the summer it is cool air we want. Now, though I consider that there are generally apertures enough in most stables to answer one purpose, we rarely, if ever, see them made for the other-in fact, in most stables there are none where they are wanted, which is at the highest point of elevation the stable will afford. Of these there should be some both before and behind the horses (made to close when wanted); for, should the air blow in either of these directions, it must follow that no escape of effluvia can take place on that side; whereas the current coming in on one side drives this steam out at the other. So, instead of having a condensed fog over the horses, we get a fine dry air, which is, or should be, too high to affect the horses so far as cold goes. 
We often hear persons laugh at many of the practices of our ancestors, though in many things I conceive the true laugh is on the other side. Let us look at a very old-fashioned bed, for instance: here we see the foundation, about fifteen inches from the ground, having an honest nine or ten feet between it and the tester. Look, then, at one of more recent date: here we find the foundation made so high that it forms a kind of first-floor of our bed-room, and by the time a paillasse, wool and hair mattress, and perhaps a feather-bed, are put on, we get into the attic, to which we are forced to climb by a movable staircase. This brings us nearly within arm's reach of the tester when we lie down. If then a set of good thick curtains are drawn around, we have a very fair succedaneum for cucumber culture. Persons sleeping thus, then, wonder they get colds, sore throats, et cetera, and feel enervated. Why, the very cucumbers suffer if the gardener omits giving them air at proper times or shutting them in if any cold wind blows. How, then, can people expect to escape? The good larlies of those forefathers we laugh at, would not have had an appetite to eat beef-steaks and drink ale for breakfast had they slept thus.

So far as relates to the general temperature of stables, in an ordinary way, I should say that $60 \mathrm{deg}$. is a fair average for horses used for road 
work, or for hunters rode with harriers: hunters, as they are now used with foxhounds, should be kept several degrees warmer, particularly about the time they are changing their coats. At this time, a few days will change a horse's coat from satin to cotton velvet, unless the thermometer in the stable is closely watched, and each horse watched also. Lucky, indeed, is the man who, if he does not strictly attend to this himself, has got a groom who will. All the comfort - nay, luxury of a fine coat in a horse will be destroyed by a few days' inattention in the autumn. Let him once get his coat up at this time, you may look forward to early summer to see him with a fine one. Nature is uncommonly obstinate in this particular: if she is permitted to put a pea-jacket on a horse about the time I mention, I defy art to take it off again unless she cuts it off.

I have heard a diversity of opinion between the good or bad effects of two different modes of keeping horses warm, some advocating very cool (I do not say absolutely cold) stables, with heavy clothing; others very warm stables, with lighter clothes: and these two opposite modes I have heard discussed by men who were quite competent judges of the matter. I should be very presumptuous, where such men disagreed to pretend to say which was wrong; but I can have no hesitation in saying the man who took the middle 
course would be right. Supposing, however, it was necessary to adopt one of the two extremes, and any one complimented me so far as to ask which I should consider the least bad, I should say a stable somewhat too warm, and moderate clothing. I reason by analogy. We will suppose two persons to be sitting in two different rooms; the one in a room at the ordinary warmth of a comfortable dining-room, say 65 degrees, and clad in an ordinary evening dress; the other to be placed in a room ten degrees colder, but so be-lamb's-woolled and be-piloted as to bring the temperature of his skin to the warmth of the other. Let them both strip to their shirt and drawers, which we will consider to stand in the place of the natural coat of the horse, and go out. I consider the man throwing off his sweaters would feel the sudden exposure of his skin accustomed to such clothing more severely than the other would the change of atmosphere. Against this, I am aware it may be said, how severely we feel the cold coming out of a theatre or crowded ball-room. No doubt we do, and so would a horse coming out of a stable of the same temperature; but when I allude to stables somewhat or rather too warm, I do not mean one at 90 degrees; and when I state I prefer one rather too warm to one rather too cold, I mean it in the case of gentlemen's horses, not of a street cab horse, or even a 
medical gentleman's pair, or the one condemned to shiver for half an hour at some old lady's or hypochondriac gentleman's door, while the worthy Esculapius is persuading either that their case requires the most delicate care, or in a case which, in justice to our medical friends let us allow, is of quite as frequent occurrence, namely, where the fancied invalid endeavours to convince the medico of the same thing. Such animals (not the invalid or medico) must be kept cool in every way both as to stable and clothing. So far as their outsides go, their warmth must emanate from (in stable slang) their "body lining;" and even then they must be brought to bear this sort of treatment by degrees; for let a medical man, in the middle of winter, purchase of a private gentleman a pair of horses which have been accustomed to different treatment, in a month, or perhaps less, he would want another pair. We should recollect that gentlemen's horses are in their stables, taking one day with another, perhaps twenty hours out of the twenty-four, and when they are exposed to the air they are at exercise or work. Consequently the proper warmth of the air they breathe in their stables is of vital importance to them; and though I most decidedly object to their breathing a hot damp air all this time, I am quite sure, clothe him as you will, a horse will never feel comfortable, or be in condition, that breathes a cold one. How 
TREATMENT FOR DIFFERENT HORSES. 57

should we like (clothe us in blankets if you will) to be kept night and day with our head out of the window? A cold stable is, in a limited sense, something like this:- let me ask my friends this simple question,- have they never on a cold night (though with plenty of bed-clothes on) put their noses under them? If they have, I need say no more on the luxury of inhaling cold chilling air, or its reverse.

Ask any man who has undergone the pleasing change of taking off his warm clothes, and been kept waiting on a cold day, in his silk jacket, on his horse (while some gentleman rider was arranging himself to his - not the man in waiting's satisfaction) how he felt on such an occasion. Coming from Mexico to Canada is heaven to it. If a man is too warm from a room being the same, but is moderately clothed, evaporation can go on; he is warm - hot, if you please-but his skin is comparatively dry: great thickness of clothing would prevent this; so the pores of the skin of the wearer would be as damp and open as if he came out of a warm bath.

To return to the upper apertures for ventilation, they may be either glazed or simply of board, as suits the taste of the builder, and should be made to open and shut by a double cord hanging down within reach of the hand. The lower windows I have had made to slide right and left into 
the wall: they are less likely to be broken than such as open inwards or outwards, or turn on their centre. But I had a far better reason for having them made thus, which was - I always had a movable frame made to fit the window on the inside; on this I had stretched the same kind of open material that is used for meat-safes; the windows can then be left open, and those positive pests to a stable in summer, the flies, are thus excluded. But I went a little further than this, and, as the expense is not more than twenty shillings once in half as many years, I venture to recommend it. I had also a framed-door, on which the same material as that for the extra window-frames was stretched. This opened the reverse way to the usual stable door; it was made to take on and off the hinges, so that in hot weather the usual door could be fastened open and the stable kept cool: this, of course, can only be done where the stable is in a secure situation; but where it can, it is a great convenience at times in extremely hot weather.

Having paid, perhaps, more attention to the comfort and safety of horses than the generality of persons, I will mention another very simple precaution I had as to stable-doors. These, I must mention, en passant, are generally made by far too narrow, and often too low. Some horses have a trick of both entering and coming out of their 
stable in a hurry, probably learnt while in a dealer's hands. When the doorway is either narrow or low, this often occasions their getting hurt; and this further increases their propensity to rush through the aperture: and I doubt not that many of those horses we see down on one hip have become so by a blow against the door-post. This idea set me to work to provide a safeguard against such a contingency, which I did in the following way: I had my frames made a foot wider than usual, and the door, of course, made to fit them. I had two round pieces of wood, similar to a leaping-bar, with the same sort of iron spindles at each end; these were fitted perpendicularly inside the door-case; so if a horse hit them in passing they rolled round, and all danger of an injured hip-bone was avoided. The difference in expense was not twenty-five shillings; and when we consider that if five horses, worth (say) five hundred guineas, inhabit a stable, and each pass the doorway twice a day, we have a thousand guineas placed within the chance of injury seven hundred and thirty times every year, which would be avoided by a single sixpence, which is about the interest of the money laid out.

The doorways of all loose sheds where valuable mares, colts, or horses go in and out of them should be made wide; for these frequently pass the doorway in a trot - sometimes, indeed, in a 
gallop. Padding such doorways will answer the purpose: but horses, particularly young ones not doing work, are mightily inquisitive, and are apt to wish to learn what the padding is made of, to ascertain which they will take the liberty of tearing it off: a clothing of furze is the best safeguard.

It is a very common - indeed the most common - plan to build stables with the stall-posts running up to the ceiling, and where that is not the case (as if the people were determined not to be without some inconvenience of the sort), they frequently put balls on a pedestal on the ends of the standing: these, made of oak and octagonally cut, certainly look well, and give a handsome finish; but they are nearly as great an objection in the stable as the long stall-posts. Ornament a stable as much as you think proper; but it should never be done at the slightest risk of injury or expense of comfort to horses.

The first objection to the long post is this. We will suppose the stall to be the full width - six feet (if narrower the objection is tenfold), and the horse to be standing turned round in his stall to have his head dressed; this being done, he has to turn round to his place. How is he to do this? It is quite clear he is much more than six feet from his head to his tail. He is aware the stall will not admit his turning with his neck in anything like a right line with his body; so 
where there is no stall-post he avails himself of it to put his head over the adjoining standing, and thus turns without inconvenience; but where there is, he is forced to tuck his head and neck round like a turkey poult prepared by the poulterer. This takes him some little time to do; and there are such things as grooms to be found who, instead of permitting him to do it at his leisure, have a habit of accelerating his motions by a flick with the duster ; round he forces himself, making the standing creak again, and looking - and, indeed, being - frightened out of his wits, from supposing he has done something wrong. But more than this, some timid horses, if told to " go round!" sharply, forgetting the stall-posts, bang their heads against it, and many an eye has suffered in such a case; master finding his favourite Quornite the next morning with one shut. Of course, the horse "did it during the night, in the dark," where perhaps that eye will for the future remain. The same objection, but in a minor degree, exists in the horse coming round: but he seldom comes round as hastily as he goes back. The elevated ball is not quite, but nearly, as bad; he can, if not too high, lift his head over this; but unless plenty of time is given him to do so, bang goes his head against that also.

I know but of one or two reasons that can be produced in favour of stall-posts: the first is, that each stall in this case, furnishing a prop for 
the support of the cross-beam of the ceiling, tends to add strength, where the timber is light; and if the standings are made, as half of them are, of deal, they gain considerable strength by it also; and this reason is very well, where a place to put loorses is only intended to be built, that at the least possible expense, and, as is universally the plan on such occasions, to build on as small an area of ground as possible. Such places are only a shelter partitioned off; but, where a man means to build a stabie, the difference between a good one and a bad one, in point of expens, is more than compensated for by the comfort of the one over the other, to yourself, your horses, and your men particularly, when health, safety, and durability are taken into consideration.

Another motive for having stall-posts may be the wish to have, for appearance-sake, arches over or rather behind the horses. Whether a stable looks better with or without them is a matter of taste; but they certainly afford no advantage; but, on the contrary, harbour spiders, flies, and, in some degree, prevent a free circulation of air two objections, I should think, sufficient to exclude their use.

There is a possibility - though, I grant, no great probability - of another very serious catattrophe occurring, both from stall-posts and balls. It is possible, because I have twice known it occur; 
but I allow it is improbable, because, among the many thousand horses that have come under my observation or knowledge, I never heard of but these two instances. This is kicking over the standing.

The first was a mare (at a particular season of the year): she was found with her leg over the standing, completely kept there by the stall-post; the groom, hearing the noise, went down, but before help could be got she had broken her thigh, and thus dropped back into her stall. The other was a horse: he, no one knew how, had got his leg over, and, being confined by the ball, could not get it back again; there he was in the morning, as it were, riding the standing with a thigh each side of it. However, they sawed the pedestal of the ball through, and then, by main force, shoved him back till he slid over the end of the standing. I am willing to allow twenty men may each keep twenty horses in a stable all their lives, and never get a horse so situated. But why run the risk, when it can be avoided? As to the former objections, they occur every day.

Supposing there to be neither stall-posts nor ornamental balls, even then the ends of the standings should not be left square, but nicely rounded off; so that in turning, no obstruction should meet the horse's head or neck.

On mentioning these circumstances to an ac- 
quaintance, I was asked how, without the stallposts or balls, the pillar reins could be fixed. To this I observed, that I conceived the use of pillar reins to be merely to prevent a horse, while waiting saddled, from straying from his stall : and supposing the standing to be the proper height, I thought that end would be completely answered, as, under ordinary circumstances, I had no wish that my horses, while so waiting, should be standing on a gag. I mention this, as the same idea may strike any one else.

Racks are made of all sorts and shapes, and placed in various situations; nor unless they are placed too high, do I consider it a matter of any very material importance where they are placed. Take them all in all as to look, comfort to the horse, economy as to forage and durability, I should say a small iron corner rack on the near side is the best. This should be low enough for a man to put the hay in without using a fork. It will then be low enough for the horse to eat with comfort, and he will not be induced to pull out more than a mouthful at a time: when he does, it produces great waste, as perhaps one third gets trampled under foot. When a horse does this, I have heard people accuse him of greediness; but it does not generally arise from any such cause, but from his having been accustomed to eat from a rack situated so high as to make the getting at 
his provender an inconvenience to him; consequently he has sense enough, when he does raise his head and neck to pull out a mouthful, to bring with it enough to last him some time, and this he discusses at his leisure. Racks should not, when filled to their utmost, be able to contain more than about ten pounds of hay. If you have a good groom, he knows that is more than enough at any one time; if he is an ignorant one, if the rack will hold half a truss, he will cram it full. If the hay is good, such practice is highly detrimental; if bad it is certain destruction if persevered in.

Iron manger's possess several advantages over wooden ones; horses cannot contract the habit of gnawing the bottoms of them, nor are they so tempted to lay hold of them in any part. Some get into the habit of licking the manger: this is all but a sure precursor to crib-biting, and should be put a stop to immediately. Let the stationary manger be well smeared over with train oil, and have a wooden lining made to fit in; this should only remain while the horse eats his corn. If this is attended to so soon as the habit is first taken to, the horse will oftentimes leave it off.

Head-collars have been much improved upon lately. The old sort were constantly being got off: those now made are quite safe in this particular, and are as good as can be, with one excep- 
tion - that is, that, unless particularly ordered, saddlers never make the forehead bands long enough by an inch on each side, by which the head-strap is brought so close behind the ear that it pinches it into a corner, which causes confinement and uneasiness; in fact, I have seen the ear chafed by it.

If any one who may read this work holds economy worth consideration, I would suggest to him, that ordering his head-collars to be made with, as it is termed, the flesh side outwards, causes them to wear nearly double the time of others.

In gentlemen's stables collar-shanks are usually of leather, which are the best_-first, for appearance; secondly, they make less noise in running up and down than rope; and thirdly, when the horse travels with his head-collar on, they roll up neatly. I say shanks: but in speaking of my own, as relates to one head-collar, I should only say shank, for I never use but one to each horse: for this reason; a horse sometimes gets his hind foot over them in scratching his head or neck: this leads often to serious accidents. Of course, where there are two, there is more chance of this occurring than with one; but the chance of his getting into this dilemma with two is much greater than the numbers go; for from the diagonal direction of each from his head to the rings, they are just in the 
way where his foot would pass from his head, and as he naturally, for his own convenience, brings his head round as much as he can to meet the foot (of course the hind one), it seems almost a miracle he does not get entangled whenever he may try the experiment. If he is tied up with one shank, bringing his head in contact with his hind foot, the shank goes diagonally in an opposite direction from his head, so that it is all but impossible for him to get the leg over it; at least, so I have found it, for such a matter never occurred in any stable of mine. It may be objected that some horses will bite at or play with others over the standing, unless they have double reins or shanks. I allow they will, if the stalls are narrow, the standings low, and the shank left too long; but standings near the manger should be too high to admit of these freedoms, which would often end unpleasantly. And there is a sure rule to go by as to the proper length of the shank. Bring the end that fastens in the head-collar to the top rail of the manger, let the shank then be of such length as just to allow the bottom of the $\log$ to reach the ground; no matter whether the horse be sixteen hands or a pony, that is the length, for each sized animal has to lie on the ground.

There is a fastening made to affix to the manger for which, I believe, a patent was taken out, but I forget in whose name; this is as secure as the 
common ring, so far as relates to a horse pulling at it in any ordinary manner. But should he get a leg over the collar-shank, and consequently be in danger of throwing himself down, he must of course force the shank strongly downwards: in such a case a spring gives way, and he gets free. I had them, and found them answer the purpose of any other fastening, and had I used double shanks I dare say I should have proved the advantage of having them: they cost little, and I venture to highly recommend their use.

It is rather remarkable how careless many persons are in some respects, while in others they are provokingly careful or anxious. This arises frequently from their not knowing or seeing apparent danger of loss in one particular, but from having a vivid sense of it in another. If a man went out leaving his desk open, in which there were a hundred and fifty sovereigns, although he might know it was a thousand to one against any one even going into the room, he would feel fidgety and uneasy till he got back and found his treasure safe; yet the same individual would, and perhaps daily does, allow an equal sum, in the shape of a horse, to be exposed to much greater risk without having an uneasy thought about it, till a broken leg, or some such casualty, gives him reason to repent his want of foresight. He then finds that from very slight causes very serious 
accidents occur. For instance, a friend of mine had his rack-chains ending in a hook, to fasten to a ring in the chain. I told him there was danger of a horse getting this into his lip or nostril : my only thanks were a laugh at my conjecture. What I considered very likely to occur certainly did not, but what was likely to end in a very serious affair, though of much less probability of occurrence, as certainly did. One of his horses got the hook completely through the upper eyelid: he had torn the hook from its hold of his eyelid, and was found in the morning bleeding profusely, the rack-chain hook covered with blood. It left a frightful gash, and a most ghastly-looking eye; and, from some cause or other, the horse ever afterwards startled at most objects that either met or passed him on the off-side. It is quite true such an accident probably never might occur again in the same stable; but, from the same cause, some other accident very likely might. And why have anything in a stable that holds out the remotest chance of injury, where it has neither look, utility, nor economy to recommend it?

There are two additional rack-chains, or it might be more proper to call them stall-chains, that I have found extremely useful with horses ticklish and inclined to bite in dressing. It is true, a horse may have his dressing-muzzle on, and the ordinary rack-chain will prevent his hitting the 
groom with the muzzle, which he would otherwise do. But he can still fly at the rack and rackstaves, by which $I$ have known a tooth broken more than once, and have seen the lip injured several times.

The two check-chains I allude to should be fixed to the standing, about two feet and a half from the wall, or rather boards, that are before the horses; and when buckled on or fastened to each side of his head-collar, effectually prevent his reaching rack, manger, or man, each chain being made so as to shorten or lengthen at pleasure. Thus the horse can be kept nearest the side the groom is not, if necessary. Horses that have a tendency to rush at persons passing by their heads while waiting on the pillar-reins when bridled, can be fastened on the check-chains, which prevents annoyance or irritation to man and horse, as in that case they stand with their heads towards the manger. I once saw a mare, in rushing at a stranger passing her head, so severely checked by the pillar-reins that it threw her on her haunches like a dog sitting, at the risk of a sprained back.

Of muzzles there are various sorts; any of them will answer their purpose, and there is but one that can be called absolutely objectionable (though still in very common use); this is made with a tin shallow basin or dish at the bottom. This I hold as a bad sort, for it stops inhalation 
of air, or exhalation of breath at the bottom; and, further, should a horse rush at the rack or manger, the chance of injuring his teeth or lips (as before mentioned) is very much increased; and indeed, in one instance, a serious accident had nearly occurred to a man of mine from one of these. I had sent him on to an inn with a favourite mare, in order to meet hounds the next day. He had omitted to take her dressing-muzzle with him (which I rather wondered at, as she had more than once had a grip of him): he borrowed one of these tin-lined ones : and after dressing her, and letting her down from the rack-chain, he stooped to do something to her fore-leg. She never gave away a chance on such occasions, and made a dash at the nearest part that presented itself, which happened to be his head: this she struck with the rivet that fastened the tin plate at the bottom, and laid his head open as completely as any Cornish single-stick player could have done, where, in their phrase, to constitute "a head" the blood must "run an inch." So much for tinlined muzzles, independent of their very common appearance.

The next sort are those in use in racing stables, made of solid leather both at bottom and also in the part that goes round the nose, with holes punched in every part to admit air. These are somewhat heating to the nose in summer time we 
must allow ; but as they are also used as "setting" muzzles, it is quite necessary to prevent the horse getting at any of his litter, which he might do if they were made more open ; and for racing stables they are certainly the best, or for any occasion where a horse has to be set over-night: a precaution quite necessary with some horses, as hunters, for, if greedily inclined, they will get at their litter if at all stinted in their hay, which is worse than the hay itself. One precaution should be always used with muzzles; namely, to have a throat-latch to them; for, if left on all night, the horse is all but certain to try to get them off. If he succeeds (where he is tied up), they get under or about his feet. This, probably, frightens and sets him plunging.

I once saw a muzzle made without any strap going over the head. It had four billets, one of which buckled to each ring of the nose-band of the head-collar, and one that fastened in front. It struck me as a safe and good mode of putting it on when used merely as a setting muzzle; and had this advantage, it did not require the bottom of the muzzle being kept so close to the horse's mouth to keep it steady; thus allowing free respiration.

One thing I most strenuously recommend all masters to insist on; namely, that a horse in the slightest degree inclined to bite should never be 
dressed without a muzzle on. The man may trust, and say the horse "won't bite lim;" but he does, and then gets a thrashing (which is sure to make him worse), all arising from idleness on the part of the man.

Having said thus much of the middle part of the stable, we will ascend into the loft; and, on returning, so soon as our feet touch the pavement, we will cast our eyes on that.

Lofts are very proper over stables, provided, and, as in legal phrase, "be it always enacted," that they are never used for the purposes to which lofts are often from necessity appropriated; that is, a receptacle for hay; or, what is worse, servants and their families. I suppose I ought, par excellence, to have given the latter precedence of the hay. However, as an amende honorable, I will make my remarks on them first. This I do for two reasons : the one being by way of compliment to the lady and her blooming ones - though, in truth, when brought up over a London stable the bloom is apt to partake a good deal of the lily's hue:my next reason for now giving them precedence of the forage is, though said sotto voce, they are by many degrees the greatest nuisance there. If, however, it is thought proper to have a colony over the horses' heads, disturbing them at all hours, the ingress and egress should always be from the outside: if a passage is allowed through 
the stable, the ten thousand errands such persons always have from the time the milk is fetched in the morning till dad's beer is sent for at night, varied occasionally by his coming home tipsy from having taken it out, give the horses about as much rest as if they were picquetted in Fleet Street or Regent Street, of which, if appropriated to a lady's use during a London season, they see quite enough during the time they are out, without being reminded of the same thing when wishing to rest themselves in their stable. No doubt the allowing a servant's family to reside over the stable certainly saves them the expense of lodgings, and consequently enables the man to take less wages than he otherwise could do; but it is a poor saving when half a dozen horses are to have their rest broken by it, independent of Jackey (if the passage through the stable is allowed), whenever he can find the opportunity, amusing himself by giving them a touch up with whatever may answer the purpose, to see "how they jumps" in their stalls - "Crikey, aint it fun!" Let any one turn a wild ourang.-outang into my stable, I would forgive it, as probably the brute would get kicked, and there his mischief would cease; but a half-tamed young imp of a boy has cunning enough to avoid being got rid of by so summary a process, and mischief enough to harass any living creature ad infinitum while he 
van do so with impunity. It has fallen to my lot to have had many lads or boys in my stables, sometimes several at the same time. Among these I have had some very good ones, who never attempted to play any of their tricks with me. This arose from several causes : they were never trusted with horses out of sight of some one of whom they stood in awe. The instant a boy is trusted alone, it matters not whether he be the heir of the family, or the fag of the stables, he is safe to be in some mischief, and woe to the animal under his control: to tease, and, in a certain degree, to torture animals is the delight of most of them. I know of few animals more annoyed than the pony of one of these young imps, apparently fond of the animal as he may appear to be. Keep a pony for mamma's darling, if you like, but, in mercy's name, never trust the animal to the boy's sole control. It is true, boys are employed in racing stables to dress, feed, water, exercise, and work horses, worth, perhaps, a thousand each ; but they are never for a minute allowed to be alone with the horse. And they are at the same time fully impressed with the firm conviction that any trick detected would be followed by the severest punishment from the trainer.

Let me, therefore, especially guard persons against employing boys in any capacity about horses in situations where they cannot be narrowly 
watched. Boys are as artful as men, and may appear steady and disinclined to mischief; but this one thing is certain - nothing but absolute dread, and constant watching into the bargain, will keep them from it. Be as kind to them as you please, and always reward good behaviour in them,-but keep alive the idea that punishment, more terrible than any man with common humanity would attempt to inflict, would be certain to follow any tricks played with horses. A person not versed in the arrangement and discipline of a racing stable would be quite astonished on seeing small boys go about race-horses as perfectly fearlessly as they do, and might see one of them pass safely under the belly of a horse that would at once savage a stranger, or, perhaps, even the trainer, if he could get at him: this, at first sight, speaks in the boy's favour, as indicating kindness to the horse, and therefore trustworthiness on the part of the urchin; in nine cases in ten, however, Jack merits little of such favourable opinion, for never being with the horse but in the presence of the trainer, or head lad, he dare not but be kind, or, at least, quiet with his horse, and as he feeds and waters him, the horse, in return, does him no harm; trust half a dozen boys with as many horses, without being well watched, in one week half the horses would be made vicious, and, probably, half the boys killed. I have said 
thus much on the subject of boys, from having seen the dire results of persons, from a mistaken idea of economy in point of wages, employing them in situations of trust; boys are useful and clever; industrious ones will stand nearly in the place of a man in some situations, but they should be only used as tools in the hands and under the observance of a first-rate workman.

There are many objections, though not, perhaps, of any very serious character, to keeping hay in a loft: one that is frequently made I consider a very futile one, which is, that the exhalation arising from the horses and the stable renders the hay bad to eat. In reply to this, I should say, that any moderately good stable is so ceiled that little of this exhalation would reach it, and it must be very badly ventilated if it would do much harm in this way: if it did, and the horses got amiss, I should accuse the stable of the mischief, not the hay. But the objections I make to the thing are these. Throwing down the hay is apt to get the seeds into the horses' ears and eyes. The opening of trap-doors, and, above all, letting them slam down, often alarms timid horses. If there are no doors, cats amuse themselves by jumping up and down; and, as their amorous dalliance begins in strains not the softest or most harmonious to any ears but their own, so it often leads to fierce pursuit; and, though I highly 
applaud and estimate the modesty of Miss Grimalkin, that induces her to rush down the rack like "one possessed," and the chivalry of Sir Thomas that brings him head foremost after her, the sober steeds are thrown in most admired disorder, and stand for the next half hour snorting their wonder at the ardour of these proceedings.

But there is a greater objection still to hay being kept in lofts. Unless they have skylights, at certain times of the year it gets dark in such places before the horses get their hay for the night; and though the groom or coachman may be a careful man, an extra glass may be enough to throw him off his guard, though not off his legs; and a dry loft is a bad place for sparks from a candle, or from a public-house either. And here let me most strenuously recommend the use of gas in stables, in lieu of oil or candles; its safety, cleanliness, certainty of properly proportioned light, and, where much is used, its economy, are beyond all praise. I had it in fifteen differentsized stables and seven boxes, all at the same time, for several years; so I am tolerably well able to judge of its advantages.

I do not make the same objections to straw being kept over the horses; in one way it has even some advantage in the summer season, as it keeps off' the heat of the tiles or slates. And straw never should be wanted at night; for two 
reasons: it should be put on the beds by day, which gives the stable a clean look; and it gets sufficiently trampled upon by the time the horses should be bedded up at night to become soft and comfortable. A clean wholesome bed is indispensable to man and horse; but stiff, fresh straw is by no means a comfortable one, particularly to fine-skinned horses, who will often in such a case be waled wherever they are not protected by their clothing. The whole bed should be at all times (after any damp straw in the middle of it has been removed in the morning) so clean as only to require fresh straw to keep up the proper quantity, and to give a fresh look to the stall during the day; then, with ordinary horses that only do moderate work, what is put under the manger is brought out at night. Hunters require often to lie down during the day; consequently, as they will then lie on straw but little trampled, it should be got as fine as possible. I greatly prefer machine-thrashed straw. It does not look so well, I allow, but it is far more comfortable to the horse. I recommend the strong, round, unbroken straw to fishmongers : to pack a salmon in, it looks clean and neat, aud I should hail its appearance if bringing one from a friend as a present, but I eschew it in a hunter's stable. I have had horses so fond of straw, that by night or day they would devour their beds; that is, so far as they could 
reach, or the straw was palatable: this, so far as the clean straw went, was, under ordinary circumstances, of no great consequence; and with a liunter who is to go with hounds next day, and has this propensity, putting on a muzzle stops him, which is the safest plan: in a general way, a little solution of aloes slightly sprinkled over the litter near his head will answer the purpose: it is not necessary to make the bed wet, or even to be called damp, for a slight smell of the aloes is sufficient.

I have heard many persons complain of straw being sent to them that was short in length; this is a great mistake. I never wish to see a straw in a stable more than two feet long: in fact, trussed straw should always be cut in half before the truss is undone. The long round straw is very well for horse-dealer's' use, to make the stable look handsome; but for private purposes it is both wasteful and inconvenient. It is wasteful, because, should one part become soiled, four fect of straw must be thrown out where only one foot is objectionable; whereas, in the same case, if only two feet in length, of course only two feet would be lost. It is inconvenient, because when it is so long it gets round the horses' legs; thus causing them to displace the order of their beds every time they move: in fact, for a hunter's or race- 
horse's stable I prefer straw that has never been trussed,

Having made our inspection of the lofts, we will now return to terra firma.

The area of the stable of course depends on the number of horses it is destined to contain; but its width should be the same whether it comprises three stalls or ten. Seventeen feet is just the width I would wish a stable to be from wall to wall; that is, where the racks are in the corner of the stall: if they are the old-fashioned ones that run across the whole front, the stable from wall to wall should be just so much more in pro-. portion to the depth of the rack, so as still to have the seventeen feet from the back of the manger to the wall behind the horses. This is wide enough to keep passers-by from any danger, and not enough to make the stable barn-like and cold.

Of pavement for the stalls there are various sorts, most of them having their advantages and disadvantages; but, at all events, the ordinary flint stones as pavement are decidedly the very worst ever proposed to pave a stall with. They cut the litter to pieces: the horse cannot stand on them with his feet bearing level, nor can he lie on them in comfort, unless he has a waggon-load of litter under him, which in summer is heating and unpleasant: and, above all, no man can keep such 
a stall sweet. Hard blue bricks, such as are termed fire-bricks, are very good, and will wear a long time; but the best are, undoubtedly, the clinker. I had once in Hampshire a stable with a chalk floor throughout, and very well (with a good deal of attention) it did ; but it is at best a makeshift. The newly-invented India-rubber floor, I should think, must in every way be excellent; at all events, it holds out numerous advantages. What per contras there may be I do not know: it is somewhat expensive as to its first outlay; but this does not prevent its being the most economical in the long-run. It strikes me the Indiarubber holds out a very considerable temptation to its use in this particular - it has no projections, and, if it had, even those would be flexible; so that in summer time, with ordinary work, a small quantity of straw would make the bed soft enough, and have the advantage at the same time of coolness. There are numberless apparent savings in what is done as regards the horse; they are, taking them all in all, really a waste of money. The animal, unfortunately for himself, and very often for ourselves, cannot complain; so we go on gradually, but imperceptibly, injuring him without being aware we are doing so; but it tells in the long-run. A horse does not show at once that he does not rest comfortably, but his loss of condition will eventually speak for him; and a pound 
or two in money goes but a little way in veterinary surgeon's bills. And in this way many pounds are spent under the idea of saving as many shillings.

All who have written on the structure of stables, or, at least, all who understand the subject, agree that for a horse's comfort the stalls should be nearly flat. Dealers have them very much raised in front, to show off the horses; livery-stable keepers to make any wet run immediately back, to save straw; the old flint-paved stalls were so made, for otherwise the centre of the bed would be a regular cesspool. Nothing but a great declension could enable the wet to meander its way backwards. A gutter or drain behind the horses is an unsightly thing, and, were horses only to inhabit the stable, it would be unnecessary; but, as mares also stand there, it cannot be dispensed with.

I consider the best way to arrange the floor of a stall is as follows: - The iron of the grate in the centre should be 10 inches square, made of good hammered iron (and not cast). It should be a full half-inch thick, and its extreme edge or border much deeper, so as to give it a firm hold in its oak frame. From wanting this precaution they are apt to get out of place, as is sometimes seen with the round iron coal-cellar covers on the foot pavement in London. The stall floor should 
be perfectly flat from the manger, till it comes within a foot of the grating: it should then have a fall to it of half-an-inch. By this the fore-feet of the horse stand on quite level ground. It should slope in the same degree a foot each side of the grate, and also from a foot behind it. This is sure to make the wet made by the horse run into the drain beneath; and his hind as well as fore legs stand level. These declivities on a well-paved stall are quite enough; and when the horse lies down, the bed prevents his feeling them. I must remark here, mares should always stand at the end of the stable; that is, the lowest end, as the gutter should be made with a slight fall.

In pursuance of my fixed principle, that what is best for any purpose is, in the long-run, the cheapest, in building a stable I certainly would make my standings of oak; that is, the boards of which they are made should be of that timber. They do not require to be made of the best sort; so the expense is not a great increase on those of deal. The posts and top-rails, being of considerable substance, will have strength enough if made of any wood; but if the boards are of deal, one kick in right earnest splits them. Where there is deal and within reach of the horses' mouths, iron hooping should always be fixed upon it. Gnawing soft wood is a favourite amusement with idle horses; and anything that induces or allows 
them to lay hold of wood should be studiously avoided. The same holds good with regard to the rack, if that is a wooden one.

I am a great advocate for roomy stalls; but there is a proper medium here : if too large, horses, finding themselves so much at liberty, are apt to get a habit of rolling; which with impatient animals, sometimes ends in injury, from their struggling to right themselves. Others, on finding themselves thus hampered, have the sagacity to lie still : in this case they are generally old offenders. I had one who, when short of work, was constantly found in the morning nearly on his back, with his legs resting against the standing, of course considerably above his head. Here he very philosophically waited till his groom came, who laying hold of the fore and hind legs next the standing, pulled the gentleman over. I often thought he must have been in the West Indies, and learned this mode of resting from the ladies there, who, I believe, however, get themselves to right without assistance. It was remarkable, that this horse never got cast after a good day's work. It was only when idle that he played some pranks, at some time of the night or morning, that got him, as Jonathan says, in "a fix." Had he been a valuable horse, I should, of course, have put him in a box; but I had not one to spare for a forty-pound hack, and he appeared so composed 
and comfortable in his transatlantic position, that it would have been a pity to deprive him of so cheap a luxury.

Horses will be very commonly found to what is termed " hang back in their stalls" the moment the stable is shut and they find themselves alone; some will even do this when persons are present: this is a habit that always excites the greatest ire on the part of a groom; the broom-handle or fork usually corrects this attempt, accompanied by swearing at the horse, and sundry condemnations of always his eyes, and frequently the limbs also. I have seen men insane enough to listen at the door, or watch at a window till they found the horse had committed this heinous sin, then rush into the stable and chastise him as unmercifully as undeservedly: we might, with as much justice, punish a man because he moved his person to get ease when we had placed him in a situation that rendered his position painful: but if any man has found he could teach the generality of grooms to think before they act, he has been more fortunate than I have in this particular.

The whole secret of a horse hanging back is, that where the stall is much on the decline, from the manger to the stall hind post, standing on an inclined plane causes his loins and hind parts to ache intolerably; he hangs back in order, if possible, to get his hind legs beyond the gutter, thus 
diminishing by many degrees his standing up hill. In good and well laid stables horses are not found to acquire this habit; so the cause of it speaks for itself, and ought to be immediately remedied, which any common bricklayer may do, if he pleases, in half a day.

Five feet eight, in the clear, I consider wide enough for any horse's stall. If he is so fatigued as to want to lie at full length, he ought to be put in a box. This is, however, a position in which horses never lie long together, unless under very peculiar circumstances; for it is, in fact, a painful one to them, unless they have an unusual quantity of soft straw under them, the rotundity of their ribs creating an unpleasant pressure.

It is a most mistaken idea that a wearied body can rest comfortably on anything but a soft, yielding substance. Rest it will, and sleep will come, for jaded nature will rest anywhere, and almost anyhow; but if we lie on any unyielding surface, it is only the most prominent parts of the body that find support. These begin to ache from undue pressure on them; the other parts from having no support at all. Some foreign horses sleep on bare boards. They live, and perhaps do well; but they would certainly be more comfortable with a good bed under them. And it must be borne in mind, that these occupiers of bare G 4 
boards do not cross Leicestershire. Oftentimes, when people say such and such a thing does not hurt a horse, the animal would perhaps tell a different tale, for in such cases it frequently happens that the kindness of the master to the animal is about equivalent to that of a grazier or butcher, who, when he tells you that this or that will not hurt his cattle, only means it will not injure the meat for the market.

We will now, for a short time, turn our attention to matters beneath the earth's surface.

Much has been said about draining stables. Objections there are, of course, to every sort of drainage; but I shall describe what I consider as the best. The drain should run just under the centre of the stalls, and should be twelve or fourteen inches deep, and wide, the lower part rounded barrel-fashion. This causes the water to run down much more rapidly than it would if the bottom was flat, and leaves no sharp corner for filth to lodge. The drain should have a very considerable fall - nearly two inches to the yard; with this, and a bucket or two of water thrown down it twice a week, it will be kept perfectly sweet. The higher end can be stopped up by a door, and the lower one should terminate in a receptable for manure; or, if that should be impracticable from any particular cause, a cesspool must be made, to be emptied when wanted. Thus 
no current of cold wind can come up the drains; nor will the urine from the horses be lost, which is a consideration, whether a man has land or sells the manure. Water thrown on foul litter will make it weigh, we know, but it will not enhance its value as manure; the liquid from the drain will. Short drains are frequently made coming from cesspools under the horse; that is, from the middle of the stall into the long under-ground one behind him (where there is one); this is a very bad plan: in the first place, it is impossible to clean the short drains thoroughly, being only able to get at one end of them; and the other objection is, it forms an angle, in fact, sharp corner, in turning into the longer one, which is certain to cause frequent stoppage, from filth getting collected. Now, the long drain under the horse being open at both ends, it can be thoroughly cleansed in a few minutes by a very long pole or two, or even three in succession if required, being tied to each other till the requisite length is obtained, and with a kind of coarse mop at the end all filth can be got away, the drain, in fact, washed.

The pavement of the stall should also be frequently washed to sweeten it, taking the opportunity of a horse being out a sufficient number of hours to let it dry thoroughly. This is not often attended to, and greatly contributes to the offen- 
sive smell of many stables from the whole of the urine (as will sometimes be the case) not going down the grate, and consequently getting between the bricks or clinkers, unless they are laid in very hard cement; what must it then be in the case of the common flint pavement? the interstices there become positively saturated with offensive matter.

I have mentioned twelve or fourteen inches as a fair size for a drain. It may be asked if a larger size would not be better. The reason why I prefer the smaller is this, if the drain is large, there being less fear of any stoppage, servants will not cleanse them sufficiently often to prevent offensive smells, whereas they are aware a smaller one requires more frequent attention, and consequently they cleanse them oftener.

Returning to the stable, we will look round and see what more is wanting there. If we should see that which in a badly organized stable is sure to be seen, namely, all sorts of stable utensils, and requisites, in holes and corners, on the window ledges, in the corn-bin (if one be in the stable), on the steps of the loft-ladder, and various other improper lodgments for them, the want which will suggest itself at once is that of a good cupboard, or rather press at each end of the building. Nothing looks more unstableman-like than forks, brooms, buckets, \&c., stancling about. Should it be at all dusk, or even by daylight, if 
your attention is occupied, the chance is you break your shin over a pail, and while dancing with agony on one leg, you hop into the dropping-scuttle, and out of that pop into the cold stopping-box.

One of the first things desirable in stable management is rule: by rule I mean a regular way of doing things; and this is a matter seldom attended to sufficiently, unless the stable is under the superintendence of a first-rate stud groom. I do not merely allude to the important matters of stable hours, dressing, feeding, watering, and so forth, but to the minor details; for, though such things may appear trivial, they will at times be found important to attend to: I will merely mention, by way of example, two.

We will suppose a horse is going to be taken out; the groom takes off his head-collar, and, if he is an ordinary servant, he lets it fall into the manger: the horse is told to "come round;" in doing so it is quite likely the head-collar may have lodged on the manger rail: if so, on the horse turning, down it goes, and perhaps a hind leg gets into it, or possibly a fore one; the horse gets hampered and frightened, if a timid one, and then it ends as the case may turn out. Or suppose it thrown down, and nothing happens at that time, probably, from the same want of stable rule, the groom never goes into the horse's stall 
before his return; the animal on reaching his stable gets up to his manger as quick as he can, and then the odds are much in favour of his getting one or both forelegs entangled in the collar; and here again it ends as the case may be, depending on the quietude of the horse. Now, if the man made it an invariable rule to fasten the head-collar to the rack-chain, he would from habit do it as a matter of course.

It is the same by the clothing, if they are carelessly thrown over the standing; the chances are they get down under the feet of the horse in the next stall, and are torn, or at least soiled. This would not happen if, on the man's return to the stable, he took the opportunity of shaking, and, if wanted, brushing them, folding them nicely up, and depositing them carefully in the horse's own stall.

From the same want of rule (but sometimes from want of convenience to avoid it) we often see a man hunting for his currycomb and brush, or any article he uses, under the manger, under the straw close to the standings, and in his various other hiding-places; all this at once shows bad management somewhere, and looks most unstableman-like.

There are a variety of little technical habits as well as phrases in a stable, for the origin of which it might be difficult to account; yet the 
non-observance of which gives the impression (and such is mostly the case) that the groom is not a workman; for instance, it may be said that if a hood is thrown over a horse's quarters, the position of the ears of the hood cannot be a matter of consequence; nor am I prepared to say it is so; but if I saw them standing an-end on the horse's back one bending forwards, the other backwards, like a hare listening, I should doubt the man being a finished stableman; they look, as a sailor would say, "more ship-shape," brought through the eye-holes, and laying uniformly neat. All things in a stable should be done not from a man recollecting that he should do it, but from habit, as naturally as he brings up his left leg to follow his right, or vice versit. In fact, a horse that has been accustomed to be attended by a stableman will want to have little niceties done to him that a hawbuck of a groom never thinks of doing.

The presses should be made so that all things wanted can stand in them, or on shelves and pegs also shut in. There will be a place for buckets, forks, chamois, sponges, dressing-tools, manecombs, water-brushes, bandages, the men's strapping-jackets, and sundry other articles in daily use.

Anything like a shelf in a stable should never be seen; not even a sill to the windows. I need scarcely say that nails or hooks in the walls are 
absolutely inadmissible. A wooden peg or two to hang a bridle on while the horse is being saddled is a convenience, and not objectionable, if never used for any other purpose.

Numerous accidents happen where utensils are allowed to stand in the stable. Horses coming in and out are almost sure to strike against them. This frightens them: they run back, hit something else, or run against other horses and get kicked. Should such a thing occur as a horse getting loose in the night (no very improbable circumstance, by-the-by, in a badly-conducted stable), probably if he walked quietly about, or even into another horse's stall, if used to each other, no harm might happen; but if in the dark he gets kicking the buckets about the stable, as Dr. Pangloss did the phials about his shop, he (not Dr. Pangloss) gets frightened, frightens the other horses, and they all get kicking and snorting together; and then, to use the doctor's pet numbers, it is "two thousand five hundred and thirty-eight" to one that some mischief ensues.

Having now got a tolerable comfortable stable, that is, one not a bit too good for a hack, and quite good enough for a hunter, I come to certain little adjuncts to it, convenient if only destined for the first-named humble inhabitant, but absolutely indispensable to the more aristocratic tenant. The first of these are (in the stable) 
gates to fall back against the wall, and fasten across from it to the stall-post at night. They are a small expense and no inconvenience in any properly proportioned stable; and in one whose six stalls contain, perhaps, a thousand guineas, they are a safeguard that it is reprehensible to omit. For, though a properly-made head-collar cannot be slipped off, in case of fright or a horse getting cast, some part of it may be broken, or if the safety-shank collar rings I have mentioned are used, the horse will disengage himself and get loose; and a broken leg from the other horses in such a case is too serious a matter to be risked.

As some proofs of the obstinacy (for I can scarcely call it by a milder term to be an appropriate one) of some persons as to horses, and, further, that the cautions I recommend are not quite futile, a friend of mine, a good judge of horse matters too, had two stallions that stood in his hunting-stable, with no other safeguard than had the other horses, namely, proper head-collars on them. I told him that some night he would have an accident. He laughed at my croaking, as he termed it. But singular enough, in a night or two, one of them did get loose, and worried a valuable horse, so as to lay him up for the season, and disfigured him for life. Any one would have thought this lesson would have sufficed, but it 
did not; for a couple of seasons after, he kept two other entire horses, sire and son, in the same stable, one four and the other nine years old: for the old horse he had refused, two years before the time alluded to, 1000, not pounds, but guineas. The young horse got loose; and on the groom's going into the stable, hearing an unusual noise, he found the sire with his thigh broken. A vet. was called in; and I saw the horse in slings in a loose box. But he could not be kept quiet; his groans were piteous. He died frantic the next night; and on examining his body, it was found that two or three of his ribs were also broken. So the poor animal's sufferings while they were pressed upon by the slings may be imagined. The gates I mention would have prevented all this.

\section{The Saddle and Harness Room.}

Something of this sort is quite a necessary appendage to the most ordinary stable. No horse appointment can be kept decently clean without it; and multitudinous are the indispensable articles of this kind wanted. If even a number of horses are kept, it is true if a man does not object to sore backs and wrung shoulders, the same saddle and neck-collar may be made to do duty for more than one horse; but in mentioning what I hold 
as indispensable to such stables as those I have alluded to, and attempted to describe, of course we do not contemplate such grievances.

I will mention a case where $I$ found that one neck-collar, though it had been made purposely for a particular horse, was not enough ; a horse of mine, that had picked up a nail, had been thrown for upwards of two months out of work, and had been merely exercised; being naturally a gross horse, he had become, by the time he was sound, very lusty. I wanted to join a party in a three weeks' summer tour; and this horse being a particularly good tandem leader, I took him, fat as he was, knowing we should only go easy and slow stages. For upwards of a fortnight all went on well; but then I found his shoulders began to chafe; and, in fact, on coming in one evening, they had become sadly scalded. I soon hit upon the cause of this; his flesh not being as firm as it ought to be when he started, he had lost in size considerably on the journey, and had got below his usual mark; consequently, though on starting his collar was tighter than usual, it had become too large for him, and then, as a matter of course, wrung his shoulders.

If people are contented to ride or drive horses in bridles and bits that do not suit their mouths, of course a very few will do; but if we want horses to go pleasantly, each must have his bridle; 
for though a horse may go moderately well in a certain bridle, a man with nice hands, and who is particular as to how he is carried, will not rest till he finds the bridle that exactly suits: thus, even supposing we set out with a small stock of horse appointments, if a man often changes his horses, that stock will, in a short time, multiply greatly. Whenever I bought a horse, if the saddle he had been accustomed to be ridden with pleased me I generally bought that also, if I could: the same with his bridle: of the latter, I should be afraid to state here how many I have had by me; but even of saddles, I have often had at least thirty. I include my own, ladies', servants' saddles, exercising, and, perhaps, three or four racing saddles, of different weights: latterly I made it all but a sine qua non, but if I sold a horse his saddle went with him.

Independent of this accumulation from circumstances, when we come to recollect that summer or winter clothing has to be stowed away, sweaters with their hoods, \&c., old clothes for sick horses, or those in physic, waterproofs to cover clothes, if travelling, \&c., it will be found that not only is a saddle-room wanted, but a good-sized one, if only, we will say, seven or eight horses are kept.

And here, to save constant cleaning of spare bits, stirrup-irons, or any thing made of steel or 
HAVING AN EYE TO THE MAIN CHANCE. 99

iron, I will mention what some persons may not know, if a box or small tub of powdered lime is kept in the saddle room, and such things are buried in it, they will keep, it may be said, ad infinitum, without care, or getting rusty.

I need scarcely say a stove is indispensable; and here, with a neatly-concealed bed, is a very proper place for one man at least to sleep. Here, also, in small establishments, may be the corn-bin -an article that I never wish to see in a stable, for two reasons: it takes up room; and the horses learn its situation so well that they get anxious and uneasy every time the groom goes near it. It is sometimes made and used as a seat; but it is a bad plan: where a seat is desirable, it should be one that falls down against the wall.

There must be boxes, as a matter of course, wherever hunters are kept; and there should be one, in case of sickness, wherever horses are located : it can always do duty for other purposes when not wanted for its general one. And here I must give a caution not always used: so soon as a sick horse ( $\mathrm{I}$ do not mean a merely lame one) is removed from a box, it should be immediately white-washed, and the floor well saturated with chloride of lime, before any other horse is put into it. These do not require to be in any degree the same size as those used in racing-stables. As places of quiet, unconfined, and undisturbed rest 
for wearied horses, sixteen feet (or even less, if necessary) deep, and eight feet in width, are all that is required for the horses' comfort. Double doors (that is, cut in two transversely) are useful in case of sickness, where there is but one ; otherwise, the single door is to be preferred. These should be made to take off the hinges, that an open railed one may be substituted in hot weather, over which, of course, on the outside, an open canvas should be stretched to keep out the flies, which is a wonderful comfort to the animal: the canvas costs, perhaps, three shillings, and will last as many years. Under no circumstances, let the door be what it will, should it open as I have often seen it do, into the box; for should a horse be taken ill and lie against it, it cannot be opened; for even with hinges to lift off, in such a case they would be inside: in fact the door must be split or sawed to admit any one; and even then, till the horse is got up, it cannot be opened. Yet, obvious as this must be, strange to say, in a very large establishment, where there were six boxes in a yard appropriated to them, they one and all opened inwards. The master, however, had them all altered the next day, when I had represented their inconvenience.

When boxes are entered by a door on the side, which is often the case, the rack and manger should both be on the side of the entrance; for 
this reason: the horse, to feed with convenience to himself, and to get in front of his food, will always be found to stand nearly corner-ways in his box; so, if the food is on the side of the door, his heels will be away from the person entering; if the reverse, they will be towards him, which, with some horses, would not only make some difference, but all the difference to the safety of the intruder.

Many persons have quite a box monomania about them, and fancy one to be all but indispensable to the well-doing of a horse. I am quite of a different opinion, though $I$ do not affirm that my own is the correct one; but keeping a horse constantly in a box I consider a mild degree of solitary confinement. I think I may say all quadrupeds that are not ferce naturce are gregarious, and horses are naturally so, and confinement in a solitary box deprives him of enjoying one of the first impulses of his nature. Turn him into a pasture, be the food ever so tempting, he will leave it, and clear the largest fence to join any horses he may see or hear near him. I am quite sure that horses are happier, and, consequently, do better in stables than in boxes, unless they are made with open work at a height that they can both hear and see their companions. Entire horses, that is, those that are highly bred, must be kept by themselves. They are so accustomed 
to it, that they would generally savage other horses if they could get at them; but this, I am convinced, arises in most cases from the mode in which from colts they are stabled. I quite agree that no entire horse, be he as quiet as he may, should ever be trusted in a situation where he can get at other horses; but I am certain that if, instead of shutting up half a dozen colts in what is tantamount to a cell, they were in boxes, with walls, say five feet high, and the upper part made of iron bars, close enough not to let their noses through, they would become as accustomed to each other as a herd of deer or a pack of hounds. It is not their nature immediately and at all times to attack each other; if it were, how could they be gregarious? which, in a state of nature, they are. Even the wild ass, who is, by far, more savage than the horse, is never found singly, but in droves. They - the deer, the dog, or the horse - would at particular seasons have a fight occasionally; but when they do, it is where the female becomes the object of contention; it is the undivided companionship of her that rouses their energies to fury and battle, not any natural hatred or antipathy to each other. For the same horses that might be seen with crest erect, tearing each other like tigers at one season, would be found herding sociably together, and knabbling each other in perfect friendship a few weeks after- 
"DO AWAy With the CaUse," Etc. 103

wards. If their combats arose from natural ferocity, or natural hatred, they would last all the year round; and this we know is not the case.

Why do we allow our dogs or deer to live in sociality? merely because they are not of sufficient value to induce us to keep them apart. And why do these animals live thus socially, and, on the whole, harmlessly with each other? They have the same brute passions as the horse, and certainly are by no means more kind or generous in their natural dispositions than he is. The reason why they do not attack each other, as our entire horses would, when they meet, is, we encourage and habituate the one sort of animal to live together in harmony, while we totally prevent the other from doing so.

I have no hesitation in saying, that in doing this we pursue quite a wrong system. Horses are valuable animals, and consequently should be so far securely kept apart as to prevent the chance of their injuring each other; but it certainly would be better for them, and ourselves, if we so habituated them to associate as to do away with the inclination to do the injury to each other.

I have known men to send a couple of hunters to an inn, in order to meet some distant pack of hounds, and the order given was, "Mind and get H 4 
a couple of boxes for your horses;" or the groom, knowing his master's predilection in this respect, would, as a matter of course, get them.

Let us see how far this proceeding, that certainly at first sight appears judicious, is, under every circumstance, to be recommended.

If I sent horses where there was only a large public inn-stable, I certainly should much prefer the boxes; not from thinking the solitude of the box conducive to my horse's comfort or content - and, by-the-by, either in man or horse, where there is not content there can be little comfortI should prefer the box from the objections inseparable from such stables, namely, my horses being constantly disturbed, and subject to the door being open at all hours.

Now, my directions would be - "Get a two, three, or four-stalled stable (as might be wanted), and get your horses together, if you can." Let us see what would be gained by getting separate boxes. The horses, having travelled together, know as well as we could tell them that, though separated, they are in the vicinity of each other. They also know well enough that they are in a strange place. The consequence of being parted is that, instead of resting themselves and sleeping, they are anxious and fidgety, and keep knukering (that is an apology for neighing) after each other all night. In such a case "a box to himself" is 
not so great a desideratum to a horse that is to meet hounds the next day as it is often considered to be.

When I decry the general use of boxes, I beg it may be understood, that I only do so when alluding to them made, as they mostly are, as cells : that is, where the animal is debarred from seeing or hearing anything to amuse him, or pass away the time. The reader may smile, perhaps, at the idea of a horse deriving amusement from seeing passing objects. I will, therefore, beg to make an observation on this subject, that, I think, goes a long way in showing that $I$ am not far astray in considering that horses Do derive amusement from such circumstances. Most people have, no doubt, frequently seen a dog looking out of a window, and turning his head in the direction of passing objects, in fact, watching their motions. He is neither forced, taught, nor told to do this; it is a voluntary act of his own; of course it amuses him, or, at all events, he finds a gratification of some sort in doing it. If a dog does so, why not a horse?

The reader who might smile, as I above said, at my opinion, may say he never remarked a horse looking out of a window. I can't help that. I have, many (not a drawing-room window, I grant); but I never saw a horse shut up loose in a box that had a window in it, that he could get 
at, that was not constantly looking out of it: nay, if a hole of three inches square only is left in the door, my life on it, look in at it, and the first thing that will meet your eye, is that of the horse looking out of it. If it is a half-door, his head will never be away from it, unless while taking his food; and when looking out, he will, as much as the dog, follow with his eye, and even head, every object he sees pass near or at a distance. $\mathrm{He}$ is not made to do this more than the dog; consequently, we have every right to conclude, that he finds amusement in doing it; and of this we totally deprive him by shutting him up in a box.

I always conceive a horse looks unhappy thus shut out from the world. Look at him through a key-hole, or in any way that he cannot see you, there he will be found standing, his head drooping, and looking, as I make no doubt but he is, melancholy and dejected.

I am quite ready to allow that to be loose I consider an advantage, a comfort, and also an amusement to the horse, giving him the privilege, if in a large box, of moving about; and such a home, I agree, is preferable to a stall, if the animal can see his companions. But when he cannot, I am sure the solitariness of a shut-in box is much more than a set-off against any advantage it may otherwise hold out. 
THROWING A LIGHT ON THE SUBJECT. 107

I may be asked, if I am not so strenuous as many other persons in my praises of boxes for horses, how I can reconcile with my ideas the fact that the most valuable race-horses are kept in them. I fairly answered such a question before, by saying they were kept in them because, from having always been so, it became in the end a matter of necessity; but it does not follow that it is right. We lit our streets for centuries with oil, and ridiculed the man who first proposed gas as a substitute. However, we now find gas does tolerably comfortably for us.

Race-horses were first kept, probably, for the amusement and triumph of seeing them win their races. They were continued with a view to putting money in their owners' pockets by winning races. They are now pretty frequently kept for the purpose of losing races, by which their owners still put money in their pockets, though very few of them keep it there. Of what "the select," alias "legs," may do, I say nothing: double irons in Newgate to them.

But we are not to bring race-horses forward as specimens of sociability or good temper, either to their own species or to us. There are few of them we could trust to be walked side by side. They will sometimes fly at each other at the starting-post, and have been known to do so even when running. Some will not run up to their 
horses: some will swerve away from them : others will not pass them. None of this shows the most kindly disposition. I do not say that their being kept solitary is the sole or absolute cause of this ferocity, but I am quite sure it contributes to it. All these things are tolerated in the race-horse. How far treating him in a different way would be beneficial or judicious, is not to my present purpose; but for whatever purpose we design the horse, there can be no doubt but the bettertempered he is the better adapted to that purpose he will be.

I always reason, or at least attempt to reason, from something like analogy; and there is much more of analogy between the disposition, temper, and temperament of the horse and ourselves than is generally supposed to exist. For instance, our bed is a soothing luxury to the sick or wearied frame; so is the box to the sick or wearied horse; and so long as the debility attendant on either remains, so long will the bed or box be welcome and grateful to the feelings to a certain extent, but no further; for the bed-ridden patient becomes tired of his monotony. And keep the healthful in the same situation, he would become nervous, timid, and silly, or morose and misanthropic, from want of community with his fellow man. The bed and the box, under the same circumstances, have, I consider, analogous effects on 
the spirits and temper where their constant use is persevered in.

I am aware that I have digressed somewhat from my present purpose in mentioning racehorses. I only did so lest my not being enthusiastic in praise of keeping horses in boxes might be at once condemmed because race-horses are kept in them. 


\section{CHAP. III,}

DIFFERENT KINDS OF FOOD.-HAY.-STRAW.-OATS.-BEANS. -BRAN.-MALT.-BARLEY.-CARROTS.-CHAFF.

WE have long since, we will say, on the judgment of a friend, got what horses we want. We have got what we conceive to be a comfortable stable - a place for holding all the requisites for stable use, and a room for saddles, bridles, harness, clothing, and the etceteras. We have now another most important thing to provide for our horses' use, namely, something for them to eat.

We are told, on much better authority than mine, though even I could form a tolerably shrewd guess as to what would be the result of the experiment, that " not e'en love can live on flowers." Now, in speaking of love, the idea of flowers always suggests itself to the imagination; - not that we are told, that even in Paphian bowers they ever stood in the place of any entremets intended for the palate. Our little friend or foe (as the thing turns out), who holds himself privileged to appear before ladies sans unmentionables, sans kilt, and, indeed, sans even an apology for one, is, we are told, mightily addicted to playing with 
flowers; but I never heard that he ate them. Now, horses do just the reverse; they do not play with them, but they will certainly eat them. Yet, upon my own authority, I venture to assert they will no more live on them than the unbreeched urchin who scatters them so profusely in the way of young ladies and gentlemen before they are married. These said flowers retain their bloom the whole time the to-be happy couple (quare) are in church-nay, form a fragrant path on their way from it; but, somehow or other (though it ought not to be so, I allow), by the time seven o'clock arrives, the loving couple (for, as I have said before, I like to draw conclusions from analogy) begin to think, like the horses, that something substantial, by way of provender, would not be amiss, and that flower-totalism won't do. "Provender!" I think I hear some pretty pouting lip, with a little - a very little - affectation, exclaim, "Provender! Has the monster ever associated with any thing beyond a ploughman and his wife? Has he ever dined at a table higher than one where bacon and its concomitant horror, cabbage, were the head and front of the offence?" Yes, fair lady, he has, though, sooth to say, he has dined on bacon and abomination, and, faute d'autre chose, with a good appetite too. He has, also, seen your lovely prototype take a tablespoonful of soup at ten sips; a particle of sweetbread, 
the size of a nutmeg, discussed in atoms; a fairy slice from the breast of a pheasant, only partly partaken of, from having been helped so abundantly; half a whipped cream trifled with, and then an ice, the only thing allowable to a lady with a little affectation to declare a predilection for at a dinner-table. Yes, I have seen this, and, per contra, I have seen a woman of fashion, but with no affectation, take a fair share of a beef steak, not a bif-stick disguised in Verey's best manner, but an honest tranche de bœuf, fresh from the common gridiron - and, further, hide her petit and aristocratic nose in a pewter containing double stout nay, more, I once saw a cigar in a very lovely mouth, coming from the Opera. Yes, I have seen these and many more strange things in my time, in places, and with persons that many wot not of. "But then these charming women, you know, will do just as they please," so says the song. And, while they charm and please every one, it would be very hard if they were not allowed to please themselves.

We will now positively return to the horse, apologising for the gentle canter I have taken on the hobby.

We were contemplating laying-in necessaries for the inhabitants of our stable, and will very shortly enter somewhat minutely into the quantities required by each. But, before we do so, let 
us see what different descriptions of forage we shall want, and then say something of its qualities. I believe if I mention - we will say for hunters hay, chaff, straw, oats, beans, malt, bran, carrots, lintseed, and, at particular seasons, a very trifling addition of clover or lucerne, and oatmeal, we shall have all that can be called into use for horses in health. Barley, however, I have found occasional use for with horses of particular constitutions. We will first speak of

\section{HAY.}

This should, for all and every horse, always be of the very best quality.

Of all the other causes put together that occasion thick and broken wind, where one horse gets into that state from any of them, or the whole combined, nineteen become so from the effects of bad hay, but supposing it to be good, the proper or improper quantities given are all but life or death to the horse; in fact, eventually they are so. The effect of oats being light, thickskinned, or taily, provided they are perfectly sweet, may be frustrated by increased quantity; but if hay is not nutritious, being, as it is, of much greater bulk, increased quantity is merely filling the animal with what does him no good in quality, but a great deal of mischief in quantity. 
I have been frequently surprised at seeing many men, who were in other far less material points careful of their horses, careless, in an extraordinary degree, in this most essential one, namely, the quality of their hay. Nothing should induce me to permit a horse to eat a pound of bad hay, or, for a continuance, hay that is not of the sweetest and primest quality. It is the first thing I look at on going to an inn, or indeed to a friend's house, if I have a horse with me. I have frequently in the former case, if the hay was bad, had my horse racked up with a little sweet straw, and made him amends by adding a proper quantity of bran and beans to his allowance of oats at night.

I have been at friends' houses who grew their own hay, and on remarking it was not quite the thing, have been told, "No, it got a little wet in making," or, "it heated and moulded a little in the rick," and this by men who kept good horses. So, because they grew it, it seemed their horses must eat it. I would have sold it at twenty shillings a ton, and bought other, rather than a horse of mine should have touched it.

To bring the effect of bad hay still more strongly before the reader, I will again mention the gentleman's gray horse before alluded to as having so fallen out of condition. On seeing this falling off, the first thing I did was to look at the hay. I 
found it not only bad, but literally offensive in smell, and visibly mouldy, added to which, it had all the appearance of being rowing, or aftermath. There needed no further inquiry as to the cause of want of condition; and the first day I drove the horse with his master, a few short hacking coughs told me the vile hay had already begun its usual effects, for the horse had always been since I knew him most particularly clear in his wind, and altogether, with the exception of very slight thrushes, one of the most unequivocally sound animals that had ever passed through my hands. The owner expressed his fears that the horse had taken cold. I had none on that point, but many apprehensions on another. Had he been an intimate friend, I dare say I should have soundly abused him, and his hay too; but that not being the case, I limited my anathemas to the hay. Some good was then bought: the horse soon showed - ay, in a few days - the difference of the two by improved appearance; and I trust the evil was stopped in time. Had it gone on for two months, if he did not eventually find he had a brokenwinded one, he would have had a greater share of good luck than I, under such circumstances, should hope for for myself.

But mistakes are sometimes made, even by otherwise good managers of horses, as to what is the very best quality. The first proof of its 
goodness is, no doubt, its fragrant smell; but even this might deceive us if we merely trusted to our nose, for I have smelt hay very fragrant that had been more heated than it should be to be for a galloping horse. Horses like it, and I have heard people say it fattens. I suspect its fattening quality is chiefly that horses, if allowed to do so, will eat a great deal of it, - no recommendation to a hunter's stable. But we will suppose the hay to be sweet, fragrant, and of a good colour, showing it had been got up free from wet, and not overheated in the rick. Now as to its quality and substance.

It used to be a received opinion among grooms, and, indeed, many others, that hunters should eat none but "good hard hay." Now, nothing in the shape of sweet hay could be more improper to give any horse intended for fast work than such hay: nor, indeed, is it desirable for any horse or beast.

First, then, for galloping horses, the great desideratum is to get into them the greatest possible quantity of nourishment in the least possible compass; consequently, whatever we give them should, of course, be the most nutritious of its kind. Of what does this "good hard hay" consist, and what constitutes its hardness? Its hardness is simply this-there is a much larger proportion of a kind of grass called "bent" in it 
than there is in softer hay. Now, let any one examine this bent, which cannot be mistaken from other grass; I think they will find it about as hard, and, in nourishing properties, about on a par with the wicker of which a clothes-basket is made, and about as easy of digestion. What set-off there is agrainst what I must consider as tolerably forcible objections, I never yet found out. Hay should, in a general way, grow on uplands, although, I allow, bent, or bennets, as they are sometimes called, generally do grow there, because in very poor uplands they are the only thing that will. But "good upland hay" speaks for itself; it should come from good upland, not from sterile, dry hills, where little but this bent will grow.

Long tangled grass (unless it is artificial grass) is as bad as the dry bent, but, from another cause, it is generally more or less sour, consequently flatulent and not nutritious. This grows on low swampy soil, and is only fit for cows, and only the best sort for them. Real good hay should (like that delightful adjunct to a dinner-table, a really good salad) consist of variety, all sweet and nutritious. Who would touch a salad consisting of only the long green lettuce? Parmentier's salad vinegar, with Kitchener's double relish added to its other sauce ingredients, could not make it tolerable.

It is quite a mistake that all soft hay is bad for 
horses. Aftermath, which is soft, of course, is objectionable, because the nourishment of the land has been nearly exhausted by the first crop; but there is a look, independent of smell, in good hay that it is easy to learn to distinguish : and, as I advise by the purchasing the horses, if neither master nor man are judges of hay, let some one buy who is.

Another very great mistake that some people make in hay is, as to its age. Some will fancy hay cannot be too old: this is quite erroneous, for however good hay may be, age will take away its nutritious qualities. I remember saying this once before a groom (but no stableman), when, to my astonishment, he said, with an intended knowing look, he did not want hay to nourish his horses.

"Then what the d-l do you give it them for?" burst from me involuntarily. "Perhaps you don't want nourishment yourself. What do you say to making half your dinner on sawdust?" I hope I need not say he was not, or ever had been, in my stables.

That new hay is by no means proper for horses in work, is quite certain; but a little even of this, as an alterative, is by no means a bad thing. Hay two years old I consider old enough for any horse; and supposing horses to be eating hay in September 1848, that was cut in July 1847, it will hurt no horse in common work, - in fact, I 
would prefer it to the older; but that cut in 1846 , I hold to be old enough for any race-horse; every day after this I consider it deteriorates in its nourishing qualities.

We will now come to quantity, the desire for which, in the animal, depends chiefly on habit; for appetite, if in a state of health, depends greatly on use - that is, if we call that appetite which is in fact gluttony. A keen relish for what is eaten is a sign of health; eating enormous quantities is sometimes the result of disease.

I have astonished a good many carters, horsekeepers to coaches, and some grooms and coachmen, respecting what I considered a proper allowance of hay for their horses. Yet I am by no means one of those who consider a fair quantity prejudicial: on the contrary, good hay is a much better thing in a horse's stomach than wind; and if we do not give enough of the former for the stomach to feed upon, it is certain to get filled with the latter, which often leads to direful inconvenience, and, indeed, danger. To come to round numbers of pounds, I should say that sixteen pounds of hay in the twenty-four hours is sufficient for any horse fed on corn, as a horse ought to be for fast work, that is, taking the average per head in a stable of horses; from twelve to fourteen quite a liberal quantity for huntess. In fact, take the stable throughout, and 
hunting days intervening, twelve pounds I think about the mark they will be found to eat.

Horses not intended for galloping or any fast work, or, indeed, hard work of any sort, not requiring any thing like the same corn as those $I$ have first mentioned, of course require a very considerable addition to such allowances of hay as I have mentioned, unless they are ponies or galloways.

It is true, that in hunting or racing stables hay is regarded as quite a secondary consideration. As a means of nutriment it is, in fact, like the small dinner-roll we use when sitting down to a plentiful board, it is a portion of food proper to be taken to prevent a too abundant use of more stimulating fare: still that, like hay, should be, and in such cases is, of the best and most nourishing quality. Hay, if of the right sort, will keep an ialle horse as fat as corn.

I will instance a case, by supposing two horses totally out of work. We will allow the one three feeds of corn a day, weighing (which good corn will) two pounds and a half per quartern measure, making (corn) seven pounds and a half; we will then allow fourteen pounds of hay, making a ration of twenty-one pounds and a half of food in the twenty-four hours; we will allow the other half a truss of hay during the same period, and no corn : if both horses are of the same size, appetite, 
and constitution, the hay-fed horse (provided the hay is only twelve months old, and of a sweet and succulent quality) will, at the end of three months, be found the fattest animal.

To give a lift to the character of really good hay, in point of nourishment, I will mention rather a curious specimen of stable management for many years pursued by a venerable divine, a friend of my father's. He kept his carriage, so had done his ancestors (and judging by the appearance of the old landau, the same had passed through several generations), a horse for his own two-wheeled whatever-you-please-to-call-it (it is a rather long but appropriate name for the article), a horse for his own riding, one for his daughter, and one for each of his two grown-up sons, making a stud of seven working horses, independent of two or three old pensioners, who luxuriated in idleness on bruised oats, bran, and whatever the worthy pastor thought would best suit their old gums and constitution. He had plenty of grass land, but no arable, and from the nature of the soil, and good management in haymaking, the parson had always by him the very sweetest and best hay in the country. On this, and this alone, without a grain of corn, the parson's working horses were all fed. It is true his carriage-horses and his own two never exceeded six miles an hour, but those of his daughter and sons not only did, but frequently 
joined a pack of old blue mottled southern harriers in the neighbourhoood. These said hounds, I believe, were awfully slow coaches-so they had need be for hay-fed nags to follow them: however, whenever I saw the parson's stud, which I frequently did, the entire were not only in good flesh, but fat, one and all. This eccentricity in stable feed did not arise from parsimony (as his old pensioners showed), but from finding that, with his work, really good hay kept his horses in good condition, so far as looks and also good spirits went.

Independent of improper quantities of hay, and also of improper hay, being often given to horses, much mischief is often done by giving hay at improper times, than which nothing can be more injurious (save and except giving bad hay): but as I think it always desirable to bring something like proof of what I say when I can, I will now produce an instance of the bad effects of giving hay at improper hours, which will probably, and indeed very naturally, bring more conviction than anything I could say merely grounded on my individual opinion.

Shortly after my taking the management of the horses that worked a coach over seventy-five miles of ground, on my going down by the coach, the coachman mentioned rather a singular circumstance respecting the middle stages of the journey, which was that the horses going from that particular 
change were frequently attacked by staggers, but he hardly recollected one instance of its occurrence elsewhere on the whole line of road: yet here scarce a week passed without a case occurring. This, of course set me thinking: it was not that the coach loaded particularly heavily over this seventeen miles of ground, nor could it be the nature of the two stages, as to pace, for one was a very hilly, slow ten-mile stage, the other a dead flat-galloping seven-mile; the horses were a fair average of the rest, and in average condition, the stable neither too hot nor too cold. As I intended stopping at this change all night, and the coachman waited here to take the up-coach, I had him in, to question him further on the subject of the staggers. I then learned what he thought to be still more extraordinary to be the case, namely, that over either ground both he and his brother coachman had found that the same horses that were so often attacked were always so in going from this particular change, but never in returning to it. This at once threw a light on the matter : it must be their treatment the twenty-three hours they were in this particular stable. I saw the horses treated the whole evening quite properly, and the same early in the morning; but going into the stable about two hours before time for putting on the harness, I found the horsekeeper cramming the hay into their racks as if he was provisioning 
them for a week. On inquiring the cause of such proceeding, he told me he "always liked 'em to have a bit in 'em; it gave 'em strength to work the stage." This, of course, was enough ; the horses were always started with overloaded stomachs; that they had not always, instead of occasionally, an attack of staggers was the wonder. I tried what little rhetoric I was master of to convince the man of the danger and absurdity of his practice; but as I found he would not be convinced, I felt he would not be persuaded to obey my directions as to discontinuing it. $\mathrm{He}$ promised he would; but I set a watch on him, found him out, and dismissed him, and sent another man to take his place: from that time we had no more staggers from this change than from any other.

To conclude my remarks on hay, let me strenuously advise all young horse-masters to be most particular in procuring the very best money can purchase; they will find it a saving in the long run, for without it those experienced in keeping horses know perfectly well that it is out of the power of the best groom to keep them in health, and, consequently, in condition.

\section{OATS.}

Oats are, of course, a most important article in stable management; and these should be, as every 
thing a horse eats ought to be, of the finest quality. It may be thought that the weight of oats is not a matter of great consequence, nor, in fact, is it to cart or common horses: but it is quite the reverse to such as we are particular about as to stamina, wind, and condition. Good oats ought to weigh close on forty pounds per bushel; for we must recollect that, in the first place, horses (excepting military ones) are fed by measure, not by weight; consequently, in giving light oats, we actually rob the horse of his proper quantum of meal, giving him husks instead; and if we fed him by weight, going on the principle that a pound of lead and a pound of feathers are both a pound, the principle would be a very bad one as regards oats; for, in that case, though the horse got his pound weight, if he gets an undue portion of it in husks, he is only filled with that which is of no use to him; so in every way light oats are bad for choice horses.

Some persons, indeed many, object to black oats. The only objection that I ever found to them is, they are apt to be taily, particularly the Tartars; but if they are neat, short, and round, I think them quite as good as the white - indeed, in one particular, better; as such as I describe as good are generally thin-skinned.

Irish oats, that is, those sent to this country, are often objectionable, as a large proportion of 
them are kiln-dried, to give the look and feel of old oats; but when not I think them quite as good as our own. People might infer that they are not so from the fact that a much larger allowance of them is made to horses in Ireland than we give; their feed being always half a peck, whereas ours, in a general way, is only a quartern. This extra allowance is not, however, made from any acknowledged inferiority in the oats, but from the want of nutrition in the Irish hay, which, from the way it is treated in the making, is generally dry, tasteless, inodorous, and bad altogether. Figuratively speaking, they know nothing of good hay, or hay making.

In point of age, I should say that, for horses in fast work, oats should not be less than two years old; after that I consider their farinaceous part begins to shrink, and that, consequently, a greater proportion of husk falls to the horse's share. The objection to new oats is, first, that they are flatulent; and, secondly, as is the case with new oatmeal with hounds, they do not, as we say in kennel language, "stay by them."

A proper stock of oats should always be kept on hand-of course proportionate with the number of horses kept. This should be done that we may not be taken short, and, consequently, obliged to buy at any price, or to put up with oats of a bad sort: but then care must be taken that corn in 
store is frequently turned over, otherwise it is apt to heat and get musty.

Next to having oats good, and of a proper age, it is a matter of vast importance to give them crushed or bruised to all horses: for this an oatbruiser is desirable, as they should be bruised fresh and fresh, that is, I should say, once a week : the advantage to the horses is very great. If horses are delicate, they eat them better: if greedy, their bolting them is of less consequence: and with all horses they digest better, and go further in point of nutriment. Added to this, a small quantity of sweet hay chaff should be given. This obliges the horse to thoroughly masticate the whole.

It is quite a mistaken notion with those who consider a hunter the most expensive sort of horse to keep (race-horses being out of the question): a hunter, take him all the year round, does not cost more than any common well-fed and wellworked hack-certainly not so much as a carriagehorse. These gentlemen, like the gentlemen who sit in front of, and sit or stand behind, the carriage, are never off their appetite, or thoroughly on it; so nothing but the best does for them, and plenty of it. The usual allowance of London carriagehorses is three half-pecks a day, with beans when (the coachman pleases to think them) necessary.

Stage-coach horses in full work and health will 
go close upon hiding away their half-bushel each, with chaff; and for some old horses, beans with it : but they earn it: their exhaustion of animal power is great, and their consumption of hay isor, at least, ought to be-a mere trifle. Doubtless, from this allowance of oats in the stable, there is a little "shouldering," as there is from the coach on the road: but where we cannot always be present, and must trust to subordinates, the only way is to make a fair, liberal, but not profuse allowance; and if things on that allowance are done well, it is bad policy to notice any little advantage those subordinates may drive on particular occasions. For instance, a coach-owner whom I knew employed a horsekeeper on a particularly fast stage - in coaching language, " both sides of the road" - that is, both going and coming. The man's horses did well and looked well; but he, like many horsekeepers, was partial to poultry, liked fresh eggs to eat, and his wife liked them to sell -in short, he had a very pretty little community of the feathered tribe. His employer, with that shortsightedness that characterises many persons, desired the man to sell off his stockpartridge-breasted game, poles, and dorkings. Going up the road some time afterward, he found this had not been done: he dismissed the man on the spot. His successor did not allow a feather to flutter on the premises, but he had his "pen- 
chant;" - he liked something more substantial: he owned a pig, that he located at the next cottage, and by Christmas had him a good fifteen scure; and it was quite remarkable that the horses got thin in precisely the same ratio the grunter got fat: when killed he exhibited a spare-rib well covered, while the horses exhibited only the usual number, and those not covered at all. The poultry-fancier was brought back, when, out of pure devilry, he brought also back a lot of Malay fowls in addition to his old stock, and turned them down before his master's face: notwithstanding this, the horses soon showed who had the care of them.

Cart-horses (a description of animal that, among most others of a domestic kind, I have had the pleasure of entertaining at rack and manger) I always allowed two bushels of oats per week, which, if the master achieves that rather difficult task of making them do a fair day's work, is not too much, with chaff (and when the work is hard, beans), which they take as a kind of whet to their appetites for hay (as some persons do oysters before dinner); of hay, cart-horses will consume half a truss in the twenty-four hours, and, if the carters are not well watched, even more: for nothing short of absolute exhaustion of the masticating powers ever yet convinced a carter that he or his horse had had enough. 
We now come to the kind of horse I will suppose the reader about to keep, namely, a moderate-sized one, for moderate work, in harness, or for the saddle. For such a horse, four quarterns of corn, and a truss of hay in four days, are quite sufficient; if a horse merely to ride for an airing, three quarterns are enough, with perhaps a trifling addition in that case to his hay. Straw is an article somewhat expensive in London; in the country we reckon little upon it, as farmers will, in some places, supply it to have the manure in return, in others for the manure and a small compensation: but we will look at the thing altogether as it stands in London, and take the horse as eating four feeds per day. We will take oats on an average at twenty-four shillings per quarter, hay at four pounds ten shillings per ton, and straw at thirty shillings. In stating these prices, I reckon on their being laid in at a cheap season of the year, bought for ready money, and at first hand. Persons who have no room for storage of provender must, perhaps, pay something more in some places than the prices here set down. I have said nothing about beans, bran, or an occasional malt mash; neither have I mentioned carrots, these being occasional additions that it would be impossible to reckon on so as to mention a price or weekly sum as the cost of keep. 
Seven pecks of oats per week, at $3 l .4 s$. per quarter $\begin{array}{lll}5 & 3\end{array}$ Seven stones of hay, at $4 l .10 s$. per ton $\quad-\quad-311 \frac{1}{4}$ One hundred-weight of straw, at $1 l .10 s$. per ton - 16

Thus we see a moderate horse is, with good management, to be kept for, say eleven shillings a week, so far as feeding goes. Horses working harder, or larger horses, must, of course, get more; but as, reckoning corn at a fair average, it will cost about two-pence farthing a quartern, if five feeds or six become necessary, there can be no difficulty in any person calculating what his horse's provender ought to cost, if kept in the owner's stable; and, allowing a horse to get the topmost quantity of oats that private horses ever eat-that is, six quarterns per day - the keep only then comes to about $13 s .4 d$. per week as to forage.

Since the first edition of this book was written, of course variations have taken place in the price of provender; but as the prices I have quoted are only fair remunerative ones to the farmer, and we cannot see into the effects time may produce on prices, I let those mentioned stand.

It may be said, and with great truth, that horses belonging to ladies particularly, are generally badly managed, and the owners much imposed upon. First, ladies cannot go into their 
stables to see how things are done: neither is it at all necessary; and, indeed, setting aside the impropriety or inconvenience of their doing so, as ladies' stables are generally managed, they are not the most agreeable places in the world. But ladies have often honoured me and my stables by walking into them without feeling any inclination to use their smelling bottles, or finding a French slipper soiled from the visit. We will presently see whether a lady may not have her horses kept in a proper atmosphere, and in proper condition, though she does not go into their stable.

The next reason to be assigned for the mismanagement and imposition practised in ladies? stables, and in those of persons not knowing much about them, is, they do not know what their horses should consume. I know they do not, and one of the objects of this work is to tell them so. Those who flatter me by reading it now will know; and a tolerably liberal share of abuse I should get from their servants if they knew I had told this.

I must do servants the justice to say that many really demand more provender for stable use than is necessary, from a mistaken idea that they cannot stuff horses too much. Now, the fact is, it would do a horse for mere park-riding as much mischief to give him six feeds of corn a day as it would be detrimental to one doing full work to 
allow him but three. Where a man, from mistaken kindness, fights for what he conceives to be his horses' due, I should rather applaud than blame him; I should merely use precaution to prevent bad eyes, asthma, or broken wind (the almost certain effects of repletion and obesity) coming into my stable.

Notwithstanding my fear of this, and having named what I consider, under ordinary circumstances, a fair allowance of provender for horses, I am aware I have to mention beans, malt, bran, and carrots as adjuncts to such feeding: with some horses these are absolutely necessary, but are little additional expenses, easily calculated, whether in occasional or daily use.

\section{Beans.}

These are an article of food, that were in much greater vogue formerly than they now are; in fact, our grandfathers considered no horse could work without them. Many certainly cannot, yet many in certain work would be materially injured by them. Of the latter I should instance horses doing very fast work, but of short continuance. With such they are heating, and by no means unlikely to produce fever and indigestion; whereas, to horses having to undergo long-continued fatigue, and particularly if exposed to inclemency 
of weather, I think them quite necessary. To instance, I would not indiscriminately give them to four horses going over a four-mile galloping stage, which they might be allowed only fifteen minutes to do it in: but over a twelve or fourteen-mile stage the thing is different. Here they want something, in stable phrase, to "stand by them:" their work is slow, but it is a long draw on the animal spirits and powers, and sheer bodily strength and stamina are wanted. Champagne, could they afford to drink it, would be a pleasing and efficacious exhilarator to men in training for a quarter-of-a-mile race; but the coal-porter (or whatever they call him), with a barge-load of coals to carry into store, wants Barclay and Perkins's strongest double stout to support his continued Herculean labour. To hunters facing, as they formerly did, cold early mornings, and then killing their fox by hunting him down, beans were quite necessary to help them from a dozen to twenty miles home again. But now, when we courteously wait till the sun is near his meridian before we disturb our fox, and then do not give him a chance of getting us twenty miles from home, they are by no means necessary. Such horses as, from delicacy of constitution, are apt to pass off their food quickly, require them; and they are of great benefit, in a general way, to old horses, whose blood flows more languidly than that of 
young ones, consequently want such a stimulus. Horses on long journeys really require beans; and, in fact, if horses are accustomed to them, they cannot work without them. Two things should, however, be strictly observed in giving beans; first, that they are bruisel (not ground), and, secondly, that they are not given just before a horse starts on quick work: nothing is more likely to produce colic. Late in the day, and night, if on a journey, is the proper time to give beans. There is, however, a third precaution to be observed as regards beans, - they must be old, if given at all. New beans are worse than useless; they are absolutely dangerous in the extreme. Old beans I consider to be to the horse what sound old port or ale is to the man: new ones are tantamount to drinking sweet-wort or port while undergoing its manufacture, and, consequently, produce the direct opposite effect to that we seek in giving them to such horses as we judge may require them. I should say that in a general way, half a quartern, split or bruised, is snough. Certain work and certain constitutions nay require double the quantity, but more than ;hat I should say would be injurious. I have, lowever, I remember, mentioned, in something I lave before said of beans in another work, a case vhere I gave considerably more, but it arose from the following cause. Some years past oats were 
for some months at an enormous price, and in the particular neighbourhood where $I$ then resided they were nearly sixty shillings a quarter. I had a strongish stud, and, contrary to my general practice, had run out my stock of oats, but had by me an unusual stock of old beans, so, during the three months oats kept at this killing price, I fed my horses on them without oats; but then they had bran in such proportion as I considered brought the mixture to an equivalent to corn; and I mus say my horses never did better. It was, perhaps in point of healthfulness, similar to drinking brandy diluted with water in lieu of sherry without it.

In by-gone days beans were given to racehorses when in training, and perhaps they were proper enough under the circumstances in which they were given: four-mile races, and those in heats, were then in vogue, and horses that ran such were not usually colts; such stamina as enabled horses to endure long fatigue was then wanted, and, doubtless, beans contributed to this. But if a trainer could, in a general way, keep two and three-year old colts in health, giving them beans in any quantity, he must have some mode of counteracting the usual effects to be expectec from their use that I know nothing of. Still : case may occasionally be found where beans may be useful even to a colt, and certainly often to olk 
horses, if given at proper times, and, of course, in proper quantities.

\section{Bran,}

If fresh and perfectly sweet, though not an article of great nutriment, is one without which a stable of horses cannot be kept for a continuance in common health. Currie is an excellent dish. Why do we eat rice with it? Certainly not to improve its relish, but that the condiment would be too exhilarating to the stomach without this corrective. Bran, after a day of unusual excitement to a horse, such as a severely contested race, a steeple chase, match against time, or an unusually fast thing with hounds, would perhaps save his life, by preventing fever or inflammation of the lungs or stomach. Nothing, in short, is more grateful to a horse, if we find him at all feverish in the evening, and it is then a safe and good thing to give either in lieu of, or in addition to, his usual food at night; and here is one of the cases where the judgment of the groom or master is called into play. Distress to the horse arises from two causes, each producing, in the first instance at least, two different results; the one excessive languor and depression, the other restlessness and fever; - the former caused by longcontinued fatigue, where the frame and spirits 
are completely exhausted; the other, where overexertion for a short time has produced distress of the lungs, heart, and abdominal vessels. In the first case, it is nourishing and invigorating remedies that are wanted to re-animate the flagging and exhausted system; in the latter, soothing and sedative ones, to allay irritation, and bring back the agitated and distressed parts to the usual state of quietude. I have seen terrible mistakes made in the hunting-field with horses that were dead beat; and many a horse in such a state has been rendered incapable of coming out again for weeks, or, perhaps, for the remainder of the season, from the (formerly almost constant) use of the lancet on such occasions. People have got wiser of late years in this respect, and have learned that when nature is pro tempore exhausted, exhausting it still more is not precisely the way to accelerate recovery. I always carry, when hunting, and indeed at most times, a lancet about me, and it has at times been of use to my friend's horses; but when requested to use it, I have much more frequently recommended a quart of ale, with some spice, and a couple of glasses of spirits in it, if a public-house was at hand, and the horse then being got to the first comfortable place of rest that could be had, and either given or drenched with some well-made gruel. There are cases, however, where copious bleeding, and 
that done without hesitation, is absolutely necessary; and in such I have used the lancet as freely as any one. 'To instance, where, from great sudden exertion, we find the horse stop, his mouth dry and hot, the action of the heart greatly accelerated, and the abdominal vessels in a state of flutter, the animal beginning to stagger, shiver, have a frightened look, and the eyes hot and bloodshot, here bleeding will probably stop staggers and inflammation going on; and bran tea, or a bran mash, if he can be got to eat it, is all he should be allowed till we find the pulse begin to beat with its usual pulsation. It will probably, shortly after, begin to beat feebly and slower than usual: in that case, we may consider that life is pretty safe; and then nourishment may, and, indeed, should, be carefully and gradually given. Laudanum, in cases of this sort, is a very dangerous article in the hands of an ordinary groom; he has perhaps just learned enough to know that it is a sedative; so it is, given at a proper time, and to prevent inflammation taking place; but where it actually has done so, it is usually as improper to be given, as it would have been judicious when we only feared its coming on; our friend bran must then be the sedative.

Bran is also most useful where we find water hard, or a horse subject to be affected by it; indeed, it is always a safe precaution to use it 
where we are not certain of the nature of the water; a few handfuls stirred in will render hard water safe and innocuous, even to delicate horses.

Bran, properly given before physic, will, in (I may say) all cases, prevent gripes, if the physic be good; but not if merely given as grooms often give it, namely, for twelve hours only before the ball is given. I always give it for two days and nights prior to this; some corn with it the first dav, but none the last: in this case the horse is half physicked before the ball is administered; and five drams of good aloes will go as far as seven or eight if otherwise treated, and for many horses is quite enough, and six I should say enough for any ordinary horse, if properly prepared. I have heard many persons say a horse does not recover from a dose of physic for some days; in such a case it is not so much the evacuation that he does not recover from, but the having really suffered while the medicine was in operation, which he certainly will have done, and severely too, if not properly mashed prior to taking it. So far fro'n a horse being depressed by medicine, if properly given (and he wanted it), he will feel himself the lighter and more cheerful after its proper operation: in short, bran is of far greater importance than is often given credit for being; for if corn puts a horse in vigour, bran keeps him in health, and, by preventing disease, plays its full part 
in promoting and keeping up that condition the other more strengthening food has brought him into.

\section{Malt}

I have alluded to, as a useful occasional article for stable use; and made into a mash after a long day, or where we think a horse feels chilled and uncomfortable, it will sometimes be taken by horses shy of a bran one, and in such cases is a most nourishing and consoling supper; it is also most useful where horses are recovering from illness; in short, in any case where we should like a basin of gruel with a fair allowance of sherry in it, in preference to more solid food: so, in a similar case, a malt mash will be found as soothing and comfortable to the stomach of the horse.

\section{BARLEY.}

This is an article but of very rare use in an English stable, though many Easterns use it entirely as stable corn; it is, however, by far too heating for our horses; possibly in hot climates, where horses sweat profusely, its heating qualities may be carried off through the pores of the skin. I have occasionally found it useful to horses who, 
from weak constitution or a nervous temper, are apt to be more loose in their bodies than we might wish.

When I had the management of my father's horses as well as my own, he had an old favourite that I fed wholly on barley, that is, as corn feed. I tried him repeatedly on oats with beans, but a few days showed the change both of condition and spirits; so barley he ate till the day of his death, which did not occur till he had carried my father thirteen successive seasons, and was twenty-four years old. He went at that age as well as ever he did in his life, had not the vestige of a windgall on either leg, never was lame, nor had an ailment of any sort. He was suddenly seized with paralysis of the spine, died, and was buried with all due honours.

I believe that barley soaked in water and then left to sprout is a good thing to bring horses out of work into condition, but I never tried it. Barley, like all stable corn, must, of course, be of a sufficient age, and bruised.

\section{Carrots.}

Having had so many horses of all sorts under my care, I have used carrots in large quantities; still I do not mean so as to the quantity given each horse. 'Towards spring, when horses have 
been many months highly fed on corn, they are extremely serviceable, indeed necessary ; in winter I used them very sparingly. They used to be given to race-horses in far greater quantities than they are now, having formerly had the character of being good for the wind; but I suspect the only merit they can claim in this respect is, that they keep the body cool and properly open, by which they conduce greatly to health and condition, and consequently to clearness of wind. About the same thing may be said of their claims to producing a fine coat; whatever conduces to health does so, consequently carrots do. But I must here add a caution, for, if given too freely, they are apt to produce eruption on the skin. To any one who has been in a racing stable, or in any well-conducted one, it may seem almost useless to say that carrots should be sliced in pretty long slices; but I have seen them given by those calling themselves grooms cut crossways: this is really dangerous, as horses are extremely fond of them, and, if at all greedy, would be apt to bolt pieces of them whole, which would be quite likely to cause some of them to stick in the throat.

Some persons give carrots with the corn, thinking it tempts horses to eat their oats, if of delicate appetite; so they might, if perfectly minced, otherwise they will pick them all out, and the 
groom may eat the oats if he pleases, for depend on it the horses would not; but if we were to make minced meat of them, I should still consider it a very bad plan to give them with oats; for should the horse get accustomed to such a mixture, he would afterwards refuse his corn without it; for this reason I always gave them as separate food; and, if bought at a proper season of the year, by the ton, in the country they are by no means an expensive one, - though they become extremely so when a London coachman can persuade his employer that they are necessary for his horses, buys them by the bunch, consumes two of those in his own family, and, if he is delicate as to conscience, gives the third to his horses; if not, they of course all go the same way. Carrots, if kept in a dry place in sand, will keep a long time, or in sand they will keep out of doors, if covered with straw, and then banked up with earth.

\section{Chaff。}

We must be not quite inattentive even to a small item in stable feeding - the produce of hay, namely, chaff. This is rather a plebeian term, as connected with racing or hunting stables, and, I believe, in the time of even our fathers was but little used in such establishments ; it is, however, 
a most wholesome and necessary adjunct to corn for all sorts of horses; it prevents them bolting their oats, causes proper mastication, and, further, gets horses that are gluttons out of the habit of wasting oats by throwing them out of the manger in their greediness to get at them. I need scarcely say chaff should be fresh, that is, not laid by long after being cut, and of the very best of hay; I have sometimes found a little cut from pure cloverhay coax horses to eat their corn if mixed with it, when off their appetite: in a general way, I should say a little chaff should always be given with corn, unless on the morning of hunting. 


\section{CHAP. IV.}

STABLE ECONOMY. - HOW TO SET ABOUT IT.-EVILS OF IMPROPER DIRECTIONS. - THE RIGHT SORT OF INSTRUCTIONS.-INGENUITY OF SERVANTS.- CHOICE OF A GROOM. - ORDINARY COST OF KEEF. - TABULAR STATEMENT. VETERINARY SURGEONS. - WHEN TO BE CONSULTED. ILLUSTRATIVE ANECDOTES.

UsELEsS prodigality in stables seldom arises, on the part of London stablemen in particular, from the amiable weakness of fondness for their horses. There is a kind of general, and, one would think, intuitive hatred on the part of all servants - or, at least, of nineteen out of twenty - to any thing that they conceive borders on economy, so far as their employer's pocket goes, in the stable or out of it. The lady of the house would find, if potatoes were sixpence a pound, and bread and meat unusually cheap, the demand on the potatomerchant would be enormous; but if bread happened to be ruinous, only hint at the vegetable being used in greater proportion as a partial substitute, a potato would no more be eaten than a sand wash-ball. 
I have had pretty much to do with stablemen and boys of all sorts and grades, from the riding exercise boy to the stud-groom and the wearer of the tier-on-tier caxon, and I must say I never found that any fanatical feelings of religion could be laid to their charge. Still I have seen instances where the researches of the two last-mentioned functionaries have been deep enough to carry them on to one particular parable, which appears to have taken a firm hold of, and made a lively impression on, their imaginations; and, singular enough, but so it is, the researches of many hay, straw, and corn dealers appear to have reached precisely the same point, for "Take thy bill, and sit down quickly, and write fifty," is pretty generally understood by both parties.

Never having been so situated in life as to warrant my giving two hundred a year to a studgroom, or, in fact, keeping a stud-groom at all, it follows, as a matter of course, that my horses, in every way, cost me less keeping than those of the man who did so. Not that they ate a grain of corn less than Lord Plymouth's; but I will answer for it, by their condition, they ate all that was paid for. Nor would I allow them to be less comfortably lodged, or the stable in any one particular less in perfect order; but I will answer its being done by proportionably fewer hands. I detest badly made, badly turned out, 
or shabby appurtenances to a horse; I would not have any of them on or about him a bit behind those of the noble lord: but their first cost, and still more their time of duration and keeping in order, would be found very different items in the amount of proportionate expense. All this, probably, is a matter of very minor consideration with a man who could afford to keep twice the number of horses he does if he could use them; but it is one of serious import to one who, like me, always kept as many as he could afford, and, if the truth must be told, sometimes more.

Why this great difference should arise in keeping the same sort of animal in precisely the same state can easily be answered, by saying it arises from the different position of the owners; but to answer it more in detail -it is caused by the different effects produced by "Eo," and "Ito," This I got far enough in the classics to understand as a boy; of course I understand it as a man; and I doubt not those I employed somehow learned to understand it also, though I never gave them the chance of trying the difference of the effects of the two.

It will be remembered that these sheets are not intended for those who only look to the stud, but for those who consult the healthful state of the "pocket and the stud." It may be said that among some of these the "Eo" would do more 
harm than good. I am aware it would. Here it will be very proper to say "Ito ; " but let it be to some one who understands what he is aboutnot in one case in a thousand to a servant, but a friend, and let it be quite understood that his directions must be obeyed.

Some servants would, I know, be in open rebellion at this: such as study the parable unquestionably would. "We arn't going to stand two masters: "- "then pray go," would often settle the matter; if not, get others.

I am willing to allow that no servant has a right, as it is called, to "stand" two masters; nor need he; for if his legitimate master or mistress knew nothing of stable duty, or, as with the latter, cannot look into it, he will, so far as duty goes, have but one to be directed by, as, in such a case, the master or mistress would do well to merely order their carriage or horses when they want them and interfere no further. With such a friend to direct, even ladies need not be imposed on, as they generally are, or have their horses as improperly treated as is commonly the case.

Should, however, a master know only enough of stable business to be able to see that it is done, when told by somebody who knows better how it should be done, he had much better candidly tell his servant, "Mr. So-and-So says such a 
thing should be done," than to give directions that are absurd or useless; or, if they should be judicious, to pretend they are the result of his own judgment, for servants are quick-sighted enough in these particulars; and if they are worth having, though they will evade obeying useless directions, will obey proper ones, come from what source they may : and the next best thing to being able to direct yourself, is letting your people know you act on the judgment of one who is. They will then know it is useless to attempt to reason or argue - a talent that some have in great perfection, and are very free in using, if permitted to do so.

If a servant who knows his master understands but little of horses refuses to listen to directions from one deputed to give them (who, of course, nust be competent to do so), depend on it the refusal has its origin in one or all of the following causes:-ill-temper, idleness, self-sufficiency, or an intent to plunder. Most servants will kick at first in submitting to what I recommend their masters to do. I neither blame a servant nor a horse for kicking if they are imposed upon, and with either would be the last to give them reason to do so. I have had both kick stoutly; but I do not mind a little larking under certain circumstances - it keeps one alive. Now some horses, figuratively speaking, like some servants, will 
kick just over their traces when called on to work, by way of experiment, to see how the thing will do. It may be very right and very proper to stop your coach and extricate them for a time or tro ; but they are cunning enough, and expecting this, will often try the same trick on again, and would then be constantly at it. The next time my gentleman makes a rocking-horse of his trace, lay the double thong well on to his ears. Let him take his entire side of the coach along for a mile, with the trace chafing his thigh; the chances are, if he gets the opportunity, he will kick himself back into his proper place, and notget on his hobby again. I must apprise those reacers who do not know it, that double-thonging a horse over the ears is one of the severest applications that can be made with a whip, and one that never should be resorted to but on extreme occasions, and where we are quite certain it is fully merited. So in any commands we give, ol in any reprimands we may use towards any pırson, justice, good feeling, and, indeed, common sense, demand that we are quite sure the command isproper, and the neglecting or disobeying it does nct proceed from its impropriety, or the impossibiity of its being carried into effect. Nothing plases a subordinate more than to receive a conmand that he has the opportunity of showing to be absurd or unreasonable. It authorises 
hesitation in obeying, and discussion on the propriety of any that may be subsequently given.

To prevent such an unpleasantness on the part of a lady, or one unaccustomed to horses, the mode can be prescribed in very few words. We will, of course, suppose that the horses and their accompaniments are wished to look as they should do for the purpose for which they are wanted. The first thing the owner should do, is to learn what proportion of work it is reasonable to expect from horses in their different capacities, and the mode in which, and times at which, such work should be called for. We will, of course, suprose they are to have a comfortable stable, comfortsble clothing, and the man to have a proper time to do his business, and all that he requires in reasol to do it with; the next thing is the proper and liberal allowance of provender of different sorts that is necessary to keep up the required condition. Having learned this, and that the horses are in good health at the time the man takes 'o them, there can be nothing unkind, unreasonabb, and still less overbearing, in her addressing hrr servant in something like the following strain:"I give you charge of my horses in good healh and condition. I shall only use them in such a way as authorises my expecting them to be kept so. I make such an allowance of provender as I am told by those who perfectly understand such 
matters is fully sufficient. I shall take care that your situation is made a comfortable one to you; and so long as you do your duty by me and my horses, you will keep it. But remember, that as I cannot go into my stables, my friend $\mathrm{Mr}$. will do so for me, and you will attend to what he says as if it came from myself. Provided my horses look well, you will find that no unnecessary interference with you will take place; but if, on the contrary, I am told they are neglected, or, what is the same thing, look as if they were so, the same day you go, unless I am told by competent judges that you are not to blame. And I never break my word."

With such an exordium, no good servant would be afraid to enter on his charge, and doubtless would do his duty; while one less well-disposed would be afraid to neglect it. He might try "the kicking over the trace;" but if he found that on the first attempt Mr. pulled him up, he would find it would not do, and would probably compliment his lady by saying that "Missus had learnt what's what; and if a man wanted to gammon her, he had got the wrong (some quadruped he would mention) by the ear."

Here, I trust, I have shown, as I intended to do, that even a lady may have her stable and horses attended to without being imposed upon, 
and without making a stud-groom of herself : but, as I said from the beginning, she could not do this without the Mr. - ; and I know some gentlemen to whom he would be all but as great an acquisition as to the lady, though perhaps it would be difficult to persuade them that such is the case. They do without him, it is true, consequently they pay for it.

If a man is positively determined, right or wrong, to go his own way to work, of course he must do so, and he will find, independently of his stud being badly done by on that account, the effect of his giving improper or injudicious directions will be that he will get no servant to live with him that is fit to go into a stable. A good ordinary strapper would not live in his service; for I must say this for stablemen - there are many that would in certain ways ill-use, neglect, and impose on their master, but would not allow their horses to be treated in the same way. I had a carter, the most confounded thief in the world, where anything for his horses was to be got at, and his ingenuity in many ways was firstrate. For instance:

He had been seen several times bringing a sack with something in it from under the granary, which stood on stone staddles. No notice had been taken, supposing it was something he had put there for a temporary period out of the way; 
but he got "bowled out" at last. It was found he had bored a hole in the floor under the corn. In this he had a bung, which went up close, and only looked like a knot in the wood till closely inspected. I did not do as some hasty masters would have done - "draw his cork" (as the fighters say), and then turn him away; but, for example sake, I got a constable, and talked of transportation, and probably should have given him a day or two of peculiar temperance in the village cage, but for the fellow's coolness and ingenuity. On my calling him a thief, he indignantly replied, "Noa, dang it, I beant no thief; I never took nothing off your premises:" and I suppose, seeing this made some impression, he added, with a grin from ear to ear, "You'll have it all back again, you know, measter." He was in ordinary cases a very honest fellow, and I am sure would not have taken a piece of bread for himself if he had wanted it.

To a man obstinately bent on acting on his own judgment it would be useless to say much, otherwise, much as I deprecate permitting servants to give their opinions, I should, in his case, remind him of a quotation - "Fas est ab hoste doceri," or, in more vulgar phrase, "Never refuse a light from any man's candle." Anybody's advice that is good is better than that dictated by your own judgment, if that happens to be bad; and, in 
such a case, the recommendation of a good servant is not to be despised. But there is one serious consideration to be discussed here. Is the groom that such a man would take competent to give advice? for I should be led to fear that want of knowledge of horses would also comprehend the same want as regards the qualifications of a groom. And we may fairly infer the sort of servant he would get would be a shade or two behindhand in point of knowledge, if compared with such men as have charge of studs at Melton. Of their opinion I should be always happy to avail myself; but then it must be remembered that they are selected by those who know perfectly well what are the duties of a stud-groom, and only keep them to save themselves trouble - not because they are incapable of giving proper directions themselves. These grooms know this, and though highly respectable men, it has no small share in contributing to their strict attention to their duties and their stud. Such servants are a great addition to the expense of each horse, we know; but they effect a very considerable saving in the long run, when compared with valuable horses being under injudicious management, whether that proceeds from master or man, or both.

Such men are not wanted, of course, by persons who keep three or four ordinary horses for ordinary purposes. Such would not warrant the 
expense; but for them, niniess their master wishes them to be always in some trouble, and himself also, a good servant is required. And then, unless he has (at least, occasionally) over him an eye that can see, and a head and tongue to direct, the chances are he will sooner or later become a bad one. If the master happens to fall short in the first two qualifications, the less he uses the latter organ the better; otherwise, should the servant be a middling one, their joint acts would only make bad worse : should he be a good one, he will leave his situation. So, under each and every circumstance, it will be seen that the only way for a person to have his business tolerably done, if he cannot, that is, if he is not qualified to direct himself, is to avail himself of some one who is.

Numbers of persons are deterred from keeping horses from conceiving the expense of them to be much greater than it really is, or, at all events, need be, if they are properly managed. Such persons often expend in omnibus, street-cab, and job cab-hire about twice as much as would keep them a well-appointed Brougham or Clarence for their family use.

A friend of mine, who lives in pretty good style, with the exception of not keeping horses, when speaking on the subject, and enumerating the probable expense of only a single horse, among his other items set down the forage of the horse 
at a hundred a year; this being, in fact, quite as much as any three ordinary horses could be got to consume in value.

I make no doubt there are persons who are cheated out of such a sum as my friend contemplated, and that such a sum is consumed in food-but not food for the horse. The baker and butcher, I consider, in such a case get an honest two-thirds, and the horse as little of the remainder as possible to keep him in decent condition. All this imposition arises from the same cause as that which will always occasion such persons to lose money by their purchases when they make them on their own judgment, that is, undertaking the management of what they do not understand.

In some proof of this being the case, a physician has lately told me, that for the keep, shoeing, little repairs of clothing, head-collars, and the supply of chamois, sponges, mops, brooms, \&c., all of which are paid by his coachman, the bills, regularly amount to three hundred a year. This for one pair of horses, I must say, exceeds anything I ever heard of in point of imposition on the part of a servant; still the master has paid it during the six years this coachman has been with him. The gentleman allowed he thought he was paying too much, and asked my opinion. I thought he was, by more than two hundred a year; but being only a mere acquaintance, I thought it no business of mine to put him right, for the 
doing of which I should very probably have got no thanks. I did suggest jobbing his horses. "Oh, he had tried that, but he found the horses looked bad, and had always something the matter with them." I asked if the same coachman fed and drove them. "Yes, he did." I smiled, but said no more than it was odd: but I did not think it odd at all: and if the worthy physician had thought twice, he would have seen the folly of supposing this rogue of a coachman would for a moment tolerate his master's jobbing horses, by which if they were done justice to, coachee could make nothing; whereas, by the other plan, he cleared annually what many a nobleman's son works six hours a day for in a public office. Now had the physician jobbed a coachman with the horses, he would have found he saved, to say the least, 150l. a year by the change of his mode of proceeding: but he perseveres in his old plan; and so he may for me: it is quite useless to take trouble for friends without thanks; it is folly to do the same thing for acquaintance; but I trust this fact shows how needful a counsellor is to any man in any matter of which he is not himself a competent judge.

'The cost of keep must a good deal depend on the description of horse kept, and the quantum of work he is expected to do. Of the feeding of race-horses I need say but little here. Generally - and, indeed, sometimes injudiciously - the 
quantum given depends on what they can be got to eat: this quantum is, however, sometimes influenced by whether they are fed at the trainer's expense or the owner's, and sometimes much more by whether the horse is a favourite with the stable or not. I say sometimes, because, in justice to trainers, I must add there is seldom any fault to be found with them as to stinting horses; how far, in the long run, they contrive to starve the owners, is another affair. As some little insight however, for the totally uninitiated, I will merely say there are some delicate, nervous race-horses that can scarcely be coaxed to eat a peck a day (and generally speaking, that peck is thrown away on such horses); others, that are good, fair, hearty horses, will, on an average, eat a peck and a half; while many gluttons will take, without any trouble, half a bushel a day.

Hunters, like other horses and men, vary, of course, in their appetites; but, to make the quantum of oats they consume something like definite, I believe it will be found - at least, I have always found it so-that, taking into account hunting days, when a mash as the last feed supersedes one feed of oats, - the day after, when some will eat but little, others perhaps none,-occasionally a day or two of indisposition, - a frost, when a dose of physic is better than a bushel of corn, - and other contingencies, - in a stable of horses during 
the hunting season, five quarterns of oats per day a horse, with occasionally a few beans, is as much as you will get them to eat on an average of seven consecutive months.

To show the difference between practically knowing the expenses of a stable, and listening to being told by interested persons, what they " must be, at least," I will just take a pair of sixteen-hands carriage-horses, and see what their expense, not "must be," but should be; and here I show no presumption in saying I care not what all the grooms or coachmen in London may say - I know I am right; not from any talent, ingenuity, or peculiar mode of treatment; not reasoning upon even the best theoretical principles, but on the broad, plain, homely facts of experience and practice - that not arising from having had the management of any one or two classes of horses, or those under one or two different situations or circumstances, but from having had the direction of all sorts - race-horses, hunters, carriage-horses, hacks, machineers, and cart-horses, - and at one period all at the same time; what I say, therefore, on the subject reflects about as much credit on me in point of intellect as we should attach to the man who had been all his life emptying coal-waggons telling us how many sacks went to the chaldron, and the chance of our being in error would be about equal. 
It will be remembered I am now taking a pair of horses that are quite as expensive to keep as any used for private purposes, for I allow each six quarterns of corn per day. No two hunters living eat as much, take the year throughout: for though the name of a hunter to some persons conveys an idea of great expense - and though hunting is expensive, it is not the keep of the horse that makes it so-a good well-worked $40 l$. cover hack costs quite as much, and more than you can get some hunters to cost you.

Two horses, six quarterns a day each, at $1 l .4 s$.

f. $d$. per quarter, say - - $\quad$ - 4100

"14lbs. of hay per day each, at 4l. 10s. per ton, say - - 20100

" Supposing straw to be scarce, $1 \mathrm{cwt}$. of straw per week, $1 l$. 10s. per ton, say - - - - - 3180

" Shoeing both, 10s. per month, 28 days* - - - - - 6100

" Wear and tear of chamois, sponges, brushes, \&c. $6 d$. per week - 160

"Wear and tear of clothing and head collars, $6 d$. each $\quad-\quad \frac{2120}{£ 75100}$

* Shoeing and occasionally altering will come to something more in London, where they charge $5 s$. a set: but as in the country they charge but $4 s$.-indeed, in some places less, - I think the $6 l .10 s$. a fair average. I take the same thing into consideration as regards keep, not supposing a horse all the year in London. 
Now I strnngly suspect that, let any lady turn to her accounts for all I have mentioned, she will find her pair of carriage-horses have cost her a little more than this, unless she limited them very much in every allowance; in which case I infer they cost her quite as much, from frequently being in the veterinarian's hands, and never in first-rate condition either.

Veterinary surgeon's bills are items no one can give an estimate of, depending, of course, on the good or bad luck people have with, or rather on the management of, their horses. For I am no little sceptical on the matter of luck; at least $I$ can only say when things have occurred to me that many persons might attribute in their case to bad luck, I always, or at least mostly, could, in some particular or other, trace them to some blundering act of stupidity or culpable inattention of my own.

However, as in other persons' cases we will call it bad luck, whenever it comes in the shape of a horse falling lame or amiss, go yourself with him ; or, if in a lady's case, send some friend with him to the best class of veterinary surgeons: it will be the least expense in the end. If you allow your man to take him where he likes, he is sure to have some friend, a common farrier, who will be sure to make the horse worse; probably in some way blemish him without there being any 
occasion for it, and do it clumsily if there is, besides keeping him twice as long under treatment as he would be kept by such a man as Mr. Field, or any other first-rate practitioner, and end by sending in a bill three times as long for doing so.

Next in point of annoyance to a groom or coachman sending for a friend in the shape of a farrier to see and of course attend a sick or lame horse, is the groom taking him in hand himself; I mean in this case, of course, an ordinary groom. It is true by his doing so, no farrier's bill is incurred; but in nine cases in ten, the horse comes off even worse than in the hands of a village practitioner, for he has most probably had experience in cases similar to the one he may be called in to see, and after having done a great deal of mischief to a few score of horses in such predicament, and done no good to a few score more, he may possibly, if an old man, have at last hit on some nostrum or practice that has done good, and in such a case his subsequent patients derive benefit from his having at last blundered on the right plan; but an ordinary groom has not even the advantage of having had these few scores of fortunate animals to practise on, and probably can only say in defence of what he may do or contemplate doing, that, "when he lived with Mister or Captain such a one, he had a horse taken just the same way; he knows what Mr Field did to him, for he saw it 
all." Now, in the first place, a man may safely bet any odds that the cases were not alike, further than each horse was sick or lame. Next he saw the horse get balls. He might just know enough to detect by the smell that these balls contained aloes; but of the quantity, or what might be combined with them, he knows no more than he does whether aloes are a gum or a vegetable root. $\mathrm{He}$ might see a horse both physicked and bled for (we will say) the same disease as that under which the one labours that he intends to cure, but he never dreams that physicking and bleeding might both be proper in one stage of a disease, but certain death in another. One that among hundreds of instances of this kind have come under my personal notice, I will mention.

A friend, on sending a horse from Dublin to London, had requested me to give him a stall, that the horse might rest for a day or two before going the last hundred and odd miles, on his road to London (for a journey from Holyhead, which was the route he came, was no joke before the railroad was completed). Prior to starting from Dublin, a veterinarian had very properly recommended a dose of physic, fearing, from the full habit of the animal, some attack on the bowels during the journey; this the groom, who thought he knew everything, had neglected, or rather omitted to give. Shortly after arriving at my 
stable, the horse was taken exceedingly ill; and on my going to see him I found him suffering under inflammation of the bowels, and this knowing groom with a physic-ball in his hand, which he was preparing to give. I remonstrated against so preposterous an act. The groom was obstinate, saying, "that if the horse wanted physic six days before, he wanted it six times as much now;" but I was as obstinate as he, and it ended in my soundly swearing no ball, at least physic-ball, should the horse get. The man swore he would do as he liked with the horse while under his care, and again prepared to give the ball. I settled this by ejecting the fellow from the stable, locking the door, and just remarking the horse was not then under his care. I immediately sent for a veterinary surgeon, told him the story, and, not being nice in his selection of terms, he said to the man, "Why, you d- - fool, if the horse had got that ball, he would never have wanted another; he would most likely have been a dead one before morning." What a treasure in a stable such a prescribing groom must be! yet many such there are in high repute with masters who know no better than themselves.

I do not mean that a man who knows what he is about need send his horse on every trifling ailment to any veterinary surgeon; but it is the cheapest plan for the man who does not. 
But in sending to a professional let me strongly recommend the most eminent that is to be had be applied to; if the case is a trivial one he will not make it serious by ignorant treatment, and if serious, of course all his skill will be wanting; and as if in corroboration of the soundness of my advice on this point at least, a circumstance occurred only a short time ago, which I will mention here.

I had, within the last month, occasion to put a horse at livery for a few days, where the owner of the yard has about twenty horses working in street cabs. Observing one of them in a coach-house, and guessing illness to have caused him or rather her to be placed there, in accordance with my usual habit I went in to see what was the matter; to enlighten me on the subject an ostler came and informed me the mare was "mortal bad: " this I had sense enough to see, without his assurance of the fact; but as the acme of professional information, he farther told me she was "bad of her inside: " now, as the unfortunate beast was blowing away like a steam-boiler, my veterinary knowledge went far enough to draw this inference also.

"Why, man," said I, " the mare has inflammation of the lungs; I don't see that anything proper has been done to relieve her; does any veterinarian attend her, - I suppose not?"

"Oh yes," said my informant, "a young man 
attends her that master has a great opinion of." Well, he deserves it, thought I ; observing, "I suppose he is going to do something for her immediately?" "No," says the ostler, "he has given her some balls, but he says she is sure to die; so he won't do nothing else." "He is quite right," said I, " as to her dying, for die she most certainly will under her present treatment." So ended our conversation.

A friend of mine, one of our most eminent and, I believe, most experienced army veterinary surgeons, called on me next morning, and, on going to the stables, I showed him the mare, as a living proof of the ignorance of common farriers. Nothing had been done; he was told the same story I was, and also of the prediction of the mare's dying. " "Die be —_," said my friend, "so she will, and that very soon, if nothing is done for her; but if I had her under my care, I would insure her life for half a sovereign." Notwithstanding the ostler told his master this, instead of sending for some man of sense, he took the word of the young man who stood so high in his estimation. The consequence may be anticipated:- a useful animal was lost through improper and want of proper treatment. 
CHAP. V.

THE DIFFERENT VALUE OF DIFFERENT HORSES.-THE BEST JUDGE OF A HORSE.- CASES IN POINT.-THE PRICE OF PERFECTION.

IN making so wide a distinction as I do between persons who understand horses and those who do not, I feel myself called on to give some little explanation of what I mean, otherwise I may unintentionally give offence where and when I by no means intend to do so; for understanding a thing or its reverse are only relative terms as to how far the knowledge or the want of it is concerned. There are certainly some men who do not know a good-looking horse from a brute thousands that are no judge of a good sort of one, or a good goer.

An uncle of mine went a good deal further. He said that, provided two horses were both black or white - or, as he termed them, red, and about the same size, he could see no difference in them. My discernment as regarded his medals or black-letter volumes I dare say was about the same thing.

There are, perhaps, few men exactly like my 
revered uncle as regards horse affairs; but there are thousands who perfectly know a handsome one when they see him, a goer when they see him move, and a pleasant one when they ride; nay, further, can ride him very well, and yet want that particular sort of knowledge that alone can enable them to manage well, and without useless expenditure. These are very ticklish gentlemen to handle; here the most candid friend, or the veterinary surgeon, sometimes gets into a dilemma.

We will say a gentleman shows a horse to a friend, or a veterinary surgeon, with something about him amiss, that it is at once seen will take a considerable time under the immediate care of the vet., and then a winter's rest to make all sure. Formerly a winter's run implied a straw-yard, and the occasional luxury of a meadow, wet as a bog in open weather, and hard and rough as a heap of stones in frost. This saved keep, it is true; but the expense of getting such a horse again into condition was more than that of - as we do now - hovelling him comfortably, and giving him hay and oats. So the expense in one way or the other for keep must be considerable, before the horse is fit for use; then comes the veterinary surgeon's bill.

The owner will, in the first place, possibly ask if it is probable the horse will come up sound? 
and gets the perhaps candid and just opinion that he will. He may be asked the probable expense; this a first-rate man will generally pretty accurately tell you. The owner, then, perhaps, calcalates, or gets the information, that keeping in the rough on corn, and six weeks in the stable physicking and getting into condition, will be, say 14l. or 15l.; vet.'s bill (medicine, keep, and firing), we will say $12 l$. Here we get $27 l$. Well, the owner may say - and, I will answer for it, does say - it is a good deal of trouble and money; but he is a very valuable horse, so it must be done. As probably neither the vet. nor friend may know the qualifications of the animal, they cannot contradict the assertion as to its value, nor is it their business to inquire into the matter; but there is one thing by no means improbable in such a case, which is, that they not only do not know his value or merits, but cannot for the life of them see either the one or the other.

Now let us look into the fact of this horse really being, as represented, "very valuable;" my life on it, the great reason the owner has for asserting that he is so is, that he gave a great deal of money for him. Well, he comes up realising all that was promised, perfectly sound, but perhaps a good deal scarred, if the remedy was effectually applied. The owner, not liking the look of this, or for some 
reason, wishes to sell him; now " pussy jumps out of the bag" - $40 l$. is all he can get for him as a blemished horse. He will now be sure to find fault with the vet. or his friend, or both, for advising him to take all the trouble and expense, and then to find his horse only worth $40 \mathrm{l}$. Here is just shown the difference between his really being a valuable horse, or merely one for which a considerable sum had been paid. The friend and the vet., of course, took the owner's word as to his value; and supposing what they were told could be borne out, their advice whs judicious, for $27 l$. would be very little consideration in getting a really valuable horse upright; and such horses as have gone under Sir Bellingham Graham, Lord Plymouth, or Forester, would not be brought down to quite $40 \mathrm{l}$. because their legs were a little disfigured. But such horses are really of known value; the value of the one in question probably only existed in the opinion of the owner. Supposing, on being accused of having given interested or injudicious advice, the vet. or the friend - beginning to suspect how the thing stood - should take the liberty of asking in what the value of the horse consisted, and found out the truth, it is by no means improbable they might say, - "Hearing you say he was a valuable horse, and judging only by what we could see, we of course thought he was one of known character 
and qualifications;" finding he was not this, they come down with the stunner, "Why, my good sir, he was never worth more than about $50 l$. before he was lame."

Respecting the value, it would take a good folio volume of many hundred pages to enable the most experienced in horses, and a clever writer to boot, to enable him to give any idea of the different value of different horses; for when once men indulge in whims and fancies about them, there is no judging what they will give to get possession of a horse they fancy, or what they will sacrifice to get rid of one that does not meet their wishes; hence the great fluctuation we often see in the price asked for and given for the same horse; for in some men's hands his qualifications would be of no recommendation, while in those of another person they would be beyond all price; as an instance of which I bought a mare for my father, and knowing the qualifications he mostly prized, - namely, being very handy, and a standing jumper, - I rode her best part of a season for him, and made her one of the most perfect standing leapers in the kingdom, and, as a dealer would say, as " handy as a fiddle," though no powers could make her fly her fences; the consequence of her qualifications was, that several others of the same mind as my good father often tempted him to part with her at a high figure, 
but (figuratively speaking) no money would have bought her; in some proof of which he rode her thirteen seasons. Now, had she got into my hands, I would have sold her for forty pounds rather than ride her, unless it had been in a very close cramp country with harriers; there she would be as a hunter beyond price, but I no more like such a country than I do the kind of hunter fit for it: it is only, in my estimation, better to hunt there than not hunt at all.

The fact is, the value of a hunter is nominal, but not often definable; it is only to be defined, in one way: if half a dozen known good riders to hounds would each give a hundred and fifty or any given price for the same horse, that price for the time being is his value; but it in no way follows, because an owner may set a given price on his horse and may find a purchaser to give it, that such is his value; the price set on him arose from his owner's estimation of the qualifications the animal possessed, and the price given was from the purchaser's estimation of them being the same as the owner's; probably no other man would have given half the money - many would not perhaps ride the horse if they were paid for doing it.

Now the value of a race-horse is definable, because it depends on what he can do, and not (as in the case of the hunter) how he does it, if he does it, - that is, if he can win: it matters not 
whether men are sportsmen or not, or fond of racing or not, the horse that can win money is valuable in all men's eyes who have any thing to do with racing, and that value depends on the class of horses he can run with and beat, that is if all is meant fair, for we might be very much deceived in the value of a race-horse if we judged by the price he might be bought or sold at, at particular times; five thousand might be offered for a horse prior to some great event coming off, in which he might be thought to be more than dangerous, yet after winning the race easily, the same party would not give one-fifth of the sum for him : why this would probably happen racing men know well ; to those who are not, it is of no consequence whether they know it or not.

Many horses that are kept for use are to be valued, and that nearly as closely as any other useful article. Cart horses can be valued to a great nicety by any man accustomed to the buying and selling of them; so can good, fair, useful thirty or forty pound harness horses for other work; even carriage horses can be estimated when they are a fair useful sort, worth we will say from a hundred and twenty to a hundred and fifty the pair ; beyond this their price is almost nominal, for what a pair of singularly beautiful wellmatched horses, with extraordinary high, grand, and fashionable action would bring, depends on the 
purse, inclination, or folly of the purchaser; such a pair would be a little fortune to an owner, if the young and beautiful wife of a rich old man took a fancy to them; the fortunate owner would not only get a heavy addition to his purse, but the good will of the lady, by making the old gentleman evince to the world the fervour of his adoration by the price he paid to gratify her whim.

But to return to the supposed case of the valuable horse before mentioned; it is true, in one particular the owner acted as I recommend, in taking the advice of two experienced men. $\mathrm{He}$ did so; but he must recollect that he acted on his own judgment first, by telling them he was showing a valuable horse. They therefore recommended what was judicious to do with such a one, but not, perhaps, what was advisable to do with the one in question. Probably, had they been allowed to form their own estimate of his value, they might have thought, and perhaps have said, they did not think he was worth a heavy expense, and would have recommended a few days' rest, and putting him up for sale, when they might estimate him at about the $40 l$. The owner would probably think them rogues, fools, or mad, to thus undervalue his hundred-guinea nag; I would, however, back such men to be pretty near the mark.

It is a common idea that an owner is the best 
judge of the value of his own horse. If the words value "to him" were added, there would be much truth in it; but without these two additional words, I beg leave to give it as an opinion that a very considerable number of owners know nothing at all about the value of their horse. Selling, or making the attempt to sell, will tell them the truth; buying does not even afford a hint on the subject.

When I say this, I must, however, state it depends a good deal on where and of whom he buys; if he buys of any person in a private way, of course each makes his bargain, and no matter whether the thing purchased be a horse or an article of jewellery, it may be bought and sold at (in mercantile phrase) fifty per cent. below or above its value; but if a stud of well-known horses are on sale, and on the day of the sale a number of persons who know the qualifications of each horse are present, a man purchasing one of them will in a general way get the horse at something like his value, that is, supposing the stud is for some particular reason to be bonâ fide sold, and the owner a gentleman; but if, as is frequently the case, a stud is advertised, and the owner merely has this done to get rid of objectionable horses, then the chances are a buyer gives far more than the horse's value, by getting hold of a roarer, a lame or thoroughly bad one.

But supposing a man is not thus unfortunate, 
but, on the contrary, gets one that persons who know the horse tell him, and tell him truly, is cheap at the price paid, he may still get him too dear, that is, he may be dear, to him: for unless he has had forethought enough to consider the kind of country the horse comes from, he may find, when he gets him into the one he hunts, that he is not worth half the money.

Now, let us take the thing in a diametrically opposite point of view, and we shall see where the owner is the best judge of his horse.

We will suppose a man has more hunters than he wants, and wishes to diminish the number; of course his wish would be to sell those that he, for some reason or other, liked the least; but rather than keep them all, he determines to sell any (say) three of them, - a sensible resolve enough, if a man is not of great wealth, and happens to be one of those who are tolerable hands at making hunters. The man of wealth has no occasion to part with anything that he likes. The man who is not a horseman and judge of horses, never should part with one that carries him to his satisfaction: the man who is, always should, if he gets his price; for, only give him spring, speed, and stamina, he can make a hunter, as a carpenter can make a table if he gets the proper wood. We suppose the person wanting to sell to be one of these, and a gentleman looking 
at his horses is one of the sort who could eat his dinner very well on the table when made; but if the table was wanting, so far as his own ability of making one goes, would be reduced to taking his soup on his knees. He may be a very clever man, probally more so than the other, but not a carpenter (of hunters) more than of tables.

On looking at the supposed horses on sale, our buyer sees a good-looking brown horse, about his cut as to size and strength - asks his character. The owner, as a gentleman, gives a true one.

"He is a very fair horse indeed, an excellent hunter in any country but one like mine, a remarkably fine fencer, and very handy, but not so fast as I could wish here : his price, $150 l . "$

Our buyer candidly says, that only hunting occasionally, he does not wish to give quite so much.

In the next stall he sees a particular splendid grey, who looks a fortune: he looks at him, but modestly says,-

"I am afraid I need not ask any questions about him: he is beyond my mark."

"Yes, you may," replies the owner, goodnaturedly smiling, "so far as price goes; I ask 100l. for him. I tell you fairly he is one of the few horses I have had that I could not make a hunter of. He cannot live a distance with hounds if the pace is good; and he is so nervous, that he 
becomes quite confused where the fences are big. He would be a delightful hunter with harriers; but as Elmore is coming to look at my horses, he will buy him for harness."

A stall or two off, he sees a plain bay horse, with rather a large long head, a little low in the crest, with wide, bony, and somewhat ragged hips, a meanish tail, and, moreover, not seeming particularly amiable as to temper in the stable. Our buyer does not much relish the looks, but wishing to be well carried, and at a lowish figure, he says, -

"Would that horse carry me?"

He here observes a certain laconic side-smile on the countenance of the groom - a kind of smile as if in anticipation of something to smile at.

"I have no hesitation in saying," replied the owner, "he can carry you or any other man in any country and with any hounds."

"What do you expect for him?" "Three hundred!"

Of course, this was a floorer.

"Now," said the owner, "if you would permit me to point out a horse to you, I think I could put one into your hands that would suit you in all respects: it is this chesnut. I took him in exchange from a friend of mine. $\mathrm{He}$ has three failings, neither of which, I should say, would be objectionable to you in the country where you 
hunt. He is particularly pleasant to ride, very safe, and handy at fences, goes a fair pace, and will go on till nightfall. But, like the brown horse, he is not as fast as I like them here, and he does not like wide water: independent of which, he is a size less than I usually have them. I should say in Surrey he would be perfect; and I will take 100l."

"Caveat emptor," "ne crede," and many other trite quotations, are things very useful to bear in mind when purchasing, but with very timid or very suspicious persons are very apt to lead them into error, by inducing them to turn a deaf ear to all the seller says of his own property. That every man may be apt to sound the praises and soften off the failings of his own, is natural enough; how far this is done, of course depends on the conscience and respectability of the man. To show that we should not always reject the recommendation of a seller, I will mention an anecdote of Beardsworth, when he had the large repository at Birmingham.

A gentleman came to him saying that he was authorised to mention a friend's name who assured him that on his doing so Beardsworth would recommend him a good buggy-horse: the little man showed him two, either of which he said was capital in single harness; the customer's suspicious disposition took alarm at the strength 
of Beardsworth's encomiums, and he declined both. "Have you nothing else you think would suit me?" says the buyer. "I really don't know," says Beardsworth: "there are plenty more; look round and please yourself." The gentleman did so, and found a mare that struck his fancy. "Will this mare suit me, Mr. Beardsworth?" "I really can't say," replied he; "I recommended what I knew would, because I have often driven both; but pray choose for yourself." "Did you ever drive this mare, Mr. Beardsworth?" "Never," said he. "Did you ever see her in harness?" "Often," said the little man. The gentleman bought her, drove her, and felt certain Beardsworth had wanted to get off two of his own, instead of this capital mare, who was, moreover, twenty pounds less in price than either of the others. On the Wednesday, that is, the second time he drove her, he came into Beardsworth's establishment with a long and ireful countenance, and abused him for selling him a mare that had kicked his gig to pieces. "Did I tell you she would not kick?" said Beardsworth; "I recommended you two that I knew would not; you kicked at my recommendation. I told you to please yourself; I hope you have done so. I told you I had often seen this mare in harness; so I have, and always saw her attempt to kick: if you had asked me if I had seen her go quietly in har- 
ness, I should have said no. Perhaps next time you will follow your friend's advice in taking mine; if you do, I will try and suit you."

There is a certain feeling of vanity in man that is not confined to the breast, which is generally pointed out as its locality, but runs, like the nerves, over every part and particle of the body; so, touch it where you will, it is capable, like the string of a harp touched by the scientific finger of a master, of producing harmony; but when the careless and rude finger of truth is applied, it often gives back a tivang that seems to jar to the very pedals.

The description of the hunter seemed to bode his suiting our buyer; but the not being objectionable to him and his country appeared to carry with it something bordering on a latent hint at inferiority that he winced at. He felt the truth of the thing, would have owned it to himself, but to have it, as it were, forced on him by another, though done without any intentional offence, made it no more palatable than Pistol found the leek, or the persuasions that induced him to swallow it. He even thought of dashing at the three hundred-pounder at once; but, as he was a sensible man, the thought merely flitted across his brain, so he compounded with good sense, good manners, and a little mortification, by asking if he might take the liberty of senuing a brother-sportsman to 
look at the little horse, and to ride him. Both permissions being granted, he took his leave; and next day the friend came. He and the seller were at home at once; they saw what each other was in a moment.

"Take him into those meadows," said the latter, "put him at any fair fences you like; if you get him into one, I shall forgive you."

The horse answered all that was said of him. Both agreed he was all that could be wished for the proposed buyer. His friend made his report, and recommended him not to miss the horse. He promised he would not; but it did not do. The "him and his country" still jarred like the string touched by truth; and then the buying a horse on a friend's trial and judgment had a want of independence about it that chafed him; and again the horse was not a wide brook jumper. True, there were no wide brooks to jump where he hunted. He was not quite so fast as his present owner wanted - this seemed like putting up with something inferior. No: he would choose for himself, and see if he could not, by giving a little more, get nearer perfection. He tried: went to a dealer, gave 150l., got one that he was told was perfection itself. This he had no great opportunity of finding out: but the first day, after one burst, he clearly ascertained he was a lame one. He would have consulted the interest 
of the pocket more by taking his friend's recommendation, and have made a better addition to the stud.

I cannot here pass over a little anecdote of one of my most esteemed friends, - a man of business, but one with whom Fate was either blind or in one of her wayward moods when she gave out the ticket of his destiny. Instead of ever looking at a ledger, he ought only to be asked to look at the rent roll of a princely estate (his own); instead of having to calculate profit and loss, he ought only to have to calculate what his heart would always prompt him to do, or how to serve his friends. I have often seen him at his desk, never on his saddle - that is, with hounds; but I am told, when he can steal a day from the former, he sails away in the front rank on the latter.

He was some time since in want of a horse; and a stud being advertised at Tattersall's, I met him there, and found he intended buying one from it. He allowed he did not know the horses, so I took the liberty of hinting it was somewhat hazardous buying under such circumstances; but as he said a friend, who had hunted where the stud came from, had told him what to buy, I said no more. He did buy one, whose shape and make was certainly not perfection. However, I saw him take away the new purchase, and thought no more of the circumstance. 
Walking with an acquaintance an hour afterwards in Hyde Park, I saw some one coming up Rotten Row, at a good or rather bad hunting gallop. "Well," said I to my companion, "that gentleman has got a brute under him at all events." When he came nearer, lo! it was my friend on the new bargain. He came up. "How do you like your mare?" "Not at all; she is lame behind, I am sure, from her manner of going." "Just trot her fifty yards, and let us see," said I. My companion and I agreed she was sound enough ; but her hind legs seemed as if nature never intended them to help her along. I told my friend she was sound; but as she was bought, I did not wish to put him out of humour with her, by telling him I thought her an awful beast. "But," said he, "she is a roarer." "Oh! your humble servant," said I, "go back to Tattersall's : she was sold as a hunter. If you find that, notwithstanding her noise, she has been regularly hunted, you are fixed; if she has not, return her." He did so, and somehow got out of her: it will be seen by this, that, though it is very judicious to take the advice of a friend, we should consider what friend, and whether his advice is worth having. 
DIFFERENT MODES OF KEEPING HORSES. - CHAQUE PAYS, CHAQUE MODE. - THE KIND OF HORSE BEST SUITED FOR DIFFERENT CARRIAGES. - ON SINGLE-HORSE CARRIAGES AND PAIR-HORSE DITTO. - THE PROS AND CONS OF KEEPING CARRIAGE-HORSES AND HUNTERS AT LIVERY. - JOBBING OF HORSES. - SUMMARY OF THE WORK.

WHEN using the term "stud," our ideas are chiefly led to the contemplation of the hunter's stable. I only mean it, as used in these sheets, to allude to horses in general; but, be the stud what it may, it is composed of horses used more or less as animals for real use or business, or for pleasurable purposes. Of course, the horses used for the park and street are for use, but not used in the light in which I contemplate the term.

Now, there are two opposite ways in which horses may be kept; and both will answer well if in all particulars the system is adhered to. There is the rough and ready plan, and there is the plan that brings out horses in fine condition; but the person is unreasonable as regards his servant and his horses, if he thinks he can combine both. If 
a lady merely wants a pair of animals to drag a machine on wheels about, so as to convey her free from wet or cold wherever and whenever she is disposed to go out, and cares nothing for their appearance, the rough plan will do, provided they get plenty of corn; and such horses, with a good tough coat on them, and waterproof-cloths across their loins, will stand inclement weather, and be no more hurt by it than the cart-horse. But then their pace must accord with their appearance and treatment; for the cart-horse, hardy as he is, would very soon get under the doctor's hands if he was subjected to heats by fast work, and then to stand while his waggon was loaded and unloaded; for though a long coat will keep off a certain degree of rain from the pores of the skin, and a dry one will keep out the cold air, a long coat wetted with sweat is anything but likely to prevent colds, if horses are afterwards to be kept loitering about at doors. Such horses, of course, in point of keep, will cost just as much as those in good condition, and, after all, confer anything but credit on their owners. If a lady thinks the term "my carriage" sufficient, no matter what that carriage may be, well and good. I can only say I consider the difference between such equipages as Lord Anglesey's, Lord Sefton's, and many others, and that of some that we occasionally see, is much greater than between the latter and none 
at all. In fact, if I had ever owned such a turnout as I have seen some ladies sport, and wished to make a morning call, I should have desired the cortige - men, horses, and vehicle - to stop a few doors off, lest I might be suspected of owning them.

Here is just the difference between the pride of the generality of foreigners, particularly Frenchmen, and Englishmen. A Frenchman on a wretch not worth twenty pounds will make him (if he or spurs can make him) curvet and prance so as to attract all eyes, and thinks him, next to himself, an animal to be admired by all beholders. An Englishman on such a creature would pray no one might see him so mounted. Not so Monsieur. With him a horse is a horse, with this exception; if the finest horse England ever produced was to walk quietly along the Boulevards, his rider would think they cut no figure at all; but give him one of Batty's cast-offs, or any creature that would dance about, making a fool of both horse and rider, he would be thought the ne plus ultra of horses.

With their equipages, unless it be with the élite of fashion, they are still worse. A cabriolet is a cabriolet, though it be a machine that has been in use twenty years, since it was only worth four pounds, and would be spoken of with all becoming pomposity. An Englishman who has never been much at the country châteaux of Frenchmen 
can form no idea of the monstrosities the remise there can produce, - but still it is the carrosse de Madame.

It is quite true private individuals of moderate means are not called on or expected to keep such equipages as the nobility or persons of great wealth, yet still may want a carriage for their families; and one that will pass without observation of any sort is here quite appropriate: but as most persons wish to make as decent an appearance as their means permit, and as my object is, as far as I can, to further their object as regards their horses and their appliances, I only beg the masters of such equipages to believe me when $I$ assure them that taking care their ladies are not in inclement weather all the morning shopping, that they under such circumstances curtail the length and number of their morning visits, do not order the carriage at eleven and keep it waiting till one to take them out, or at one in the morning and keep it till three to bring them home, will just make the difference of having an equipage that is at least creditable, or one that would occasionally induce a cabman to call out, "Who wouldn't keep a carriage?"

It is true we see the most splendid equipages out in the most inclement weather; but what are they doing? Taking their lords or masters to or from the House, to dinner or a party, bringing 
their ladies from a villa to the town-house, or to a party or the theatre: they then go home and are dried. There are other horses and other harness, if wanted, to fetch their owners back; but we do not see such owners starving their horses and servants, cheapening bonnets or silks at half-a-dozen different shops. Many hundreds who do, if they were going to ten different ones close together, would not, if they lived two hundred yards off, walk there, and, knowing they should be three hours, order their carriage to call for them at a certain hour, for the world. What, lose letting the ten shops see they kept a carriage! Oh, the delight of "Put those things in to the carriage!" or "William," beckoning their servant into the shop, "put this in the pocket of the carriage!" Pleasant and salutary ail this, for clipped horses.

I have in my eye a family of a certain grade, and, from the animus of each member of it, pretty accurately guess what would be done should they perpetrate a carriage of any sort. If they wanted to go to dinner at seven, it would be ordered to the door at five, to be seen there! If wanted to go shopping, which it certainly would be two hundred and fifty days a-year, it would be ordered at two, to go at half-past three! Would it not be "to and again," as people describe our canine friend in a fair? Would not the tablets to write on, and the 
"tablets of the memory," be taxed to rake up all and every person they ever spoke to, and to find out their residence, to make a call in the carriage? Would not Thomas be taught to give a regular "Londonderry" at the door, only somewhat longer and louder? As the boys say, "Would not he, though?"

All this, we must say, is a very plebeian and petty sort of pride and affectation, evincing bad taste, bad tact, bad education, and at once showing a being totally unused to such appliances: it is something like what a deceased acquaintance of mine, one of a firm of our most eminent brewers, was in the habit of doing. He had purchased a magnificent white marble chimney-piece for one of the sitting-rooms at his country-seat: this said chimney-piece had two large bulls' heads, elaborately carved. These our man of malt and wealth was constantly in the halit of seizing by the horns whenever any stranger happened to be there; and as the act was accompanied by the address of "Ah! bully, bully!" in a voice somewhat of the Stentorian order, it never failed calling the attention of every one unused to it to the desired point. Then came a full statement of what it cost; and the purchaser no doubt thought he must look of great consequence in the eyes of his hearers. In some, perhaps, he did; but extremely little in those of some others; for it 
spoke plainly of the parvenu, and of one who piqued himself more on the pocket than the stud, or any thing else.

Whatever weal or woe to the community one of our Ex-chancellors may work, whatever may be the laws or customs he may adopt or abrogate, and whatever may be the share of praise or censure that may follow, I really consider the public are under very considerable obligations to him for bringing in that truly commodious carriage the Brougham. Of course improvements have been made in the original: I do not mean Lord Brougham, for he cannot be improved. Now this remark I really consider a hit, and a stroke in politics beyond the usual wont of Harry Hieover; for each party may apply it as suits their own ideas of the justness of its application. The general utility of the carriage, however, cannot be disputed; and if we miss many of the more imposing equipages that formerly graced our streets, we also miss, from this substitution, a host of turn-outs that reminded us of No. 527 with the plate off.

The only objection that may be alleged against the Brougham is, that, with some ladies, the families grow too numerous for it; but so far as a couple of darlings go, they can be squeezed in, and, as papa does not as yet feel the pinch of them, he bears it cheerfully. Two more. however, 
require the getting of another carriage to hold them. This is still bearable, and pa good-humouredly calls the omnibus a Clarence. A couple more bring calls for cash that make it necessary to abandon the Clarence, and somewhat decreases the good-humour. $\mathrm{Pa}$, however, must have some means of locomotion, so he now gets a gig. This he appropriately enough calls his "sulky;" but next year a seventh blessing puts down the sulky, brings on the sulks, and pa, striking his forehead in despair, now cries, "God send me a hearse!" For whom he invokes it, is best known to himself; but if it is not wanted for some one else, I strongly recommend him to use it for himself: I should in such a case.

Before getting to this extremity, and while keeping some other sort of carriage, let us look at the pro and con as to keeping it and the horse or horses at livery. Here the expediency of doing so or not does not only arise from the consideration of the horse, but as regards the man. If he is wanted to wait at breakfast, and confine himself the whole morning to the house, it is quite clear he cannot have anything to do with the equipage. If only wanted occasionally, then he can both drive and take charge of it. So far as merely the driving it goes, there can be nothing objectionable in any man doing that; but I must say I have always considered it as extremely bad taste and a 
very poor affectation to see a man in a footman's livery carrying a tray about a drawingroom, who we know was strapping at a horse some time the same afternoon. When living in this mediocre way, superior women-servants are far preferable. The horse or two horses can be kept, we know, cheaper in private stables than at livery; but if you devote a man exclusively, to one or even two, he will altogether cost as much as the horses; so the question merges into this: Which is preferred - keeping the carriage and horses at home, and having a coachman; or sending the equipage to livery, and keeping a footman only? I should say, in a family in this position of society, the latter is by far the preferable plan.

The difference between the expense of keeping a single-horse carriage, and one that always requires two, is very disproportionably great, that is, if both are done even in tolerable taste; for it is by no means the mere additional expense of the extra horse that occasions it, but it arises from other causes.

In the first place, a regular pair-horse carriage requires a regular coachman : this gentleman holds himself as far above the mere driver of a single horse, as does the valet over the teaboy, requires twice or three times the wages, more clothes, and more allowances of all sorts ; independent of which, as they have generally made some lady happy, 
they require suitable accommodation for their families, and it is quite correct and reasonable that master or mistress should in some way (probably in all ways) be put to a large expense, because the loving pair think proper to have a large and charming offspring. Then a regular coachman will usually no more dress a horse, wash a carriage, or clean a set of harness, than he would sweep the Mews his stable is in; he would be held as a low fellow by his brethren of the whip, if he did so. The other ladies of the clique would not visit his; she must be a low creature also, to permit her husband to do these things; for the Duchess of Sutherland, though most undoubtedly at the height of aristocracy, must not suppose she has all the aristocracy to herself; her coachman's lady, who uses silver teaspoons, would no more associate with one who used Britannia metal, than her ladyduchess would with her seamstress, and most unquestionably would give herself ten times the airs towards an inferior.

Secondly come the horses. It is true, we see very fine ones driven in single-horse four-wheeled carriages; still to look well, they are not required to be of the high and superior stamp of those where a pair are used; and beyond this, supposing a man gives a hundred for a very superior horse for his Brougham, if that horse was well matched, the pair would be worth something like three times 
that, and should an accident happen to one of them, and consequently a match be wanted for the other, fifty pounds or more beyond his fair price would be asked, when it was understood for what he was wanted, particularly if the purchaser was known to be precise as to getting an exact match.

For such horses the coachman will have every appliance of the most expensive kind, whether necessary or not. The term will may sound singular as applied to a menial; but if from indolence, affectation, habit, a disregard of expense, or all these causes combined, people will allow menials to become, in effect, masters in their vocation or department, they will find that if the term will be not used in speech, its effect is carried out in the end, and such will probably always be the case more or less in the establishments of the wealthy or fashionable.

The idea that horses will not be done justice to at livery, is, in a general way, a very unjust and fallacious one; for I have no hesitation in saying, that, provided you apply to a respectable person in his line, and he knows your horses are to remain with him, they have a far greater chance of being well done by, than if left to the care of half the (soi-disant) coachmen in London. The carriage, harness, and horses will be properly attended to, for this simple reason - it is the master's interest they should be in order to keep your custom, and 
to get that of others by your equipage being well turned out; and he saves nothing by allowing his men to be idle. If the horses are not done justice to as regards feeding they will show it; and he will lose both them and his character. If your horses look badly from your using them unfairly, it is your fault; and for his own sake he will shortly tell you that you do so, and will not be very nice as to whether you take them away or not, for, in fact, keeping them will injure more than benefit his yard. Send for a known respectable man; agree by the quarter, or half-year, or year, for your horses, at a price that will enable him to feed them properly as regards your demand on them as to work; put them under his charge; pay the stableman who takes care of them liberally; and your horses will have every justice; for it must be borne in mind that, though the majority of helpers in dealers' and livery yards are scamps unfit for private families, they are first-rate stablemen, and your horses will be under the eye of a man who knows how to treat them - an advantage that it is by no means certain they would derive from being overlooked by the generality of masters, setting aside ladies.

There are two ways of doing most things, namely the right and the wrong; this, on the broad scale, is a sensible enough remark, or rather saying; but though one way may be either right 
of the reverse, there are gradations as to how far we diverge from the line, be it the right or wrong, and in accordance with this we shall generally derive advantage or disadvantage to ourselves and others from our conduct. This is, in nine cases in ten, brought fully to our conviction. As regards servants, be they our own or those of other persons acting for us, though I quite concur in the opinion that paying for services with too lavish a hand only renders those serving idle, arrogant, and perhaps impertinent, the paying with a niggard one is infinitely worse; particularly so when we have only the conscience of those serving us to depend upon as to the manner in which they do this; and in few cases, are we more dependent on this, than where our horses are under the care of the servant of another, or indeed of our own, if we trust wholly to him ; but supposing our horses to be at livery, we will say the master was anxious to do them justice, but we should not do him justice if we did not pay his servants reasonably and liberally; for let him watch as closely as he will, the horses of the niggard will not get the same attention as those of the liberal man; the former may change his livery stable from Belgrave or Portman Square to Whitechapel or Blackwall, he will find it all the same: and it is very proper it should be so; men of all sorts have a right to be fairly paid for their attention and labour, and he who from 
folly and affectation pays too much, and he who from parsimony pays too little, will both suffer in some way for it; the first by being ridiculed, the latter by having his horses more or less neglected: che medium will generally produce a proper line of conduct in those to whom it is applied.

There are many persons who are great advocates for the abolition of all douceurs to servants. I am not; and can only say if a livery-stable-keeper were to propose as a rule of his yard that no fees or rewards were to be given to his men, his would be the last stable I would send my horses to. True I could, and most certainly should, under the rose, break through his novel, and to some persons perhaps tempting, regulation; but I should be quite sure it would not be the best sort of stablemen he would get under such a system, and with horses, ignorance is as bad as roguery, in many cases much worse; a rogue we may in most cases guard against, but a fool we cannot, as we never can guess what he may take into his head to do; a clever rogue can be bribed into doing a little extra for us; so indeed may the fool-if he knows how ; if, however, he does the extra service wrong we are in a worse predicament than ever, and if a situation is such that a man can derive no advantage by strenuously striving to please, we may fairly reckon on meeting a very sorry workman, for none but such would fill it. 
COUNTRY SPORTS AND LONDON MEN. 201

This much observation has taught me: Take a hundred horses kept in the private stables of the generality of persons, and a hundred kept in the best livery stables - more rough coats, impoverished looks, colds, coughs, cracked heels, and other sickness from bad management, will be found, by three to one, in the former than in the latter.

I should say just the same thing by a man keeping a hunter if he lives in London. Many persons do this and send their horse down the night before to meet any of the hounds within twenty miles of town. This is done by some from a very mistaken motive of kindness to the horse; and from the same mistaken notion that they are consulting their own interest by having the horse when in town under their own eye, and under the care of their own servant. We will look a little at this. In the first place, under such circumstances, so far as his stable treatment goes, for three days out of the four, that is, the day he goes out of town, the hunting day, and the day of returning - if sent such a distance - he is scarcely under their eye at all, or at all events only under that of the servants. Then comes the query, "Is their eye of any great advantage to him when it is over him?" and the care of their own servant is not always a guarantee that the care is of the very best sort. In fact with the ordinary run of 
London grooms, I will answer for it that it is not. And supposing that it was, how can a horse, situated as he must be in London, ever be fit to go with hounds? The most proper thing that is done with him during the week, is the preparing him by his twenty miles' walk the day preceding hunting; and against this we have to set the very improper act of dragging a stiff and tired horse home the day after hunting twenty miles along a turnpike road, in lieu of one hour's gentle walk on turf, just to stretch his legs and conduce to recover his appetite. If he is brought home, that his owner may have him to ride in the park the intermediate days, the idea is unreasonable; probably, in fact almost to a certainty, if there was anything of a run, a horse thus treated through the week will refuse his corn at night, and quite as probably the next morning. Five hours on the road, with an empty stomach, and aching limbs, is not a very proper preparation for a show-off in the park: and where is he to get a gallop to prepare him for the next hunting day, unless he be sent to some of the places stated to be for the exercise of hunters close to town, where their feet and legs are battered to pieces in the spring and autumn, and smothered with mud if sent there in the winter?

It is all very well to send a horse to Banstead downs in the morning, take a canter with the harriers, and trot him quietly home afterwards. 
The horse would be the better for the exercise twice a-week, and his master too; but to expect one to be bottled up in London, and really go with fox-hounds, or the Queen's, is out of the question. I will venture to say there are more horses killed, injured, and lamed, and consequently more falls from those sent down to hunt under such circumstances, in proportion to the number out, in one season, than occur with all the determined riders in Leicestershire in half a dozen. And so it must ever be where horses are expected to go without their wind, stamina, and muscles being properly braced up by proper treatment.

When I say with fox-hounds, or the Queen's, or, I might add, any stag-hounds, I must remark, I consider that to a horse not fully and properly prepared for hunting, it makes a great difference to him whether he goes with the former or the latter. With fox-hounds a horse in most cases gets a little trotting or cantering before a fox is found or goes off; this gives him time and disposition to empty himself before he is called upon for the full exertion of his speed and lungs. With stag-hounds he has no chance; the deer-cart arrives, all is quiet, the deer is uncarted, and in a few minutes the hounds are laid on and a sure burst takes place, for which a horse ought to be as well prepared as for a steeple chase. Distress must follow this, and unless the rider has con- 
sideration enough for his horse to nurse him when it does, some fatal or bad results must take place, and either immediately or gradually show themselves by debility and loss of condition.

But beyond this with fox-hounds, - though the man who can only get one day a week fervently prays that may not be a blank one, - such an event is of vast relief to the horse, for his condition may be quite good enough to enable him to bear fatigue, though such as to render severe calls on his lungs an almost certain prelude to fatal results. Not so is the case with staghounds, whose great recommendation to many men is the certainty of a run. I had seven successive seasons of stag-hunting; it is true I only hunted one day a week with them, and this because they only hunted that one day in my part. of their country; but then my nags were always up to the mark for them, if even the Hendon deer were uncarted, as I could al ways get two days a week with fox-hounds, and had harriers within reach, independent of the then King's which always hunted one day a week in Windsor Park; so the want of proper exercise and practice was no excuse for me or my horses if we went badly. And if such was the case, which doubtless it was more frequently than for my credit it ought to be, what can be expected where neither man nor horse has as good a chance? Candour compels 
me to allow that when I had the best of it, I deserved little credit; and when the worst, that I did my part like a regular muff.

Let us now look at another plan; and see, setting aside being well carried, how, in point of actual money, the thing would work. I am alluding to keeping a hunter at a hunting-stable at livery or at home.

We will say a fair horse, with average runs, will carry a man three times a fortnight - which a good wear-and-tear horse will do on the former plan. If the distance is such as to bring you to the Queen's stag-hounds, or to any foxhounds out of the rench of the omnibuses, your man must be out nine days a fortnight, paying for your horse, of course, sixpence a feed for oats, and the usual charge for hay; compare these expenses to what you would have to pay at a regular hunting stable,- the balance in your favour would not be a fortune. At such a stable you have but the one expense, your horse is taken wherever the fixture may be; there is no blunder in mistaking places - so sure as the hounds are there, so sure is your horse. He has had his proper exercise, or a sweat, if wanted. If a frost sets in, without your troubling yourself about it, he gets a dose of physic; and if ordinary exercise cannot be given, artificial means are resorted to, to give it. You have the advantage of a stud-groom over 
your horse or horses, without keeping one. In fact, you ride a horse in condition, and equal to his task, instead of one to whom that task must be a labour of more than ordinary or necessary severity; for I consider that unnecessary which could be remedied without any material additional inconvenience or expense, or of perhaps any.

It is extraordinary what very fallacious ideas many persons entertain as to the different expense of keeping a horse at home or at livery, and also of the profits of a livery-stable-keeper. Taking the price of forage on an average, his profits are much smaller than people imagine; in fact a man could barely live in London if he confined himself to livery horses.

People are apt to compare the cost of what a horse would eat in their own stable, and then calculate that nearly all the difference between that and the livery charge is profit to the owner of the stables. It is true a horse can be well fed, we will say, for twelve shillings a week, and his owner, bargaining by the year, gets him kept at a guinea. When we come to calculate that in a good situation the rent of a yard perhaps makes the weekly cost of each stall at least half a crown, the weekly wages of the man who has the care of him three shillings a horse more, we have now seventeen and sixpence; then come stable 
utensils, use of clothing, occasional bandages, \&c. And though I have the "esprit de corps" about me quite strong enough to make me at all times uphold the character of sportsmen and men fond of horses, they are not absolutely immaculate, and such things have been heard of as livery bills being left unpaid. Only twenty pounds loss of this sort takes a good deal of bringing up out of livery profits.

It is true the hunting livery-stable-keeper charges a higher rate of livery and his rent is less; but against this we must consider he has to keep more men for the same number of horses than the London man has, he has the loss of time of his people taking horses to cover, and though some horses are summered at his stables, many are not; so, like Shakspeare's apothecary, he has a "beggarly account of empty boxes" several months in the year. Still I should say he does far better than the London man, of the smallness of whose profits we may draw an inference from the fact, that there is not, to the best of my knowledge, such an establishment in London as any large one appropriated solely to livery purposes, which unquestionably there would be if the profits were large. And further, $\mathbf{I}$ never heard of any one man who had accumulated much money as a bare livery-stable-keeper. As job- 
masters many have, who only took horses to livery as being better than vacant stalls.

I can conceive few things so unpleasant as telling persons anything that looks like assuming to oneself superior judgment to theirs. It is never grateful to their feelings, and there is something diabolical in willingly saying what can be considered as mortifying to that little amour propre that actuates us all. I have friends whom I value highly, who are always in some dilemma with their horses; in fact, they are a constant source of loss, and anxiety, and annoyance to them. I am sure to hear of their grievances, and $I$ as surely and sincerely condole with them. Some of them have every feeling of liberality and kindness to do all that is right and proper, do nothing perhaps glaringly wrong; and if they were to ask what they did wrong, unless I could watch all that was done, and under all circumstances, I probably could not tell them. But where things for a continuance go wrong, it is not chance or fate that usually brings it about. With others in the same predicament, it might be no difficult task to point out where they erred. But then, in telling them of one error, the same want of knowing how to do right would probably only change the error, so that one might be as bad as the other. There are persons, who, if they inquired in what their bad management consisted, could only be 
fairly answered by being told, in everything. You are cheated in buying, buy a bad sort, manage them badly, ride them badly, and drive them badly, and the people you employ can do no better. Now, this is that kind of sweeping charge that no man could make up his mind to make. It would be true enough, though, as regards some people: let us hope there are but few in such a case. But wherever any man finds a constant something amiss with his horses, if he is one of the best judges in England, I should say, consult with another; something is wrong, and, figuratively speaking, the physician is wanting. You may have tried various remedies; but somehow you take a wrong view of the case - thousands are in this predicament with their horses.

It matters not what a man undertakes to manage ; if he does it badly and wishes to do better, there are two qualities of which he must lay in an abundant stock before he can do this; viz., good temper, and diffidence as to his own knowledge of the matter in question. Many will very patiently learn or be taught to do that which they have never before undertaken; but to bear to be told they must, to do right, do that which they have not done, and leave undone the greatest part of what they have done, it is not merely a bitter pill but a regular nauseous bolus, unpleasant to swallow, and apt to produce irritation when down. 
If a man manages things tolerably well, but has certain errors of opinion or want of knowledge on some points, a little well-timed flattery as to his general way of doing things will induce him to listen to hints as to where he errs. But where, as is sometimes the case, every thing is done wrong, it would be difficult to decide as to whose task was the most unpleasant, that of the adviser, or of him to be advised. A man may very soon get into a right way of doing most things if he has only to ask what he should do and is then willing to do it; but if he has also to learn how to do it, the case is hopeless. The only hope such a man has is, that when he is too old to want horses, experience may have taught him how to manage them:- - about as encouraging a prospect as that of the generality of writers who depend on writing for support-that they may get bread when they have no teeth to bite it; but then the lucky dogs escape all the horrors of indigestion.

We will now, however, look at the stud under another sort of management, and see how that will work as regards the pocket.

There is another mode of keeping the carriage and horses, that is, jobbing them; the advantages of which, as of most things, depend on the peculiar circumstances in which persons are placed. In a "eneral way it is by no means the most economical 
MAKING THE MOST OF ONE'S TALENT. 211

one. Its pleasantness depends, in a great measure, on the turn of mind, or rather pursuit of the person. Some men job hunters; agree for price, and the number they may choose to have placed at their disposal. So far as my particular turn goes, I should derive no more pleasure from riding Tilbury's horses during a season, than I should in riding a post-horse to Hounslow by way of an airing. I have been accustomed to own nice ones, had ( $I$ hope a pardonable) pride in them, and, I am free to confess, in their condition, and sometimes performance. Now I cannot conceive anything flattering to this little harmless vanity in riding such a horse, the property of another, and under the management of the servant of another. But the feeling of having made a horse the clever animal he is, and bringing him into the condition he is, does go somewhere towards showing you know what you are about. I am quite willing to allow that making a hunter, bringing him out in king's plate condition, and riding him well (supposing the latter to be done), is no great matter to be vain about; but if a man's mind and talents are not framed to the performance of great achievements, it would be hard to deprive him of enjoying the little triumph attendant on the performance of minor ones.

We should have been sorry to see John Kemble sing a comic song between the acts of "Hamlet." 
Now, I certainly could not play Hamlet, but I fancy I could manage "Jim along Josey." Well, it is better to be encored in that than hissed in Hamlet. So I have always fancied I could manage condition in hunters. In this cast of character I have been applauded - I hope I shall be encored.

Families who have a great deal of night work, and only intend to keep a pair of horses for their carriage work, would perhaps do well to job; for this reason-as I said before, horses cannot stand all sorts of usage - not that there is any cruelty in night-work, but if horses are wished to be in blooming condition, they cannot stand it; so the job-master keeps horses for all purposes gives you one pair for the day, and a pair of old, seasoned, hardy ones for night.

A lady who keeps a pair of horses, if she is to trust herself and them to the sole guidance of her coachman, had better job; for though she will have a round sum to pay the job-master, she will always have a pair ready; whereas her coachman, by one means or other, will contrive to get as much out of her pocket as the job-master, and she may not always be able to have her carriage, if coachee has a friend coming to see him, or wants to go to a party.

From what I have said I trust I have borne out my assertion, that whoever undertakes the 
management of their stud, if they manage it badly, must suffer in the pocket so long as the same management exists; this refers equally to the buying, managing and using it, be it for what purpose it may.

But to return to the jobbing of hunters, which is sometimes done by masters or managers of foxhounds; its advantages and disadvantages depend so much on circumstances, that it is impossible to decide which, in a general way, preponderate. If we are well acquainted with the habits, judgment, mode of riding, and management of any given person, it would be no difficult task to recommend the best mode for him ; that is, under ordinary circumstances. If a man is careless about the management of his horses, is too indolent to attend to them, or has not good judgment in his management, he has but three plans to adopt, by which he has any chance of having his stud fit to go; he must either engage a first-rate stud-groom and keep his horses at home, send them to a hunting stable, or job them. To such a person, I should be tempted to recommend the latter; for he would then be sure of always having a given number of horses ready and fit to meet hounds, which might not be the case on either of the former plans; but when a man engages to keep you a certain number of horses for your use he will, of course, use every exertion to place trusty men 
about them, and to see that they do their duty; a respectable man as a stud-groom, will probably do nearly the same. But if a master is a careless, unfair, or, to say the least, injudicious rider in the field, the best stud-groom that ever had a horse under his care cannot keep the stud going, the sick and the lame will make a fearful array against the sound and hearty ones. With such a customer as this, no doubt, whoever lets his hunters on a job, calculates and charges accordingly; such a man must pay for his folly in some way, either by giving a considerably greater sum for the use of horses than the same number would cost another man, - or, if in his own stables, losing by the lamed and maimed he sells out in order to get others fit for the field.

If I mistake not, Count Segur went further in the jobbing system than most private individuals, and I believe Tilbury supplied him with horses. I never had the honour of any further acquaintance with the Count than an occasional nod, but I have seen him "go," and go he certainly did, and, as a sailor would say, go ahead he did, and more than once over his horse's head I have seen him go; but the Count was not a man to be dismayed at such a contretemps; he got up, shook his feathers, and, like a true good one, away he sailed again. We ought to cherish such in these omnibus and railroad times, to keep up 
emulation in the field at home, and to show the illiberal and uninformed the fallacy of their ideas, that true pluck and high courage only exist where roast beef is at a premium. A Frenchman is no fox-hunter: he does not, nor as yet cannot, enter into the spirit of it; but those must have remained at their mamma's side all their lives, who would attribute any failure in anything on the part of a Frenchman, or indeed any foreigner, to any lack of personal courage.

I have said that I would as soon ride a posthorse an airing as a job-hunter with hounds: such is my feeling; but I am quite aware it is not that of a true sportsman, or true fox-hunter. I doubt my being either at heart; for the man who makes the great pleasure of hunting to consist in riding fine or neat horses, with as neat bridles and saddles, does not show, in the first rank, as a true sportsman. Now, our truly orthodox writer in the "Sporting Magazine," Acteon, is every inch a sportsman, every half-inch a fox-hunter; his heart and soul are in his hounds and their hunting; he would ride in a balloon, if he could see his hounds hunt, or would ride a butcher's hack rather than not see hounds at all, and, in truth, few men can screw a queer one across a country better, or as well as he can. All those who know him, only wish him a stud as good as he could ride, a pack as good as he could hunt: and if I could com- 
mand my fate, it would be, that I could hunt with him; for if not so true a sportsman as he, and if fond of what $I$ have been often quizzed about, shining coats on my horses and neat appurtenances, I do still hold my head above those who merely hunt if it does not interfere with a party in town. I love fox-hunting; but I love nice horses, and cannot enjoy the one without the other. De gustibus non est disputandum : if the truth of this quotation is allowed me, I have courage to again say, I do not like riding post, and such $\mathrm{I}$ hold to be riding job-horses.

Mr. Tilbury's (whose name I have mentioned) horses do well, because they are well done; the job-master's carriage-horses do the same from the same cause; so will your hunter or other horse, if sent to proper places to livery. They will, of course, do equally well at home, if equally well managed, either by the master or stud-groom. But a person may candidly say, "I cannot manage well myself, nor can I keep a studgroom." This is precisely the sort of person for whom I have written. It will be found I have not done so altogether with a view to instruct any one how to manage; for to learn this properly requires years of experience: but the one short (not flattering I allow, but honest) advice, do not manage at all, is very easily learned. It is singular, if among a man's ac- 
quaintances he does not know one to whose judgment he can trust; if a man really does not know such a person, then I should say, "Send your horses to livery at once." If, however, a man will not do this, really has no one he can consult with, or does not choose to do so, and cannot manage for himself, I can only say, in such a case I can give no more advice than I have; and it is one in which "the patient must minister to limself."

I am, however, not left without a further piece of advice to give my friends, and (with permission) my readers also; for though I have had much experience and practice in the matters on which I now write and have written, it in nowise follows as a matter of course that $I$ have turned that experience and practice to the best account; consequently, those not conversant with such matters may remain still somewhat astray in the management of them. For though a man may manage tolerably or very well for himself, he may not have the talent or tact to write so as to make others do the same thing. Still I hope some hints may be gleaned from what I have said, or rather written, that may be useful. If, however, any owner of horses cannot manage them himself cannot glean from what I have said, or the better advice of others, sufficient knowledge to do soI can only bring forward the wholesome bit of 
advice to which I allude - namely, if he finds that, for some reasons or other, he cannot act so as to prevent the stud making greater demands on the pocket than the pleasure of it compensates for, as a pis aller, he had better at once pocket the stud.

THE END. 


\section{BOOKS ON RURAL SPORTS, \&.}

BLAINE'S ENCYCLOPEDIA of RURAL SPORTS. New Edition; revised by HARRY Hizover, Ephrmera, and Mr. A. GrahaM: With above 600 Woodcuts............................................. 8 vo. 50 s.

Colonel HAWKER'S INSTRUCTIONS to YOUNG SPORTSMEN in all that relates to GUNS and SHOOTING. Tenth Edition, improved by the Author's Son; with numerous Illustrations.................... 8vo. 21s.

RECORDS of the CHASE, and MEMOIRS of Celebrated sportsmen. By Cecil. With Two Plates by B. Herring.

Fcp. 8vo. 7s. 6d.

HINTS on SHOOTING, FISHING, \&c., both on SEA and LAND, and in the FRESH-WATER LOCHS of SCOTLAND: Being the Experiences of Christopher IdLe, Esq.................................. Fcp. 8vo. $5 \mathrm{~s}$.

STABLE PRACTICE; or, Hints on Training for the Turf, the Chase, and the Road. By Crerr ........................ Fep.8ro. 5s.

The POCKET and the STUD; or, Practical Hints on the Nanagement of the Stable. By HuRRY HIEOvER ................... F cp. 8vo. 5s.

The STUD FARM ; or, Hints on Breeding Horses for the Turf, the Chase, and the Road. By CECr. ......................... Fep. 8vo. 58.

The STUD for PRACTICAL PURPOSES and PRACTICAL MEN : A Guide to the Choice of a Horse for Use more than for Show. By HARRY HIEOVER........................................... Fcp. 8vo. $5 \mathrm{~s}$.

-

The Hunting.Field. By Harry Hieover With Two Plates Fep. 8vo. 5s.

STABLE TALK and TABLE TALK; or, Spectacles for Young Sportsmen. By Harry Hieover ......................2 vols. 8ro. 24s.

London: LONGMAN, BROWN, GREEN, LONGMANS, and ROBERTS. 
REMINISCENCES of a HUNTSMAN. By the Hon. G RANTLEY F. Berkelex. With 4 Etchings by JoHN LeEch (1 coloured). 8ro. 14s.

The RIFLE and the HOUND in CEYLON. By S. W. BAKER, Esq. New Edition, revised; with 13 Wood Engravings ......Fep. 8vo. 4s. 6 d.

PRACTICAL HORSEMANShip. By Harry Hieover. with Two Plates................................................ Fep. 8vo. 5s.

Captain RICHARDSON'S HORSEMANSHIP for the SCHOOL, the ROAD, and the FIELD; or, the Art of Riding and Managing a Horse. With several mlustrations..................... Square crown 8 vo. 14s.

The GREYHOUND : A Treatise on the Art of Breeding, Rearing, and Training Greyhounds for Public Running. By Stoveresgr. With many Illustrations .................................... Square crown $8 \mathrm{vo} .21 \mathrm{~s}$.

The CRICKET-FIELD; or, the Science and History of the Game of Cricket. Second Edition; with Illustrations............... Fcp. 8vo. 5s.

The ANGLER and his FRIEND; or, Piscatory Colloquies and Fishing Exeursions. By Joнn DAvY, M.D., F.R.S. ............ Fep. 8vo. 6s.

The ANGLER in the LAKE DISTRICT; or, Piscatory Colloquies and Fishing Excursions in Westmoreland and Cumberland. By JoHN DAvт, M.D., F.R.S.................................... Fep. 8vo. 6s. 6d.

EPHEMERA'S HANDBOOK of ANGLING; teaching Fly-Fishing, Trolling, Bottom-Fishing, Salmon-Fishing. With many Woodeuts.

Fcp. 8vo. 5s.

EPHEMERA'S BOOK of the SALMON ; comprising the Theory, Principles, and Practice of Fly-Fishing for Salmon: With copious Lists of Flies, coloured Plates, \&c. ................................ Fep. 8vo. 11s.

\section{RONALDS'S FLY-FISHER'S ENTOMOLOGY. With}

Observations and Instructions relative to Trout and Grayling Fishing. Fifth Edition, thoroughly revised by an experienced Fly-Fisher; the Plates coloured after improved patterns. With 20 coloured Plates................................. 8 ro. 14 s.

London: LONGMAN, BROWN, GREEN, LONGMANS, and ROBERTS. 









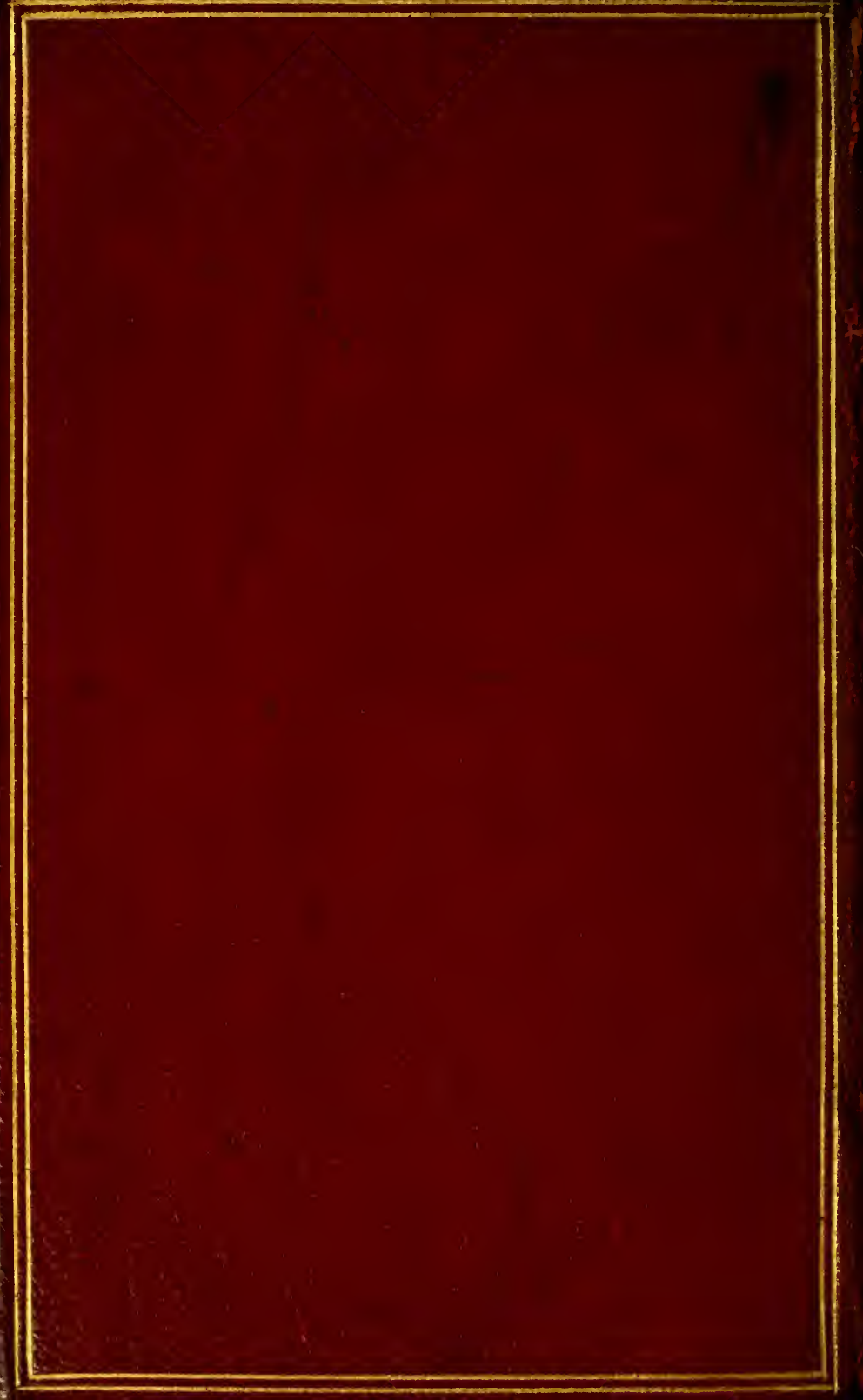

